\title{
Reconciling the dissonance between Historic Preservation and Virtual Reality through a Place-based Virtual Heritage system.
}

\author{
Danny J. Bonenberger \\ West Virginia University, dbonenbe@mix.wvu.edu
}

Follow this and additional works at: https://researchrepository.wvu.edu/etd

Part of the Geographic Information Sciences Commons, Graphics and Human Computer Interfaces Commons, Historic Preservation and Conservation Commons, Human Geography Commons, and the Urban Studies and Planning Commons

\section{Recommended Citation}

Bonenberger, Danny J., "Reconciling the dissonance between Historic Preservation and Virtual Reality through a Place-based Virtual Heritage system." (2019). Graduate Theses, Dissertations, and Problem Reports. 4106.

https://researchrepository.wvu.edu/etd/4106

This Dissertation is protected by copyright and/or related rights. It has been brought to you by the The Research Repository @ WVU with permission from the rights-holder(s). You are free to use this Dissertation in any way that is permitted by the copyright and related rights legislation that applies to your use. For other uses you must obtain permission from the rights-holder(s) directly, unless additional rights are indicated by a Creative Commons license in the record and/ or on the work itself. This Dissertation has been accepted for inclusion in WVU Graduate Theses, Dissertations, and Problem Reports collection by an authorized administrator of The Research Repository @ WVU. For more information, please contact researchrepository@mail.wvu.edu. 


\title{
Reconciling the dissonance between Historic Preservation and Virtual Reality through a Place-based Virtual Heritage system.
}

\author{
Danny J. Bonenberger \\ Dissertation submitted to the \\ Eberly College of Arts and Sciences \\ West Virginia University \\ in partial fulfillment of the requirements for the degree of \\ Doctor of Philosophy in \\ Geography
}

\author{
Trevor M. Harris, Ph.D., Chair \\ Kenneth Fones-Wolf, Ph.D. \\ Theodore Ligibel, Ph.D. \\ Kenneth C. Martis, Ph.D. \\ Timothy A. Warner, Ph.D.
}

Department of Geology and Geography

Morgantown, West Virginia

2019

Keywords: Virtual Heritage, Virtual Reality, Historic Preservation, Digital Heritage, Geographic Information Science, Place, 3D Modeling, Serious Games, Vernacular Architecture, Rebecca Harding Davis, Wheeling, W.Va.

Copyright 2019 Danny J. Bonenberger 


\section{Abstract \\ Reconciling the dissonance between Historic Preservation and Virtual Reality through a Place-based Virtual Heritage system.}

\section{Danny J. Bonenberger}

This study explores a problematic disconnect associated with virtual heritage and the immersive 3D computer modeling of cultural heritage. The products of virtual heritage often fail to adhere to long-standing principles and recent international conventions associated with historic preservation, heritage recording, designation, and interpretation. By drawing upon the geographic concepts of space, landscape, and place, along with advances in Geographic Information Systems, first-person serious games, and head-mounted Virtual Reality platforms this study envisions, designs, implements, and evaluates a virtual heritage system that seeks to reconcile the dissonance between Virtual Reality and historic preservation. Finally, the dissertation examines the contributions and future directions of such a Place-based Virtual Heritage system in human geography and historic preservation planning and interpretation. 
To Kim 


\section{Contents}

List of Illustrations $\quad$ V

Acknowledgements vii

List of Abbreviations $\quad$ ix

1. Introduction: Virtual Heritage Dissonance \& Opportunity 1

2. Heritage Principles and Challenges for Virtual Heritage 17

3. Envisioning a Virtual Heritage System for Historic Preservation 47

4. A Methodology for Reconstructing Place in Virtual Heritage 72

5. Case Study: Gathering \& Processing Data on Rebecca Harding's Wheeling 95

6. Case Study: Reconstructing Place in Unity3D \& HTC Vive 117

7. Evaluating the Place-Based Virtual Heritage System 127

$\begin{array}{lr}\text { 8. Conclusion } & 139\end{array}$

$\begin{array}{ll}\text { Reference List } & 148\end{array}$ 


\section{Illustrations}

1.1 Types of Historic Preservation Activities 4

3.1 Verbree's Plan View, Model View, and World View Re-envisioned 48

3.2 Shared Concerns of Historic Preservation, Cultural Geography, and Virtual Reality 49

4.1 Schema for a Place-Based Virtual Heritage System 73

4.2 Schema Detail: Natural and Human Data 75

4.3 Schema Detail: Material Cultural Data 77

4.4 Schema Detail: Immovable Cultural Heritage 79

4.5 SketchUp 3D Models of Wheeling Heritage $\quad 84$

4.6 Low-Polygon Human \& Animal Prefabs $\quad 85$

$\begin{array}{ll}\text { 4.7 Schema Detail: Intangible Elements } & 87\end{array}$

4.8 “Game Immersion” NPC Comic. $\quad 91$

4.9 Vive HMD Virtual Reality System 93

5.1 Venturi and Rauch’s 1976 “Ghost Structure” at Franklin Court 100

5.2 The Harding House Depicted in a 1906 Photograph 102

5.3 Component Folders of Place-Based VH Case Study 104

5.4 Side-by-side Comparison of Harding House on 1884 and 1853 map. 105

5.5 North Wheeling Historical GIS Detail 107 
$\begin{array}{ll}\text { 5.6 Width of Dwelling Facades } & 108\end{array}$

5.7 Dwelling Width Correlated with Number of Bays 109

5.8 Historical GIS of Webster Street Showing Four Data Classes 110

5.9 Rendering Hierarchy of Low-polygon 3D Models 111

5.10 Elevation Textures of Second Presbyterian Church 113

5.11 Addresses \& Types of Demolished Dwellings Modeled at Level $3 \quad 114$

6.1 Digital Elevation Model of Wheeling near the mouth of Wheeling Creek 118

6.2 Early Unity3D Trial: DTM, Water, Vegetation, Fog \& High-Polygon Buildings 119

6.3 Bird's-eye View of the Case Study in Unity3D Scene View 120

6.4 Audio Elements of the Case Study 122

6.5 Vernacular Working Class Dwellings in the HTC Vive 123

6.6 Steam Locomotive \& Planing Mill 125

6.7 Rebecca Harding's Place Explored in the HTC Vive 126 


\section{Acknowledgements}

I sincerely appreciate my professors and fellow graduate students in WVU's Department of Geology and Geography and my dissertation committee for their insightful comments and questions. I am especially grateful to my committee chair and mentor, Trevor Harris. He taught me geography far beyond Geographic Information Systems and demonstrated how to be a professor. His support has strengthened my ability to research and write beyond measure. Thanks to Ken Fones-Wolf, Barb Howe, and Michael McMahon for their substantial role in my academic development, for introducing me to the history of common people and places and showing me that the history of Wheeling and its working class is worth pursuing. Special thanks to Emory Kemp for believing in me and showing the way to lead a research institute. Thanks also to Marshall McLennan, co-founder of Eastern Michigan University's Graduate Historic Preservation Program for his work at the intersection of geography and historic preservation revealing the potential of cultural landscapes and vernacular architecture to yield insights into past and present places. Ted Ligibel and Nancy Bryk, the past and present directors of EMU's Historic Preservation program, and professor Matt Cook have continued this tradition while displaying tireless enthusiasm and encouragement, and always placing people and personal relationships first.

Our students have inspired me with their talents, curiosity, and creativity. They have produced countless digital models of vernacular dwellings based on digital heritage best practices, though the polygon count of most of their models proved too high for direct use in VR. Among those that should be thanked individually, Judith White and Steffany Wood invested incalculable 
energy and creativity to support my study of the history and geography of Wheeling. Along with Yang Yang, they also contributed greatly in GIS and digitization efforts. Ginny Schomish, Christina Miranda, Rachel Ellenson, and Amara Frontczak researched digital heritage and vernacular architecture in the fledgling Digital Heritage Preservation Lab at EMU. They transformed an empty room into a digital preservation laboratory.

Thanks to the people of Wheeling who have opened doors for me and shared their time and resources in support of my research and teaching on antebellum dwellings. Bekah Karelis, Jeanne Finstein, Erin Rothenbuehler, Margaret Brennan, Barbara Pirhalla, Jackie Herrick, Michael Kelly, Thad Podratski, Ray Carney, and Mike Stahl have been especially generous. Thanks also to Beverly Fluty, Snookie Nutting, Heidi Friend, Mike Baker, Wheeling Heritage, the Wheeling Historic Landmarks Commission, and countless others that have devoted countless hours and energy to preserve Wheeling heritage.

Thanks to my friends and family for their interest and intangible contributions to this work, especially Zach Mehl and Dave Padot who helped facilitate my study of C\#, Pete Batra, who shared insights on assessment, Chris McElroy who recorded Irish voices for the project, and to James Pauer and all of the Woods Warriors who helped keep me going. Above all, I appreciate my wife Kim, children Joe and Nina, and my parents Keith and Mary for their support and encouragement through long years of study, research, and writing. Without them, this dissertation would have been impossible. 
Abbreviations

$3 \mathrm{D}$

Three-Dimensional

ACM Association for Computing Machinery

CAA Computer Applications in Archaeology

CAVE Cave-Automatic Virtual Environment

CIPA International Committee of Architectural Photogrammetry

COTS Commercial off-the-Shelf

CRGIS Cultural Resources GIS

DH Digital Heritage

DHPL Digital Heritage Preservation Lab

DEM Digital Elevation Model

DTM Digital Terrain Model

EPOCH European Program for Open Cultural Heritage

FPS First-person shooter

GIS Geographic Information Systems

HABS Historic American Buildings Survey

HAER Historic American Engineering Record

HALS Historic American Landscape Survey

HGIS Humanities GIS

HMD Head Mounted Display

HP Historic Preservation

ICCROM International Centre for Preservation \& Restoration of Cultural Property 


$\begin{array}{ll}\text { ICH } & \text { Intangible Cultural Heritage } \\ \text { ICOMOS } & \text { International Council on Monuments and Sites } \\ \text { IEEE } & \text { Institute of Electrical and Electronics Engineers } \\ \text { LiDAR } & \text { Light detection and ranging } \\ \text { MIT } & \text { Massachusetts Institute of Technology } \\ \text { MMORPG } & \text { Massively Multi-player On-line Role-Playing Games } \\ \text { MR } & \text { Mixed-Reality } \\ \text { NHPA } & \text { National Historic Preservation Act } \\ \text { NPC } & \text { Non-Player Character } \\ \text { PC } & \text { Personal Computer } \\ \text { PTSD } & \text { Post-Traumatic Stress Disorder } \\ \text { RecorDIM } & \text { Recording, Documentation, and Information Management } \\ \text { SfM } & \text { Structure from Motion } \\ \text { TICCIH } & \text { The International Committee for the Conservation of Industrial Heritage } \\ \text { TLS } & \text { Terrestrial Laser Scanners } \\ \text { UNESCO } & \text { United National Educational, Scientific, and Cultural Organization } \\ \text { USGS } & \text { United States Geological Survey } \\ \text { VAST } & \text { Virtual Archaeology, Science, and Technology } \\ \text { VH } & \text { Virtual Heritage } \\ \text { VR } & \text { Virtual Reality } \\ \text { VRND } & \text { Virtual Reality Notre Dame } \\ \text { WVGISTC } & \text { West Virginia GIS Technical Center } \\ \text { VSP } & \text { Virtual Systems and Multimedia } \\ \text { World Soundscape Project } \\ \text { W }\end{array}$




\section{Introduction: Virtual Heritage Dissonance and Opportunity}

This study explores a problematic disconnect associated with the immersive 3D computer modeling of cultural heritage. The oftentimes astonishing visualizations of great historic buildings produced under the banner of virtual heritage $(\mathrm{VH})$ over the past two decades would indicate enormous potential. However, a closer look at the products of such work reveals that VH often fails to adhere to long-standing cultural heritage praxis or maintain recent international conventions associated with historic preservation, recording, designation, and interpretation. The goal of this dissertation is to envision, design, implement, and evaluate a virtual veritage system that reconciles the dissonance between Virtual Reality (VR) and historic preservation (HP), by drawing upon the geographic concepts of space, landscape, and place, advances in Geographic Information Systems (GIS), first-person serious games, and head-mounted VR displays.

The creation and implementation of such a system is examined through a case study. Set in the rapidly industrializing, ethnically diverse, economically stratified, and politically divided town of Wheeling, (West) Virginia on the eve of the Civil War, the case study reconstructs the place where Rebecca Harding Davis penned her seminal Life in the Iron Mills (Harding 1861). Based on field and archival research, the project documents the former house and neighborhood of Davis, revealing the cultural heritage of lost spaces and components of the mid-nineteenth century landscape, along with intangible elements of place, such as the sensuous and emotional elements emphasized in Davis's writing. In seeking to reconcile the dissonance between the Virtual and Heritage spheres of $\mathrm{VH}$, this study begins by examining the core concepts of VR and HP (also known as heritage conservation) and the history of the interrelationships between them. 


\section{Heritage Conservation and Historic Preservation}

Heritage refers to the objects, monuments, buildings, structures, historic sites, and landscapes that are passed down from generation to generation and bestowed as a legacy for future generations. Geographer David Lowenthal (1985) suggested that heritage is local and mythical while history is scholarly and expert. Graeme Aplin (2002) argues that history is what happens but that the term heritage is open for debate, for it depends on what is select to preserve for

future generations. Susan J. Smith (1993) notes that heritage typically privileges the significant, monumental, and grand due to the dominance of powerful state experts, and thus cultural heritage can marginalize groups and be contested. Japan has led an international movement to move beyond the recording and preservation of the material aspects of heritage to recognize certain intangible elements as essential components of cultural heritage. Intangible cultural heritage $(\mathrm{ICH})$ consists of such things as customs, rituals, language, oral traditions and stories, and folklore. Thus, beyond simply being what is passed down from one generation to another, heritage represents the local, subjective, intangible, contested, and personal qualities of culture. Heritage includes not only the physical objects that are preserved for future generations, but the knowledge produced by archaeologists, works of historians, memories of community elders, rituals, and customs of various social groups. Because heritage has come to cover such a broad representation of the tangible and intangible aspects of the cultural and natural world, the preservation and management of heritage necessarily involves a wide range of disciplines and activities.

The physical remains of heritage inevitably decay over time. Efforts to slow this process are undertaken under the banner of heritage conservation and historic preservation. The latter term 
is used in the United States, while the former is preferred internationally, but they essentially mean the same thing and will be used in this dissertation interchangeably hereafter. Narrowly defined, the terms refer to the physical steps taken to minimize decay, such as repairing windows or repointing masonry of historic structures. The broader definition, as explained in UNESCO's Nara Declaration, recognizes that a wide array of efforts are involved in slowing the decay of heritage, and that the "bricks and mortar" work is but one step in a long process that begins with the identification of heritage, the documentation of existing knowledge about it, the recording of existing conditions, and the analysis and management of such information (Larson 1995). These aspects have been grouped under the umbrella term RecorDIM, meaning "recording, documentation, and information management (Letellier 2007). In addition, communication, education, and interpretation are also critical steps throughout the conservation process, in raising awareness and facilitating collaboration among local groups and individuals with research communities (Fig 1). Without this diverse concert of conservation activities, preservation efforts are quite temporary (Tyler et al. 2018, Silberman 2009, Letellier 2007).

\section{RecorDIM}

Identification

Documentation

Recording

Information Management

Designation

\section{Bricks and Mortar}

Analysis

Materials Conservation

Rehabilitation

Restoration

Reconstruction

\section{Communication}

Presentation

Interpretation

Education

Advocacy

Figure 1 Types of Historic Preservation activities. 


\section{Digital Heritage \& Virtual Heritage}

Since the 1960s, digital computer technologies have touched almost all aspects of heritage conservation. Early digital library catalogues were followed by digital archives, Computer Aided Drafting, and GIS but a wide range of additional digital technologies have been used for recording historic structures and archaeological remnants. Indirect diagnostic tools for conservation, such as photogrammetry, ground penetrating radar, and other remote sensing tools actually predate the computer age, but over the past twenty years they have been revolutionized by digital technologies (Fidler 2007). The trend toward incorporating digital technologies within cultural heritage equally applies to the information management tools used in conservation, as well as communication, education, and interpretive efforts (Letellier 2007). Today, these activities are at the intersection of heritage conservation and computer science and are grouped under the umbrella of digital cultural heritage or simply digital heritage which covers the application of digital technologies in disciplines and professional fields related to cultural heritage (Cameron and Kenderdine 2007; Kalay 2007; Addison et al. 2013; Guidi et al. 2015).

The 1990s were a fruitful decade for computer applications in heritage, including notable work in archives, museums, tourism, history, cultural geography, and archaeology. The most conspicuous digital heritage activities during this period included digital libraries, cultural heritage informatics, and computer-based heritage visualization such as the $3 \mathrm{D}$ modeling of historic buildings. The annual International Cultural Heritage Informatics meetings (now "Museums and the Web") began in 1991 (Bearman and Trant 1999). These meetings were followed by the United States government's Digital Libraries Initiative, which provided academic research laboratories with extensive resources to work in partnership with some of the 
largest federal agencies (Griffin 1998) to address the long-term access to digitized materials. 3D computer modeling also was applied to several fields concerned with heritage during the 1990s, and the terms virtual archaeology, virtual tours, and virtual heritage appeared in rapid succession to describe such work. Academically, historical geographers and quantitative archaeologists led the way, developing digital terrain models (DTMs) of ancient landscapes for viewshed analysis (Harris 1984) and publishing papers on Virtual Archaeology (Reilly 1991). In 1994 Queen Elizabeth II unveiled an on-site 3D computer model of ca.1550 Dudley Castle as a virtual tour. Subsequently, the term was co-opted by others in reference to just about any image-based or multimedia-based interpretation of cultural heritage objects accessed via personal computer or interactive kiosk (Lukesh 1995). Scholars associated with Gifu University VR Laboratory in Japan adopted the term virtual heritage in 1998, and referred specifically to the creation of 3D virtual models of historic structures (Stone 1999).

As with the earlier term virtual tour, virtual heritage quickly gained acceptance, but was somewhat ambiguous due to variations in the usage of the word virtual. Virtual means "Almost or nearly as described, but not completely or according to strict definition," so VR can be inferred to be "almost but not quite" reality (https://en.oxforddictionaries.com/definition/virtual). However, the terms virtual archaeology, virtual tour, and virtual heritage emerged in a decade when VR seemed to be approaching the hyperrealism seen on television in Star Trek's Holodeck (Murray 1998). Thus it came to be that two very different phenomena, an Internet-based, twodimensional multimedia tour and an immersive 3D model, could be described as a virtual tour or as virtual heritage, for both served as surrogates for a traditional real-world tour of a heritage site. Using the broader definition of virtual, however, almost anything could be considered virtual heritage, so to avoid confusion, this study uses virtual heritage (or $\mathrm{VH}$ ) in its most 
common parlance - as the intersection of VR with Cultural Heritage, and this includes a range of projects and issues related to immersive digital 3D models of heritage. Thus VH is a subset of heritage visualization, which in turn is a subset of a broader range of activities characterized as digital heritage.

\section{Virtual Reality}

VR has evolved dramatically in the past 25 years (Blascovich and Bailenson 2011; Lavalle 2017), and can be evaluated according to three essential qualities that emerged from the VR literature of the early 1990s: reproduction fidelity, presence, and the extent of world knowledge (Milgram et al. 1994). Reproduction fidelity has two main components. The first component is the quality of the 3D models that range from wire mesh modeling to fully-rendered scenes with color, light, shadow, and textures. The second component relates to the display system, which ranges from a single video monitor to the six-wall high-definition, stereoscopic 3D CAVE (Cave Automatic Virtual Environment) systems (Naimark 1991) and the latest head-mounted displays (HMD) such as the Oculus Rift and HTC Vive (Matney 2016). The term presence refers to the extent to which one is immersed in virtuality (as opposed to reality), and this is related to the responsiveness of the system and verisimilitude, or the believability of the immersive environment. The ability to simulate a real world experience within a virtual world depends not only on the plausibility of the scene, but also on having the freedom to move about intuitively in real time, and the ability to interact reflexively with the virtual environment (Robinette 1992; Zeltzer 1992). Finally, the extent of world knowledge refers to the breadth and depth of a virtual world, including the range of phenomena represented and the amount and quality of data 
associated with each phenomenon (Milgram et al. 1994). Addressing the limitations of all three characteristics has dominated the VR research agenda since the 1990s as found in conference proceedings published by ACM and IEEE and in journals such as Presence.

Steady gains in computer processing speeds and display capabilities have enhanced all three aspects of VR technology, providing remarkable opportunities to expand the ways in which people document, interpret, analyze, communicate, experience, and learn about cultural heritage. In the realm of $\mathrm{VH}$, the presence, reproduction fidelity, and extent of world knowledge revealed in the work presented at Virtual Systems and Multimedia (VSMM) and other conferences in the two decades following the launch of its Virtual Heritage Network in 1998 have varied widely, mirroring broader trends in VR. Most VH projects have been intricately rendered, with color, texture, light, and shadows, while others have been simple massed models (i.e. unadorned three dimensional shapes). Some projects were designed to be viewed in a CAVE or HMD, while others were designed as first-person games for personal computer (PC) use. Until recently, access to immersive and interactive VR systems has been extremely limited. Furthermore, the majority of this $\mathrm{VH}$ material has been disseminated at conferences merely as still images or flythrough animations, though an increasing number of systems have been made available for immersive exploration at $\mathrm{VH}$ conferences. The content of these projects has been impressive, and typically has focused on the rendering of famous works of art and other precious objects, world heritage sites, monuments, architecture, and reconstructions of ancient archaeological sites. For VR, heritage has proven to be a valuable subject with which to demonstrate the capabilities of immersive technologies. The potential for communicating information about cultural heritage is clear, however, from the cultural heritage perspective, $\mathrm{VH}$ has been the target of significant criticism from a number of scholars concerning its more limited contributions 
toward the broader goals and activities of historic preservation that includes the research, documentation, recording, analysis, interpretation, and the preservation of remnants of the past.

\section{The Dissonance in Digital and Virtual Heritage}

The London Charter for the Computer-based Visualization of Cultural Heritage is the most comprehensive summary of the widespread discontent that has been voiced about VH since the early 1990s (londoncharter.org). As published in 2009, the charter expresses a general dissatisfaction with the lack of intellectual transparency in $\mathrm{VH}$, suggesting that heritage visualization too often emphasizes "hyperrealism" at the expense of rigor, documentation of sources, and uncertainty (Denard 2012). As a result, such 3D visualizations often serve not to advance knowledge about the past but rather to actually obscure what is known and hide what is conjecture. Related to this shortcoming, the authors of the Charter decry the lack of sustainability and accessibility in heritage visualization. To counter the effects of what amounted to a cult of photorealism and hyperrealism, which has contributed significantly to limiting the functionality of heritage visualization, the Charter argues that creators of such work should be mindful of their motivation and purpose in creating any computer-based visualizations. Such work should complement traditional methods and heritage visualization be used only to accomplish goals that traditional methods could not achieve. With so many disciplines and professions devoted to researching, preserving, and communicating about heritage along with the many diverse subjects, aims, projects, and audiences in the field, the London Charter focused on the basic principles that transcend disciplines, technologies, and heritage subjects. The Charter authors encouraged disciplinary and application-specific methodologies in the production of 
particular types of heritage visualization. This dissertation draws heavily upon the principles of the London Charter and identifies additional challenges facing virtual heritage. In the process, this study proposes additional guidelines for virtual heritage residing as it does at the intersection of VR, HP and geography.

\section{Research Goal \& Objectives}

The goal of this study is to envision, design, implement, and evaluate a virtual heritage system that reconciles the dissonance between Virtual Reality and Historic Preservation by drawing upon the geographic concepts of space, landscape, and place through the combination of GIS, game engines, and VR technologies.

The specific objectives of the study comprise:

1. Unpack the term virtual heritage $(\mathrm{VH})$, its origins and early development, and identify the dissonance seen to exist between its Virtual Reality (VR) and historic preservation (HP) spheres.

- What is heritage and how is heritage preserved?

- What is virtual heritage and how does it relate to other early computer applications in heritage?

- What is Virtual Reality and what are its principle characteristics? How do the early products of VH reflect VR's emphasis on presence?

- What perceived deficiencies in $\mathrm{VH}$ and other heritage visualizations have been identified by heritage specialists? 
2. Examine HP traditions in documenting, recording, and producing knowledge about historic buildings, cultural landscapes, and intangible heritage, and the challenges such doctrines pose for $\mathrm{VH}$.

- How have heritage delineators approached the recording of heritage in both two and three dimensions and how have HP principles and praxis evolved over the past one hundred years?

- How do the metric-based recording traditions of accuracy, accessibility, and precision challenge VH representations?

- How is VH challenged by concerns for vernacular architecture, more mundane cultural landscapes, and other geographic contexts?

- What challenges to VH are presented by intangible cultural heritage and the lived experience of place?

- How is VH challenged by the functionality, inclusivity, and sustainability principles codified in recent international heritage doctrines and charters?

3. Examine how VH scholars have addressed the challenges posed by HP doctrines, and draw upon geographic concepts of space, landscape, and place to envision a VH system that addresses virtual and heritage principles.

- In what ways do the concerns of VR overlap with those of historic preservation?

- How have VH producers addressed reproduction fidelity in terms of accuracy, transparency, accessibility, and precision?

- How have common cultural landscapes and the stories of diverse people been recorded, analyzed, and displayed in historical GIS and VH systems? 
- How have scholars recorded and interpreted the intangible cultural heritage and embodied elements of place such as sound, emotion, and ritual? How can VH contribute to ICH research and vice-versa?

- What are serious games? What opportunities may be afforded by linking VR, serious games, and geospatial technologies to serve multiple goals in HP?

- What other qualities and functionalities should be included in a VH system that is responsive to its HP and VR principles and mindful of space and place? How might such as system be used for preservation planning, education, training, and interpretation?

4. Design a VH system that reflects traditional HP principles while drawing upon the opportunities afforded by VR, GIS, and serious games to enable the virtual reconstruction of heritage space, landscape, and place.

- Using commercial off-the-shelf (COTS) software, how might VR, GIS, and game engines be combined in order to digitally reconstruct historic buildings and other essential elements of cultural landscapes and place?

- How can GIS facilitate the use of historic maps to recreate the topography of lost landscape elements as a context for VH?

- What sensuous, emotional, and other intangible elements of heritage can be integrated into a VH system? Can such elements enhance a sense of presence and place?

- What COTS game engine is most suitable for integrating and visualizing 3D building models, landscape elements, and intangible phenomena?

- What VR platform is the best choice to demonstrate the potential of a place-based VH system? 
5. Produce a place-based VH system demonstration project centered on the now-demolished historic residence of Rebecca Harding Davis in Wheeling.

- How would Rebecca Harding Davis' home be recorded using traditional heritage recording methods and conventional VH?

- How can historic maps, historical GIS, and a traditional historic building survey aid in the virtual reconstruction of past urban spaces? How can one account for accuracy, transparency, and accessibility in locations where nearly all of the antebellum buildings have been demolished?

- Can one use a game engine, GIS, and VR to reassemble 3D models of significant elements in the cultural landscape?

- How can the writings of Rebecca Harding Davis be used to explore and experience the sensuous and emotional aspects of place in $\mathrm{VH}$ ? What other living and intangible elements may be incorporated into a place-based VH system?

6. Evaluate the model, discuss contribution, limitations, and directions for future research.

- How might the VH system be used in local planning, historic preservation, education, and heritage interpretation?

- How did the place-based VH model account for accuracy, transparency, and accessibility?

- How valid was the use of sensual intangibles such as emotion, perception, and experience in the place-based virtual heritage environment? 
- How effective was the place-based VH model in enabling users to explore the heritage site of Rebecca Harding Davis? Does the system's transparency, accessibility, sustainability, sensuality, and diversity transcend traditional approaches to $\mathrm{VH}$ ?

- What are the implications for future approaches to VH? What further avenues of inquiry should be pursued? Should a place-based VH system support analysis in historic-geographical studies? If so, how? If not, what good is it?

- How might a place-based VH system be incorporated into 'main-stream' VH work and contribute to HP and human geography?

\section{The Study Outline}

This introduction has begun to unpack the term virtual heritage (VH), including its origins and early development, and its relationship to Virtual Reality (VR) and historic preservation (HP). In the process $\mathrm{VH}$ is explored in the context of early computer applications in cultural heritage preservation such as virtual tours, virtual archaeology, and other heritage visualizations. A brief exploration of the principle characteristics of VR has provided a framework for critiquing VH in the light of HP principles and goals. Concerns regarding the lack of transparency and accessibility in such work will be further examined, and other challenges associated with VH will be identified by reviewing such work in the light of the evolution of cultural heritage recording praxis and cultural geographic thinking on space, landscape, and place. 
Chapter 2 begins with a review of cultural heritage principles that emerged through three important phases of the historic preservation movement. This review examines the challenges that have emerged since the term virtual heritage first appeared in a special issue of Massachusetts Institute of Technology’s VR journal Presence (Stone 1999). First among these challenges are accuracy, access, precision and transparency, a set of metric concerns expressed by virtual archaeologists and other heritage delineators Other challenges are related to the issue of contextualization in HP including the environmental and landscape contexts of historic sites, along with the common people, dwellings, and places of the past, often associated with identity, class, gender, race, and ethnicity. A third set of challenges are those related to the intangible aspects of cultural heritage and the lived, subjective experience of place. Finally, a fourth class of challenges are presented by recent international heritage doctrines that share a concern for the functionality, inclusivity, and sustainability of HP activities.

Because each of these challenges contributes to the discord between VR and HP, the dissertation turns in Chapter 3 to seek common ground among the principles of HP, the traditional concerns of VH, and key concepts in cultural geography. The chapter suggests that VR's traditional concern for reproduction fidelity mirrors HP's concern for accuracy and authenticity and the geographic concept of space. Second, it is noted that the goal of expanding the context and diversity of historic monuments in HP is similar to VR's desire to expand the extent of world knowledge and corresponds to the geographic concept of cultural landscapes. Third, it is proposed that the intangible aspects of cultural heritage relate to the geographic concept of place and concern for subjective human experience and the sense of presence in VR. These three areas of convergence provide a pathway to envision a place-based $\mathrm{VH}$ system that addresses the dissonance between HP and VR. 
Three basic qualities of a place-based VH are proposed. The first quality is that the system must be capable of delineating architectural and geographic space with fidelity and transparency and provide access to data, paradata, and assessments of uncertainty. A second quality is that the system must broaden VH to include "common" landscapes associated with the poor and working class. A third quality is that the system must provide a path toward experiencing the place-based aspects of heritage sites. Toward this end, the chapter examines literature on soundscapes, the sensuous past, embodiment, mobility, and non-representation theory, along with first-person serious games. A vision of a place-based VH system for sustainable HP is outlined.

Building on this vision, Chapter 4 examines the practical design considerations of such a system including the software and hardware components. Among the critical components is the need to model historic buildings, objects, and terrain associated with a historic place. In addition, game engines and GIS are used to integrate both tangible and intangible elements of heritage. A headmounted VR display serves as the main user interface to the place-based VH system.

Chapter 5 and 6 examine the implementation of a place-based VH system through a demonstration project centered on the 1850s home of realist author Rebecca Harding Davis in Wheeling, (West) Virginia. In contrast to traditional heritage recording and VH approaches, the case study demonstrates how historic maps, extant landscape elements, and GIS can be used to analyze the spatial characteristics of the lost urban landscape and its historic buildings and heritage. The system provides a framework for the virtual reconstruction of antebellum Wheeling by assembling 3D models of common house types, commercial and industrial buildings, and physical elements of the landscape while accounting for uncertainty and conjecture and providing access to data, paradata, and other digital assets. The platform explores 
the integration of the intangible elements of place such as memory, emotion, affect, and the sensuous aspects of being and place. The system and case study are evaluated in Chapter 7 , which includes a discussion of the project limitations, contributions to the field of $\mathrm{VH}$, and directions for future research. The transparency, accessibility, sustainability, sensuality, and diversity of the system are evaluated, along with the extent to which the tangible and intangible aspects were synthesized into a virtual experience of place. In so doing the chapter examines the potential utility of such work in local planning, HP, and interpretation along with potential contributions to human geography and $\mathrm{VH}$, and future directions given both the findings and limitations of the system and case study. 


\section{Heritage Principles \& Challenges for Virtual Heritage}

The London Charter revealed a lack of intellectual rigor and accessibility associated with computer-based visualizations of cultural heritage (Denard 2012). As early adopters of 3D digital technologies, archaeologists and geographers had encountered similar problems in the late 1990s and early 2000s while working in the fledgling years of Virtual Archaeology and 3D GIS, respectively. The emphasis on photorealism, stemmed from a focus on that central desire in VR of enhancing presence, to make a virtual model as convincing as possible and create the illusion of actually being present in the virtual world. This trend led to quite remarkable renderings of heritage sites, yet this focus was not accompanied by an equal emphasis on system functionality and this limited their impact as research and educational tools. Maurizio Forte (2000) was an early critic of the seemingly undue emphasis on verisimilitude because of the desire to create near perfect representations of ancient sites. Invariably, however, these representations were based on fragmentary ruins but without any disclosure of model estimation or conjecture. This lack of intellectual transparency and the inability for users to consider alternative interpretations of heritage objects in instances where the existing evidence was unclear was detrimental to archaeology and other cultural heritage fields where accuracy and verifiability are paramount. Concerns also arose about the obsession with the visual at the expense of other senses such as sound and smell, and the call was for more sensuous and reflexive heritage models (Gillings and Goodrick 1996). Gillings (2002) also expressed concern about the implicit emphasis on Cartesian geometry and the few attempts to seek alternative ways of knowing about place. He was one of the very first to suggest the use of phenomenology in VH to shift the focus from 
recording and rendering to one of "being" and experiencing sites. Where Forte had questioned the functionality, accuracy, and authenticity of 3D digital heritage, Gillings suggested that authenticity means something more than merely recording physical forms of structures with metric exactitude. At the keynote of VAST 2004, Neil Silberman, director of the Ename Center, challenged VH practitioners to break out of the "Cultural Heritage pipeline" and serve "others." Rather than focus on great buildings of the dominant culture, he argued that VH research should pay greater attention to common people and places. In this he revealed a populist and inclusive agenda influenced by critical social theory (Silberman 2004). The diverse perspectives expressed in these early critiques reflect not only the input from different disciplines, but also the differing ontologies and epistemologies of the people working in cultural heritage preservation. These diverse critiques suggest that rather than being a pure union of cultural heritage and VR, VH was in reality more a study of heritage squeezed through the filter of VR. Consequently, this chapter examines three major shifts in HP praxis and how these shifts reflect the influence of competing ontologies hinging on different interpretations of authenticity, a key term in cultural heritage.

\subsection{Heritage Recording Traditions \& HP Principles}

To better understand the critiques and challenges facing VH since its inception, three distinct shifts in the history of heritage recording can be identified. Although the London Charter's emphasis on accuracy can be linked to trends dating from at least the eighteenth century, heritage surveys of the nineteenth century reveal a propensity toward recording and preserving idealized forms of structures and adding conjecture, shadow, light, atmospherics, and life to perspective 
renderings. These tendencies made structures appear more realistic and evoked a sense of grandeur and melancholy about the past. The second quarter of the twentieth century demonstrated a shift toward the implementation of methodical surveys of structures that emphasized a dispassionate, objective, and accurate delineation of architectural monuments along with steps to make the resulting heritage records accessible. During the 1960s and 1970s there was a critical turn in heritage studies that emphasized the broader cultural, environmental, and geographic contexts of heritage monuments and a recognition that sites associated with the poor and working class were important but neglected elements of world heritage. Toward the end of the twentieth century a humanistic shift occurred in heritage studies toward the documentation, preservation, and interpretation of the personal and intangible elements of heritage. It is important to note, however, that even as new trends emerged each of the antecedent paradigms were not superseded entirely, but rather maintained an influence on how the field of heritage studies operated.

The practice of recording historic structures and places with measured drawings is part of a larger and widespread tradition in HP and included artists, architects, geographers, and others in the delineation of heritage buildings and ruins in historic landscapes. Tracing the history of such work reveals a long-standing precedent for including subjective, atmospheric, human, and natural elements and this is in stark contrast to the objective pursuit of metric accuracy that dominates the modern western tradition and is captured by the London Charter, the Historic American Building Survey (HABS), and the International Committee on Architectural Photogrammetry (CIPA). A closer look at the rendering of architectural antiquities suggests neither a revolution from idealistic/picturesque to realistic/scientific nor a continual march toward more accurate and precise delineation. 
The sixteenth and seventeenth centuries witnessed a proliferation in heritage delineation, mostly by Italian, French, and British artists and architects, and their sketches, paintings, and engravings depict a range of exotic and mysterious landscapes, ruins, buildings, and monuments of ancient civilizations that were rediscovered and sometimes "restored" in this era. Many artists, such as Bartoli in the 1670s, influenced by the Renaissance, often restored missing or ruined components in their drawings. Others, such as his contemporary Bernini, and predecessors such as van Heemskerck and Gioconda a century and a half earlier, depicted existing conditions with remarkable accuracy, even producing measured drawings (Jokilehto 1990). The eighteenth century saw the rise of picturesque influences in the drawing of ruins and heritage, which was a style that would remain popular into the late nineteenth century. The work of artists and architects spanning the Early Modern era, from Piranesi and le-Duc to Stuart, Roberts, Denon, and Friedrich exemplify the diversity of heritage delineation approaches that persisted into the late-nineteenth century and demonstrated that there was no steady transition toward more objective and accurate drawings (Burns 2004; Tracer 2005; Sanders 2008). As such, the somewhat sterile and objective mode of delineation of heritage buildings that arose in the twentieth century may be seen more as an aberration rather than an inevitable sign of modern progress.

Within the long and varied history of heritage delineation, $\mathrm{VH}$ can draw upon centuries of intellectual and practical development that it is not merely the domain of architects and engineers, but also of artists and humanists. This is particularly relevant as humanities scholars seek ways to contribute more to $\mathrm{VH}$ and to infuse humanist representation into the often lifeless products of VH. The legacies of the Gilded Age and Progressive Era -- of scientific, industrial, mechanical, objective, and modern impulses -- continues to drive heritage recording and 
delineation, whether analog or digital. Yet a review of subsequent heritage recording practices within the context of heritage conservation praxis reveals a more inclusive set of principles that may be used to outline a cultural heritage-based agenda for $\mathrm{VH}$ that complements and challenges the rise of VR and its incorporation within $\mathrm{VH}$.

In the twentieth century, engineering, architecture and photogrammetry pushed heritage delineation toward a more mechanical, detached, and objective course. The work of engineer Auguste Choisy, for example, reflects the growing influence of the analytical, objective mindset

(Tracer 2005; Lancaster 2009). Contemporary surveys of historic American architecture such as Ware's 1890s "Georgian Period" and Whitehead's 1910s "White Pine Series" reveals a similar emphasis (Davidson and Perschler 2003). The International Society for Photogrammetry, founded in 1910, was devoted to developing orthographic methodologies in photography focusing on the precision of metric geometry (Hobbie 2010). The First International Congress of Architects and Technicians of Historic Monuments (Athens Conference 1931) and the first concerted survey of historic American buildings (HABS) reflect this modern objective mindset, and established the scientific standards and principles by which western heritage delineation is judged today.

\section{HP Principle One: Accessibility}

In 1931 the delegates of the First International Congress of Architects and Technicians of Historic Monuments concluded that each country should conduct a survey of their built heritage and submit related documentation to central repositories, both regional and international. This 
seminal meeting on heritage conservation, later known as the Athens Conference, was silent about methodology but provided a vision that heritage survey records should be accessible. HABS followed directly in both time and spirit. Beginning in the winter of 1933-34, Charles Peterson led a nation-wide survey of the United States and made the results available through a collection housed in the Library of Congress. Peterson's agreement with the Library assured that the records would be preserved and be made accessible at a national repository in Washington, D.C. The drawings in the HABS collection reflect a concerted, if contested, effort to root out vestiges of subjectivity in American heritage delineation. United States heritage delineation henceforth came to imply objective, measured drawings devoid of "extraneous elements" (Davidson and Perschler 2003).

HP Principle Two: Accuracy \& Intellectual Transparency

Since the 1930s, heritage delineation traditions in the United States have been exemplified by HABS, with priorities and values codified to the Secretary of the Interior's Standards for Architectural and Engineering Documentation, also known as the HABS/HAER standards (Vogel 1983). The four standards reveal a central concern about the reliability, accuracy, and availability of heritage data, and emphasized accuracy, clarity, transparency, honesty, use of primary sources, and permanence of the record. Above all, heritage delineators in the United States were charged to strive for accuracy and to record the remains of the past based on field survey and primary source materials. Any conjecture or uncertainty in a delineation had to be noted on the drawings and explained in the detailed field measurements and supporting historical research that must be stored along with the original pencil drawings and final ink-on-Mylar 
submissions made to the Library of Congress. This emphasis on record transparency is

maintained through the formal partnership with the Library which ensures permanent access not only to the records but also to the documented evidence upon which such heritage delineations were based (Vogel 1983). The scientific tradition that arose in the twentieth-century demands that heritage delineation be accurate and accessible in order to maintain transparency and enable validation. Applied to computer-based visualization of heritage, these principles were captured and expressed in the London Charter, which also decried hyperrealism and the temptation toward ever more precise details in the quest for verisimilitude.

\section{HP Principle Three: Precision}

The terms accuracy and precision in HP are often confused. Whether the intent is to digitize a document, delineate a historic house, or digitally reconstruct a cultural landscape, the common emphasis on accuracy is meant to minimize distortion and provide full disclosure of sources, methodology, and limitations. The value placed on accuracy is evident in HABS/HAER Standard II that "documentation shall be prepared accurately from reliable sources with limitations clearly stated to permit independent verification of the information" (Vogel 1983). Notice, however, that the standard does not specify a level of precision, which may vary depending on the purpose of the project. The earliest HABS surveys of the 1930s demonstrated efforts to measure and delineate historic structures to the nearest half-inch. Subsequently, the desired level of precision has been changed to one eighth of an inch. For the International Committee for Architectural Photogrammetry or CIPA (UNESCO 1968), which studies new technologies associated with metric surveys as an aid to conservation work, the level of precision 
for one project may be much greater than that for another project that sought to interpret a larger extensive area. Thus a recording team, whether analogue or digital, must choose a level of precision that is appropriate for the intended use of the product within the overall limitations of the project (Stovel 1990).

Whatever level of precision is dictated by the scale of the project and resources available, producing accurate and accessible records of important cultural heritage resources has been a core value of historic preservation since at least the 1930s. That these principles remain central to HP surveys of the twentieth-first century is apparent in two of the most important international documents on heritage recording in the digital age: The London Charter (Denard 2012) and the RecorDIM initiative, which are addressed further below (Letellier 2007).

\section{HP Principle Four: Authenticity.}

Three tumultuous decades passed between the 1931 Athens Conference and the second major international heritage convention, held in Venice, Italy in 1964. In 1951 UNESCO organized an International Council on Monuments and an international center for conservation (today's ICCROM) launched in 1959 (www.iccrom.org). The 1964 conference approved the Venice Charter, written by ICCROM, and established an International Council on Monuments and Sites (ICOMOS) to carry out the intent of the Charter and to advise UNESCO on heritage matters (www.icomos.org/en). The authors of the Venice Charter went much further than had their predecessors at the Athens Conference, stating in Article 1 that the built heritage should not only be studied, inventoried, and the information then be archived, but also that buildings and sites should not be selected for preservation merely based on aesthetics; instead, all relevant historic 
structures, whether great or "more modest" should be protected. In other words, a building did not have to be great or "beautiful" to be worthy of preservation; rather, humble, vernacular building forms, and even fragmentary ruins were also considered valuable in their own right and as sources of evidence. The charter emphasized authenticity above all else and this criteria occurred in at least five of the sixteen articles, and reflects the continued dominance of the empirical paradigm of the Athens Charter and HABS (www.icomos.org/charters/venice_e.pdf).

That authenticity was of central importance to the Venice Charter is a sign that it was perceived as a major problem in mid-twentieth century preservation practice. This concern is reflected in the early work of HABS that did not always fulfil the scientific dictates of early HABS directives. Some heritage delineations were rendered with color washes, while others depicted "superfluous" details such as vegetation and atmospherics. Other deviations included the conjectural reconstructions of a cultural landscape based on the distant memory of local inhabitants and other examples where architectural additions were "removed" from structures by the delineator without explanation. These issues reflect a resistance by the latter-day heritage community to the goal of a "pure" objectivity and the charge to record existing conditions (Davidson and Perschler 2003) and the persistence of the nineteenth century trait to include subjectivity and idealism and to imagine and render a fuller and more humanist reconstruction of the past.

Authenticity also proved elusive in the contemporary open-air heritage parks of the United States. Colonial Williamsburg and Greenfield Village stand as two of the most famous largescale examples of early twentieth-century preservation and heritage interpretation in the United States (Tyler et al. 2018). The widespread demolition of nineteenth and early-twentieth century 
structures at Williamsburg, Virginia and subsequent construction of dozens of buildings approximating eighteenth-century structures was undertaken in a monumental attempt to rebuild a colonial city. Ford's gathering together and arrangement of his collection of historic American buildings, as with Rockefeller's venture at Williamsburg, exhibits a certain idealism in HP albeit at the cost of failing to distinguish between reconstruction and conjecture and what was genuine or authentic. These efforts are reminiscent of the preservation ideology of Violet le Duc, who argued that conservation should serve a higher aesthetic purpose not to preserve the past exactly as it was, but rather what it might have been under ideal circumstances (Francou 1997). Although controversial today for adding "extra" towers during the restoration of twelfth-century cathedrals, le Duc had a profound influence on modern historic preservation, for he pioneered the modern scientific notion of recording historic monuments prior to any restoration work so that what is new can be distinguished from what is old (Poisson 2014). From this perspective, infilling "missing" details is not necessarily bad practice but depends on the circumstances and one's perspective. Le Duc, at the very least, was honest about his reconstructions. Concepts of authenticity vary, like concepts of reality, across social groups, time, and space. Thus, as discussed below, authenticity is a contentious issue in cultural heritage that continues to challenge the profession.

\section{HP Principle Five: Geographic Context}

Significantly, the Venice Charter also expressed concern for the geographic context of historic buildings and the composition and protection of the environmental setting. Article 6 of the Venice Charter explained the importance of a heritage site setting, suggesting that a protected 
area should extend well beyond the walls of the structure itself. This concern was partly a reaction against the escalation of modernization in cities at mid-century and the impact on historic neighborhoods as seen in Urban Renewal and the Interstate Highway System of the United States (Jokilehto 1995). The Charter also expressed concerns for cultural landscapes in line with a major thrust of geographic thinking in the twentieth century (Meinig 1979; Leighly 1965; Wallach 2005). After the National Historic Preservation Act of 1966, the conventions employed by American preservationists expanded to demonstrate a general concern for a historic site's many contexts (cultural, natural, social, political, geographic, etc.). The identification and development of such contexts has become a critical part of the documentation, recording and interpretive process of historic buildings (National Park Service 1997), engineering structures (Burns 2004), and cultural landscapes (Birnbaum 1994; Stipe 2003).

\section{HP Principle Six: Vernacular Significance}

The Venice Charter's concern with preserving the topographic context of heritage landmarks extends to include the cultural landscape and the humblest and most commonplace building types that should be recognized and preserved along with the great and beautiful (UNESCO 1964). Moreover, the Charter was followed a decade later by the World Heritage Convention, that sought to recognize and protect cultural heritage sites of international significance. The Convention considers both cultural and natural heritage sites that include not only great monuments but also buildings and settlement patterns with outstanding universal value (World Heritage Center 2017). The roots of such concerns in the United States may be traced from the early HABS program, which was influenced by earlier folk studies along with the cultural 
landscape focus of the "Berkeley School" dating from the 1920s (Leighly 1965). These and related concerns were reflected in later Critical Social Theory that sought to document the power structures and spaces of "other" often marginalized social groups manifest in the landscape (Harvey 1989). For such scholars, what is authentic and most important about the world are the differences between social groups, marginalized communities, and deconstruction of the material culture of a society, such as their texts, symbols, spaces, and landscapes. Such sentiments for the commonplace are found in living history museums that by 1970 numbered nearly two dozen across the United States (www.ALHFAM.com) as well as in the inclusion of more commonplace buildings that "embody the distinctive characteristics of a type, period, or method of construction" on the National Register of Historic Preservation (National Park Service 1995). More recently these concerns can also be seen in the proliferation of preservation activities associated with buildings, landscapes, and objects associated with race, class, gender, religion and ethnic differences (Joyner 2003, 2005, 2009; Tomlan 1998) such as New York's Tenement Museum (https://tenement.org) and the National Museum of the American Indian (www.si.edu/Museums/american-indian-museum).

Thus internationally, the Venice Charter, the World Heritage Convention, and subsequent cooperative developments have moved beyond sole consideration of the great monumental structures of the past to consider preservation of commonplace buildings and landscapes associated with social groups in their geographic context. The United States followed UNESCO in recognizing the universal value of commonplace architecture and landscapes, and such concerns have deep roots in American geography and heritage delineation practices. Authenticity remains a central concern, but what is authentic is now open for debate and has 
been broadened to include places that account for a wider range of the human experience. By the 1990s, however, even this broader definition of authenticity was inadequate.

\section{HP Principle Seven: Intangible Heritage}

The Nara Document on Authenticity marked a new era in international heritage management practices and priorities (UNESCO 1994). The Document was a reaction against the definition of heritage authenticity as embodied in the 1972 World Heritage Convention, which focused on the material aspects of heritage and dismissed eastern perspectives that treasured traditional rituals, skills, and shared experiences over those of physical objects. The Nara Document acknowledged variations among societies and social groups in what they consider to be authentic, genuine, trustworthy, and valuable, and in so doing it validated non-western value-systems and ways of knowing.

About a decade after Nara, UNESCO ratified the Convention for Protection of the Intangible Cultural Heritage and opened a pipeline of World Heritage designations to ICH (UNESCO 2003). Between 2008 and 2017, the first ten years of such designations, 470 local customs, rituals, craftwork and other intangible aspects of culture from 117 countries were added to the World Heritage List (https://ich.unesco.org/en/lists). Thus the recording and preservation of the world's greatest cultural treasures are not limited solely to material objects but also to intangible phenomena. Such intangible heritage representations challenge traditional methods for preservation such as conservation in a lab, curation on a shelf, or restoration in-situ, and required different approaches. These phenomena offer a special challenge for delineators as well in that 
they cannot be measured, drawn, photographed, or described adequately in the same fashion as material culture. Therefore, ICH designations reflect alternative forms of ontology and epistemology indicative of humanistic influences in geography and other academic disciplines and more recent interest in the personal, subjective, and immaterial components of the lived experience of various cultures, social groups, and individuals.

HP Principles Eight, Nine, Ten: Functionality, Inclusivity, and Sustainability

Nara was the harbinger of a series of international doctrines representing new and revised ideas about heritage and how its preservation and interpretation should be accomplished in the twentyfirst century. The Convention for the Protection of Intangible Cultural Heritage was followed by the RecorDIM initiative (Letellier 2007), the UNESCO Ename Charter on Interpretation (Silberman 2009), and of course the London Charter on computer-based visualization (Denard 2012). Each of these doctrines addressed best practice in different aspects of cultural heritage, and remarkably the principles of functionality, inclusivity, and sustainability form a common thread in each of the international efforts. The 2003-2009 RecorDIM initiative, led by the Getty Conservation Institute, was an effort at bridging a gap between heritage recording professionals and those who do "bricks-and-mortar" preservation work (Letellier 2007). Among the RecorDIM guiding principles was that heritage recording should focus on process rather than product. Because heritage recording and documentation are preliminary steps in any preservation effort, from stabilization to restoration, to a relatively simple interpretive effort, the RecorDIM argued that such recordings should be conducted mindfully with functionality in mind and potential users included throughout the process. The authors of the RecorDIM principles 
argued that inclusivity and focus on iterative functionality contributes to the efficiency, sustainability, and ultimate success of any preservation effort.

The London Charter echoed these sentiments. It argued that computer-based visualizations should only be undertaken when necessary for the goals of the project. Whether as an aspect of heritage recording, an aid to heritage conservation, or to support analysis, education, or interpretation, the effort should be purposeful, and the design should reflect its ultimate function. During the Charter rewrite for 2012, which moved beyond a strict focus on 3D visualizations, the principle of sustainability was added, and accessibility was included as a separate principle, rather than being included as an aspect of transparency (London Charter 2006; Denard 2012). .

The Ename Charter on the Interpretation and Presentation of Cultural Heritage (Silberman 2006) also espoused the principles of sustainability, functionality, and inclusion, and reiterated many of the principles of the early and mid-twentieth century delineators such as the importance of accessibility, geographic context, authenticity, material and immaterial notions, and local and universal significance. Crafted at the Ename Center in Belgium, the Charter argued that it was critical to preserve and interpret common places, to draw upon diverse sources that reflect multiple truths and points of view. Inclusivity therefore is of central importance, for it influences the entire process, from planning, to data collection, and processing the heritage information with and for the public. As Silberman (2009) explained, all activities leading to communication and interpretation at a heritage site must be inclusive in order to be functional, for without these two qualities, preservation efforts are likely to be unsustainable. Inclusive collaboration increases interdisciplinarity along with the responsiveness of the preservation effort to meet local needs, which in turn makes the project and processes more useful and relevant to the community and 
thus contributes to the long-term sustainability of the conservation effort. Because sustaining heritage assets is the sine qua non of historic preservation, the interrelationship of functionality, inclusiveness, and sustainability reflected in the most recent doctrines represents a critically important set of principles.

\subsection{Seven Challenges Facing Virtual Heritage in Light of Heritage Principles}

Together, these principles reflect the evolution of heritage praxis over the past century or more, and provide guidance for the diverse sites, communities, disciplines, efforts, and challenges involved in historic preservation today. The principles of inclusion, functionality, sustainability, and intangible heritage can be added to those that arose earlier in the twentieth century: Access, transparency, appropriate level of precision, authenticity, geographic context, and concern for the commonplace. Together, these principles inform the critique of virtual heritage work of the past twenty years, which in turn provides guidance for envisioning a VH system that more fully reflects fundamental heritage principles. The critique begins with an examination of how the work and scholarship of early virtual heritage was disseminated and made accessible.

\section{Challenge 1. Provide Access to VH data, paradata, and products}

A brief look at the early years of virtual heritage, reveals that the main route to accessibility was initially (1999-2004) through conference papers and demonstrations and later peer reviewed books and journals. Virtual Systems and Multimedia (VSMM), launched its Virtual Heritage Network in 1999 with the support of UNESCO held several special sessions on virtual heritage. 
The second major conference disseminating VH research called VAST (Virtual Archaeology, Science and Technology) was held with support from the European Union in conjunction with EPOCH (European Program for Open Cultural Heritage). Paper sessions at the annual VSMM and VAST conferences were typically organized around common themes such as technical issues, modeling, data capture, rendering, analysis, display, avatars, integrated system technologies, and methodology. These papers showed finished VH products, usually in the form of animated "flyovers," which were often visually impressive and often seen by millions of viewers on television networks such as the History Channel and Discovery Channel and at some world class museums. Virtual Reality laboratories embraced the field of heritage with alacrity. Over the next decade, cultural heritage emerged as one of the top subjects of VR research (Gutierrez 2008) and within a few years, a number of journals emerged to publish peer-reviewed papers in the fledgling field. By and large, however, the leading books and journals published about $\mathrm{VH}$ and other aspects of digital cultural heritage were edited and published by organizations such as IEEE, ACM, and MIT Press that specialize in the computational or "virtual" side, rather than within cultural heritage. Moreover, after a decade of research in VH, it was apparent that neither the models themselves nor their supporting data, nor their limitations had been made available for independent verification and validation.

As Maurizio Forte (2010) explained at the concluding conference of the RecorDIM initiative, almost without exception, $\mathrm{VH}$ projects follow a tragic path. For a brief moment $\mathrm{VH}$ products are presented in conference papers, including a few selected illustrations and perhaps an animated flythrough, and disseminated in conference proceedings or a journal article. After a short existence, digital VH models quickly die, never having existed beyond the lab. Forte estimated that less than one percent of the products of Virtual Archaeology and VH were available to 
scrutinize, analyze, or otherwise evaluate less than a decade after their debut (Forte to Bonenberger 2010). The files, sources, models, and products of VH are by and large unavailable aside from conference papers, still images and animated fly-throughs. If, as discussed in the introduction, heritage is what is passed down to the next generation and virtual is "almost, but not quite," then ironically, these VH products have become "almost but not quite" heritage. Without changes VH products are unlikely to be passed down to future generations. This inaccessibility runs counter to the Athens Charter (1931), HABS Standards (1983), RecorDIM (2007), and the London Charter (2009).

One notable exception to this trend is the Great Buildings online gallery of digital 3D models depicting landmarks in the history of world architecture (www.greatbuildings.com). Of course there are limitations within the scope of the thousand or so buildings, for as its name suggests, Great Buildings is predominantly a collection of outstanding grand architectural monuments with only a few examples of humble vernacular dwellings included. The Great Buildings also lack landscape as context, signs of life, and generally may only be viewed as models rather than explored from a first person perspective. Accessibility is limited to downloadable 3D models without accompanying paradata that might enable scholars to independently validate or verify the work. Great Buildings though serves in some respects as a model for making digital 3D modeling of heritage widely accessible, and since it dates to the late 1990s, it stands as a model for sustainability as well (www.greatbuildings.com 1999). Newer models for making virtual heritage accessible are emerging from partnerships among VH producers, publishers, and digital archives. For example, the Digital World Heritage Lab and its recent journal Digital Applications in Archaeology and Cultural Heritage curate all digital models associated with papers that are published in the journal, thereby ensuring continued access to such work 
(Frischer 2014). To the same end, the Virtual Archaeologists engaged with the ongoing archaeological research of 7100-6700BC ruins at Catalhoyuk, Turkey have partnered with San Diego State's Special Collections to archive a collection of 3D models, renders, Unity3D asset packages, and metadata related to the virtual reconstruction of the Neolithic site (Lercari et al. 2018). These projects demonstrate that VH scholars are seeking to identify creative ways to incorporate accessibility into the design of their systems and research projects, and provide access to primary sources, data, products, and paradata regarding how the models were created and produced.

\section{Challenge 2. Maintain Accuracy \& Intellectual Transparency}

The principle of authenticity as expressed in the Venice Charter requires that the material remains of heritage should be recorded, conserved, and interpreted with accuracy and transparency. As suggested in the London Charter, accuracy, transparency and access have been elusive concepts for VH. For example, one of the highest profile projects of early VH, called VRND (or Virtual Reality Notre Dame) used the Unreal game engine and featured a friar (built in 3D Studio Max) to serve as a non-player character (NPC) guide. Nearly twenty years later, the flythrough video remains impressive (https://www.youtube.com/watch?v=x283cGFN0hQ). The project's claim to be “90\% architecturally accurate," however, was vague and unsubstantiated, for there was no way to know the basis of that statement nor verify or validate the claim (House 2001). The team, led by VR experts, had as a goal the "total suspension of disbelief" (Deleon 1999), so it was no wonder that paradata for the project was limited. This aspect underscores that the competing priorities of authenticity and verisimilitude are among the biggest challenges 
to VH because VR strives above all to promote a sense of presence to the user in the virtual environment. That the first peer-reviewed journal of Virtual Reality was called Presence (MIT Press, 1992-present) rather than Reproduction Fidelity or Extent of World Knowledge underscores the emphasis that early researchers placed on this aspect of VR over all other principles. The resulting undocumented conjecture runs counter to authenticity, which the heritage recording and HP standards of the United States and abroad hold as the highest principle.

The United States Secretary of the Interior's Standards states: “Documentation shall be prepared accurately from reliable sources with limitations clearly stated..." (Vogel 1983, emphasis mine). For HP, all conjecture must be disclosed. For VR, in contrast, it seems that all conjecture must be hidden in order not to lessen the sense of presence. Beyond this, Lon Addison (2010) suggested that the lack of transparency and accessibility in digital heritage and $\mathrm{VH}$ is due also to the reluctance of people to share their intellectual property, which results in a great deal of wasted energy and redundant research. The prominence of transparency as an issue in the London Charter for the Computer-based Visualization of Cultural Heritage underscores the importance of this principle, which is reflected not only in the international organizations that participated in the London Charter, but also the papers presented at the annual conferences and symposia of the International Committee on Architectural Photogrammetry (CIPA), English Heritage, ICCROM, and TICCIH (Blake 2009).

In contrast, the priority in $\mathrm{VH}$ has been placed largely on making plausible models, which, combined with the lack of accessibility and documentation often leads to questions about the accuracy of such work. If not transparent and documented, with clear explanation of limitations, 
scholars cannot necessarily accept many of the representations that are produced. Without provenance, there is no authenticity. If inaccuracies, conjecture, and uncertainty are mere distractions to VR that must remain hidden in pursuit of the goal of presence, then the lack of disclosure itself is a distraction that breaks the spell for heritage scientists.

Thus VH must balance scientific priorities with the need to reconstruct missing elements based on the best available information, a practice rooted in earlier centuries but taboo according to HABS and their focus on the certainty of existing conditions. The challenge for $\mathrm{VH}$ then is to represent not only existing conditions but also to reconstruct the missing elements of past buildings and landscapes in a way that is intellectually honest and provides sustained access to the data, 3D models, and supporting information on sources, methodologies, and areas of uncertainty, while also fostering a sense of presence in the virtual world.

\section{Challenge 3. Identify the Appropriate Level of Precision}

It is difficult to evaluate the VH cannon in terms of precision. Without access to the products of $\mathrm{VH}$ and their paradata, the level of precision, like accuracy, remains unknown. Over the past century, the metric-based recording tradition of HP has striven for increasingly accurate and more precise methods. During the 1930s, HABS surveyors measured architecture to the closest $1 / 2$ inch, but by the 1990 s as CAD and digital photogrammetry became more commonplace in the field, the standard of precision had increased to 1/8 inch (Bonenberger 2008). Recent digital laser scanners enable measurements approaching 1/1000 of an inch. The level of precision achieved with the latest 3D laser scanners can be measured in millimeters for objects and 
centimeters for terrain recording and far exceeds what was possible with analog recording methods. There are times when conservation and restoration priorities may demand accuracy to the millimeter, such as when monitoring the stability of small imperfections in a historic structure or delicate work of art (Eppich 2017; Bryan et al. 2009).

In $\mathrm{VH}$, however, there is a tradeoff between the desire for real time navigation of the environment and the drive for ever-increasing precision in representation. The enormous data sets associated with Light Detection and Ranging (LiDAR) and Terrestrial Laser Scanners (TLS) are simply too large to be processed effectively in current real time VR environments. This issue hinders the ability to navigate a virtual environment in real time to the detriment of presence and the potential richness of the experience - depth and breadth - and the extent of world knowledge. Structure from Motion (SfM) has recently emerged as a viable alternative to laser scanning, and provides an accurate if less precise means of 3D modeling based on the overlap of photographs taken from multiple viewpoints (Martos and Ruiz 2013, Smith et al. 2013). SfM and indirect data capture methods may be useful in 3D modeling and reconstructing historic environments where precision can interfere with other project goals such as real-time navigation, exploration and interactivity. Indeed, there is a case to be made for decreasing precision to $+/-3$ inches or even greater in $\mathrm{VH}$ when the scope of the reconstruction or simulation is at the neighborhood scale. Thus the challenge for VH is to identify the appropriate level of precision and detail for a given project, relative to the scale and desired purpose of the effort, and there is a necessary tradeoff between precision and system response. 


\section{Challenge 4. Reflect the Significance of the Commonplace \& Vernacular}

The World Heritage Convention (1972) argued that there were two equally significant types of structure in HP: buildings associated with important people or unique works of art (i.e. great buildings) and outstanding examples of vernacular buildings representative of particular sociocultural groups and places (http://whc.unesco.org/en/basictexts/). Unfortunately, the preponderance of $\mathrm{VH}$ effort has been devoted to modeling great buildings with seeming little concern for vernacular architecture (Silberman 2004). Perhaps this imbalance is due to an outdated perception that lingers among some HP traditionalists that greatness equals significance. Examples of great buildings in VH research such as the Pyramids at Giza (www.3ds.com/stories/giza-3d/), the cathedral at Notre Dame, and the great buildings of ancient Rome are indeed conspicuous. The latter of these examples provides a particularly useful case study in how public interest in great buildings can be turned toward a greater appreciation for the commonplace and vernacular, and shed light as well on the geographic cultural landscape context (http://vwhl.squarespace.com/rome-reborn/).

Virtual archaeologists perhaps have been more in tune with the commonplace than others, as researchers in that field routinely seek to understand the often minimal remains of ruins and traces of human occupation. For example, Bernard Frischer, the leader of Rome Reborn, lamented that commercial interests had taken $\mathrm{VH}$ down a false path where significance was seen to be synonymous with greatness and photorealism more important than transparency. Instead Fischer sought to digitally reconstruct fourth-century Rome from the greatest to the humblest of structures and to involve scholars in validating individual building models (Frischer 2008). In another example, North Dakota State's On-A-Slant Virtual Village reconstructed a late 
eighteenth-century Mandan Village that was available to download and explore via a PC-based first-person game environment (Hokanson et al. 2008). In his keynote address to the VAST conference Neil Silberman (2004) also lamented the predominance of focus on monuments and he urged practitioners to break out of this traditional "cultural heritage pipeline" and to serve "others" both in subject matter and audience. Silberman would later spearhead the Ename Charter on Interpretation, which emphasized inclusion and diversity as principles to be followed in interpretation and presentation. Cameron and Kenderdine (2007) echoed these pluralist notions of knowledge production and Gillings' earlier call for reflexivity (Gillings and Goodrick 1996). Thus VH in the United States and international arena has been challenged to give greater attention to the commonplace and the great buildings as significant parts of history and culture worthy of designation and preservation. VR and VH professionals must recognize the importance of these other kinds of buildings and places, especially those associated with minority social groups that have heretofore been largely neglected.

\section{Challenge 5. Explore Cultural Landscapes \& Geographic Contexts}

The Venice Charter and NHPA concluded that heritage sites should be preserved in situ and that their environmental surroundings are of critical importance to appreciating and understanding those sites and are also worthy of preservation. In contrast, $\mathrm{VH}$ projects typically focus almost entirely on the "great" structure itself, with little if any concern for the surrounding landscape context (Bonenberger and Harris 2010). This issue was especially problematic in the early years of $\mathrm{VH}$, when scholars almost without exception focused resources entirely on structures with no geographic or landscape context whatsoever. Even the exemplary work of VH such as VRND 
(Denard 1999) and the Enichiji Temple project (Calef et al. 2002) focused solely on the great building situated in a geographic vacuum. The traditional focus of HP on the conservation of the structure itself, reinforced by the empirical emphasis of HABS, CIPA, ICCROM, the Association for Preservation Technology, and the RecorDIM initiative has been to the cost of consideration for their historic location and surrounding cultural landscape context.

In VH, exceptions to the lack of geographic context are to be found in Frischer's work on Rome Reborn, which examines the broad expanse of the fourth century urban landscape of Rome (https://www.romereborn.org/), and in North Dakota State's On-A-Slant. Recent work in this area offers some promise including the Great Pyramids at Giza (Der Manuelian 2013) and a Unity3D game-based reconstruction that opens with the user arriving by boat to the dock at Russian Fort Ross in the U.S. Pacific Northwest before being led into the fort by an NPC guide (Lercari et al. 2013). Projects at West Virginia University have used Sanborn insurance maps to digitally reconstruct urban landscapes of the late nineteenth and early twentieth centuries (Harris et al. 2017; Harris et al. 2008; Bonenberger and Harris 2013). Together these projects suggest the enormous potential for incorporating cultural landscape contexts as a major element in $\mathrm{VH}$ projects and indicate that GIS is an underutilized element in VH that might facilitate such work and enable additional analytical and functional capabilities, particularly when integrated with first-person serious games. In sum, VH is challenged to move beyond modeling individual structures in $\mathrm{VH}$ and toward crafting a broader and more diverse cultural landscape that incorporates knowledge of landscape environments, past and present into virtual heritage. GIS and serious games may provide opportunities for accomplishing such work. 


\section{Challenge 6. Intangible Heritage \& Experience}

The Nara (Japan) Document on Authenticity revealed the limits of a western approach to heritage conservation, and urged a "greater respect for cultural and heritage diversity to conservation practice" (UNESCO 1994). A decade later, the Convention for Safeguarding Intangible Cultural Heritage ( $\mathrm{ICH}$ ) recognized the importance of designating and preserving humanistic and sensuous heritage such as oral traditions, performing arts, social practices, rituals, and traditional craftsmanship. In addition to the humanistic and sensuous nature of $\mathrm{ICH}$, the Convention's expression that such things are "living, rooted and tradition, and constantly recreated" is particularly relevant and challenging to VH (https://ich.unesco.org/en/convention). By its very nature, VH seems an ideal medium for recording and interpreting dynamic rituals, customs, and practices. However, with a predominant focus on great buildings taken out of their cultural landscape context, VH products typically reveal few if any signs of life or intangible elements of heritage. In this way, $\mathrm{VH}$ reflects a long-standing practice of focusing on material culture in western cultural heritage conservation management. In contrast, ICH is sensuous, dynamic, and constantly, if slowly, evolving. The typical focus on product rather than process leaves $\mathrm{VH}$ users stuck in a static time slice where little, if anything, changes through time and there are rare opportunities for exploration or interaction with other players or NPCs.

There were, however, a few exceptions in early $\mathrm{VH}$, and the past five years have seen greater progress in addressing ICH and incorporating life and lived experience into VH. VRND (Deleon 1999), On-A-Slant (Hokanson 2008), and Revolution (Haas 2008), all enable users to interact with NPCs or other players and constitute notable advances in VH. That all three employed game engines suggests the potential of such technologies as a means of promoting interaction, 
collaboration and experience in VH. These examples did not, however, explicitly address ICH, including animal life, or the sensuous and emotional aspects of heritage.

ICH was among the conspicuous themes of the first Digital Heritage International Congress, held in 2013, which was a landmark in the history of digital heritage because of the disparate interests, organizations, conferences and symposia, including UNESCO, CIPA, ICOMOS, CAA, VSMM, Space to Place, Museum and Technology, Arqueologica, Eurographics, Archeovirtual, and others that finally came together at one venue. The Congress also included several papers and demonstrations using Unity3D as the new game engine of choice (Lercari et al. 2013; Frischer and Fillwalk 2013; Pietroni et al. 2013), and use of SfM for 3D image capture (Martos and Ruiz 2013; Smith et al. 2013), which may have important implications for ICH interpretation. Some papers addressed ICH explicitly while others incorporated sensuous, dynamic, and other intangible elements. Karivia and Georgopoulos (2013) evaluated the five domains used by the World Heritage Convention to classify ICH, considered how each could be digitally documented, and suggested that GIS could be a means of spatial analysis and communication. Bernadette Flynn's study of embodiment in VH examined visitor movement and "kinesthetic engagement" within an immersive virtual environment. She documented feelings among users of "engaging with a reenactment of movement from the past and thus an activation of place from the past into the present" (Flynn 2013). These papers suggest that VH may serve as a platform for documenting and interpreting ICH and that a phenomenological experience of place may be achieved in $\mathrm{VH}$ by incorporating intangible elements and enabling visitors to move about freely and linger in such environments. The challenge for $\mathrm{VH}$ scholars is to incorporate ICH elements as somatic, sensuous, emotional elements of the past as an equal partner with material culture. Furthermore, if the $\mathrm{VH}$ is to serve as a platform for recording and 
simulating dynamic rituals, customs, and practices, and exploring the experience of heritage reconstructions first hand to gain some sense of the place, it must be undertaken in collaboration and with respect to the social groups in question.

\section{Challenge 7. Functionality, Inclusivity, and Sustainability}

Just as the ICH Convention revealed that heritage is not static and that different social groups hold different conceptions of authenticity, the latest international heritage doctrines from the London Charter, RecorDIM initiative, and Ename Charter recognize that heritage recording and interpretation should be dynamic, inclusive, functional, and continuously evolving. If heritage research, historic preservation and interpretation is to have a lasting impact, it must be inclusive and useful to the community. Almost without exception, the products of VH look impressive if not breathtaking, thanks to the aesthetic and historical significance of the subject matter and emphasis on verisimilitude. However, beyond visually communicating photorealistic 3D images of great historic buildings, the functionality of $\mathrm{VH}$ has been limited and the broad range of historic preservation activities described in Chapter 1 (Fig 1) have been served inadequately.

Maurizio Forte's dissatisfaction with the early work of Virtual Archaeology he argued was due to an obsession with photorealism at the expense of other functionalities (Forte 2000). Since then, however, VH technologies have been used to analyze, visualize and debate knowledge about ancient sites and peoples in new ways, even enabling disparate researchers to meet and collaborate within reconstructed virtual environments (Forte 2010). In addition, significant functionalities are seen in VH projects such as On-A-Slant (Hokanson 2008) and Rome Reborn. 
Both these projects serve as constructivist tools for educating students in archeology and historic preservation (Frischer 2008; Frischer 2017). The former project enabled archaeology students to virtual travel through time from the present archaeological site to reconstructed landscapes of the past. The latter project addressed validation issues with an interdisciplinary team of experts working in partnership with computer modelers to verify the models produced in a long-term effort to virtually reconstruct Ancient Rome. More recently, the leader of Rome Reborn pioneered another step toward sustainability of $\mathrm{VH}$, when Bernard Frischer established the journal Digital Applications in Archeology and Cultural Heritage to curate digital heritage models that are the subject of its peer-reviewed papers (Frischer 2014), enabling the journal to function as an iterative, accurate, and sustainable platform that promotes VH scholarship, historic preservation and heritage interpretation. Thus scholars are challenged to recognize that $\mathrm{VH}$ is a tool that can aid in the broadest range of HP activity and is capable of sustainability, inclusivity, and functionality. The principles introduced above and the related challenges that have been explored have included examples of scholarship that may serve as potential models for expanding $\mathrm{VH}$ as a tool for identifying heritage, documenting existing knowledge, recording existing conditions, and analyzing, managing, interpreting, and disseminating heritage information and knowledge.

\section{Summary}

This chapter has identified seven challenges that must be addressed if $\mathrm{VH}$ is to serve the principles of HP and international heritage doctrines. These challenges can be considered in three groups that stem from the eras in HP development discussed above: the scientific 
challenges of accessibility, accuracy, and precision; the challenges of preserving vernacular and common heritage, cultural landscape and geographic context; and finally, the challenges of Intangible Heritage, functionality, inclusivity, and sustainability. Given the dissonance identified between HP and VR, one might expect the principles of HP to be irreconcilable with those of VR. The next chapter, however, begins with a search for common ground and identifies possible convergence between those two fields which provides the basis for envisioning the qualities and potential components of a $\mathrm{VH}$ system that responds to the principles, needs, and challenges of HP and VR. 


\section{Envisioning a Place-based Virtual Heritage System}

The review of cultural heritage doctrines and the critique of virtual heritage (VH) projects presented above reveals numerous ways that such work has often been at odds with the principles of cultural heritage. Examining the dissonance between cultural heritage and virtual

reality (VR) and identifying associated challenges are important first steps toward designing a VH system that fulfills international heritage principles. This chapter envisions the characteristics of such a system based on common ground between the principles of historic preservation (HP) and the essential aspects of VR. The areas of convergence are explored in detail to envision $\mathrm{VH}$ as an empirically accurate delineation of architectural and geographic spaces, as digital restorations of cultural landscapes, and as an immersive first-person experience of place. These areas of convergence correspond with the three basic modes of analysis for digitally representing geographic space introduced by Verbree in his seminal 1998 work on multidimensional GIS: the Plan View of the traditional 2D map or GIS, the Model View represented by traditional orthographic projections or faux 3D computer representations, and finally, the World View in which one is immersed within the model itself and can explore from a first-person perspective that simulates how people experience the real world (Fig 3.1). 

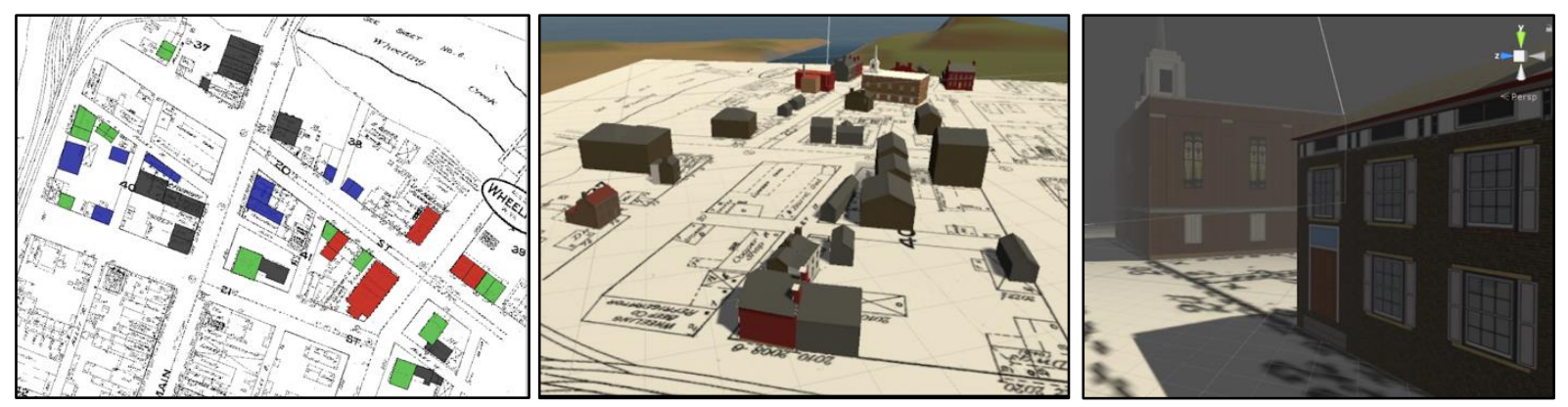

Figure 3.1 Re-envisioning the Plan View, Model View, and World View of Verbree (1998) in terms of Space, Landscape, and Place (Left to Right) for virtual heritage.

This correlation provides a potential path for envisioning, designing, and implementing a VH system that reconciles the dissonance between VR and HP through the concepts of space, landscape, and place, arguably the most pervasive concepts in geography over the past century. A close review of these areas of convergence (Fig. 3.2) reveals opportunities afforded to virtual heritage where the three main concerns of VR align with the principles of HP and key concepts in cultural geography. First, reproduction fidelity in VR relates very closely with the traditional empirical principles of HP and geography. Accuracy, access, and authenticity drove the survey of historic monuments and the Cartesian mapping tradition of geographers, and thus one may envision a VH system resting on an empirical foundation of architectural and geographic space. Second, VR's concern for the extent of world knowledge follows HP's mid-century emphasis on contextualization and the heritage of common people and structures, which aligns with geography's contemporary concerns for cultural landscape and in turn, with critical social theory. Third, the goal of presence in VR corresponds with geography's engagement with the humanistic experience of place and later embodied and subjective geographies, which are mirrored by HP's emerging concern for intangible cultural heritage (ICH). Therefore, subjective and intangible 
elements must be incorporated in VH to move beyond the detached view of models or landscapes and achieve an embodied, personal experience of place. Thus nearly all the HP principles that challenge $\mathrm{VH}$ may be addressed in a system organized and designed around the geographic concepts of space, landscape, and place. Before turning to the design characteristics of such a system, technologies used to model architecture and geographic spaces and landscapes must be evaluated in light of these empirical challenges. In addition, because intangible phenomena have been neglected in $\mathrm{VH}$, concepts related to place will be examined. Finally, the potential of serious games will be explored as a central component of a place-based virtual heritage system.

Principles of Historic Preservation Fundamental Geographic Concepts Aspects of Virtual Reality 1. Accessibility, Accuracy, Transparency $\leftrightarrow \rightarrow$ Space $\quad \leftrightarrow \quad$ Reproduction Fidelity

2. Geographic Context, Commonplace $\quad \leftrightarrow \quad$ Landscape $\quad \leftrightarrow \quad$ Extent of World Knowledge

3. Intangible Heritage and Experience $\quad \leftrightarrow \quad$ Place $\quad \leftrightarrow$ Presence

Figure 3.2 Shared Concerns of Historic Preservation, Cultural Geography and Virtual Reality.

\subsection{Core Technologies to Reproduce Spaces \& Landscapes with Fidelity}

The fields of Virtual Reality and Historic Preservation share a concern for reproduction fidelity though each reflects different ideas about what the term means. Reproduction fidelity in VR has generally been seen as a measure of how detailed the 3D models are and how well the system displays the models in terms of pixels per inch and in display refresh rates. The term 
"reproduction fidelity" literally means how faithful the system and its 3D models represent reality. As such, reproduction fidelity takes on great importance in HP. If VH is to support HP planning activities such as in recording, documentation, and analysis, or to serve communication, interpretation, or educational goals, the system must be capable of representing what is known and unknown about the heritage subject. Fortunately, VH researchers can draw upon decades of United States and International heritage praxis, to provide methods for gathering heritage data and recording knowledge of historic architecture and how it came to be known.

Methods that account for accuracy, transparency, and accessibility in HP span the modern history of international heritage doctrines from the 1932 Athens Charter to the recent RecorDIM initiative (Letellier 2007). The disclosure of uncertainty and degree of conjecture in model building and the accessibility of records are essential elements of authenticity (Venice Charter 1964). Recent research in digital, geospatial, and VH technologies reveal opportunities to enhance how accuracy, precision, uncertainty, and conjecture are handled in a $\mathrm{VH}$ system to facilitate transparency through open digital access to 3D models, data, and paradata of historic architecture and cultural landscapes. Recent GIS applications in history and cultural heritage research demonstrate that GIS can aid in the identification, analysis, and management of historic resources and cultural landscapes and in visualizing historic and geographic aspects of place in both two and three dimensions. Furthermore, researchers can use GIS and geovisualization to document and critically analyze people of the past in their geographic context. 


\section{Modeling Architectural Spaces with Accuracy, Access, and Transparency}

Just as the Historic American Buildings Survey system produces accurate drawings of historic buildings and ensures physical access to documentation and field notes as a means to validate and communicate knowledge, the envisaged VH system must produce accurate digital 3D representations of architectural and geographic heritage based on field and archival evidence and provide access to the sources and methods used in their production via metadata and paradata. Toward these ends, a body of research has emerged that provides models capable of transparent access and creative ways to disclose sources and limitations of the data and knowledge associated with digital 3D models. In response to RecorDIM and the London and Seville Charters, numerous individual researchers and academic publishers have taken steps to enhance access to their models and paradata (ICOMOS 2017; Kuroczynski 2017; Quintero and Vileikis 2011). Academic publishers such as Elsevier now promote the sharing of research data since it reduces redundant research, increases exposure to methods and results, allows scholars to replicate results or identify new insights into the subject matter, may lead to new collaboration, boost faith in the research results, and can influence public policy (www.elsevier.com 2018). For example, the journal Digital Applications in Archaeology and Cultural Heritage, established by Elsevier in 2014, provides a means of promoting open access to digital heritage projects by digitally archiving data associated with projects described in the articles published by the journal. Such qualities may be incorporated into a VH system that shares research data and discloses conjecture in the name of intellectual transparency.

By disclosing paradata, levels of uncertainty, and areas of conjecture, a VH system can support conjectural models that reconstruct archaeological sites and provide a forum to debate the 
underlying hypotheses and alternative interpretations of various data fragments (Forte 2000; Rua and Alvito 2011). Among the earliest potential solutions to the unearned credibility and persuasiveness of photorealistic digital 3D models was to realistically depict what is known while excluding uncertain elements or using colors to represent uncertainty (Barcelo 2000). In what has become the most common approach, Virtual Archaeology and VH scholars employ abstract non-photorealistic visualization to indicate graphically the quality of the sources used in the digital reconstruction (Packer 2006; Muenster 2017). Solutions for representing error and uncertainty have included error bar glyphs, blurring, fuzzy surfaces, and false coloring (Johnson and Anderson 2003). Haegler, et al. (2009) offered an alternative solution in their work on procedural modeling that uses graphic transparency and the decolorization of texture as a means of disclosing levels of uncertainty in the reconstruction without spoiling the photorealism and experience of the observer. Others have employed a graphical system to communicate not only different levels of certainty, but also levels of precision (Apollonio 2016; Apollonio, et al. 2017). Most recently, Erdman and Payne (2018) base their virtual reconstructions of a neighborhood on the United States Secretary of the Interior's standards and guidelines for cultural landscape reconstruction, arguing that such work may be undertaken with intellectual rigor and employ photorealistic rendering as long as the work is based on the best available sources, discloses uncertainty, and provides access to data and paradata. These methods fulfill an important goal of heritage delineation: to produce accurate knowledge about the objects, buildings, landscapes, and people of the past. 


\section{Modeling 2D Historic Geographical Spaces with GIS}

Virtual Reality and HP have a mutual concern for the extent of world knowledge. In VR, this term refers to the depth and breadth of the elements that are included in the virtual world. The term also has ontological and epistemological implications regarding reality and the production of knowledge. For example, the complete body of work in $\mathrm{VH}$ over the past twenty years suggests that portraying heritage is largely comprised of great buildings. For HP the extent of world knowledge includes common places, objects of everyday life, and their cultural landscape context, and thus $\mathrm{VH}$ can contribute to the preservation and interpretation of significant but underrepresented places associated with the common person, and thereby shedding light on the living spaces and neighborhoods of diverse social and cultural groups of the past and present (World Heritage 1972; Silberman 2004). GIS is a key technology to enable the envisioned system to extend from models of historic buildings to complex cultural landscapes.

GIS has been applied to a range of topics related to cultural heritage management and historical analysis, including critical insights on common people and landscapes. Cultural resources surveyors and managers have used GIS increasingly over the last two decades, both internationally (Box 1999) and in the United States following the establishment of the CRGIS program of the National Park Service (2000). GIS has been used in urban and regional planning and as a means to avoid and mitigate negative impact on historic and archaeological sites. State Historic Preservation Offices and Tribal Historic Preservation Offices employ GIS to aid in the inventory, management, and interpretation of designated sites. Much of this work is centered on creating spatial databases of earlier surveys, but through the use of GPS enabled field survey tablets and other geospatial technologies, CRGIS has also served as an aid in new surveys and 
inventories of historic places. Such work ultimately enables on-line queries and display of layers of cultural resource types with links to basic metadata and additional documentation of individual features. Combined with remote sensing, GIS analysis of aerial and satellite imaging has identified previously undocumented ruins such as those uncovered with synthetic aperture radar at Angkor Wat in Cambodia (http://archive.cyark.org/angkor-map). Integrating such intensive survey data with historic cadastral maps has revealed patterns in the landscape, and helped researchers identify the earliest surviving buildings in an urban community (Bonenberger et al. 2018). Thus GIS provides new forms of access and value to augment earlier extensive surveys of cultural resources and enhances the ability of researchers to conduct intensive surveys to identify, document, and preserve ancient ruins and historic structures and thus may provide the spatial foundation for digital reconstruction of historic landscapes (Bonenberger and Harris 2013; Eppich 2007; Shapiro 2015).

GIS is used in the analysis of historical data to produce new insights into the places, events, and people of the past. Historical and Humanities GIS projects include studies of geography, religion, archaeology, literature and other disciplines (Gregory and Ell 2007; Knowles 2008; Bodenhamer et al. 2010). HGIS research has typically (though not exclusively) focused on published data from the eighteenth century onward (Spence 2000; Isoda et al. 2010; Ray 2002; Campbell 2000; Lowerre 2005; Campbell and Bartley 2006; Harris 1986). Several signature themes emerged in HGIS literature including two that have particular relevance to VH (Knowles 2005). Representing error and uncertainty (Plewe 2002; Gregory and Ell 2006; Schroeder 2007) is related to performativity, or unearned credibility associated with GIS, maps, and VH alike (Denard 2002; Plewe 2002). HGIS also emphasizes quantitative data and social scientific analysis, which reflects the dominance of objective, positivist methods in historical geography 
and in GIS and the corresponding lack of subjective or qualitative HGIS (Knowles 2005; Harris et al. 2010). However, HGIS and geovisualization research often examines topics that reflect poststructuralism and critical social theory and related concerns for diversity and economic justice. Such work, called Critical GIS, may contribute to the extent of world knowledge and contextualization in the envisioned system.

Critical GIS evolved from a concern about the role of GIS in reinforcing social and economic injustice (Pickles 1995; Harris et al. 1996; Schuurman 1999; Elmes et al. 2005). Participatory GIS (PGIS) and community integrated GIS (CIGIS) were at the forefront of the early Critical GIS agenda (Craig et al. 2002; Matthews et al. 2005; Pickles 2005). Feminist GIS emerged at the forefront of Critical GIS scholarship in the early 2000s decrying the lack of women and qualitative data in GIS and pondering a feminist GIS research agenda (Schuurman 2000; Kwan 2002b; Kwan and Knigge 2006; O’Sullivan 2006; Pavlovskaya and St. Martin 2007). Subsequent studies employed GIS to empower the marginalized or document, record and analyze the marginalization of people, often based on gender and sexuality, but also due to race, ethnicity, and class (Pavlovskaya 2002; McLafferty 2002, 2005; Kwan and Ding 2008; Kwan 2008; Gilbert and Masucci 2011).

Significant work in Qualitative, Critical, and Feminist GIS, explores emotions and/or mobility to gender and ethnicity (Kwan 1999, 2007, 2008; Kwan and Lee 2004; Kwan and Schwanen 2017). This work is part of the larger movement about embodied experience pioneered by feminist scholars, and including emotional geographies (Davidson et al. 2007), emotional cartography (Nold et al. 2009), emotive and affective GIS (Aiken and Craine 2006), and the convergence of geospatial technologies, hope, and fear (Klinkenberg 2007). Likewise research on GIS and 
marginalized "others" has provided insights into race, class, and gender (Gilbert and Masucci 2011; Brown and Knopp 2008). This work builds upon a remarkable array of historical GIS literature that focuses attention on the injustice and marginalization of women (Ray 2002), the poor (Cunfer 2002) African Americans (Hillier 2003, 2010), and immigrants (Beveredge 2002;

Gregory et al. 2001). Taken together, ethnicity and race are among the most prominent topics in HGIS investigations, and the literature on gender in GIS continues to grow (Nazgol 2014; Kwan and Schwanen 2017; Buckle 2018). Much of this research is applicable to a VH that examines common cultural landscapes and marginalized peoples. Particularly relevant is work that uses GIS and geovisualization to explore critical phenomena in three or four dimensions (Kwan 2008; Jones and Evans 2012).

\section{Geovisualization, Multidimensional GIS, and Procedural 3D Models of Cultural Landscape}

GIS and geovisualization, as with $\mathrm{VH}$, are computer representations of time and space. By its very name, geovisualization expresses scientific values, for it emphasizes sight, which is viewed as the most objective sense (Classen 1993). Geovisualization involves the gathering and display of data in multiple dimensions, and in many cases can depict elements of temporality. GIS and geovisualization tend to be relatively broad in scale, displaying global, regional, and urban data (MacEachren and Kraak 1997; Dykes et al. 2005; Noellenburg 2007). Recent work, however, applies 3D GIS to the modeling and conservation of ancient buildings (DellUnto et al. 2016; Landeschi et al. 2016) and other cultural heritage sites (Agugario and Remondino 2014; Polig 2017). 
The virtual globes of the early 2000s have become ubiquitous and increasingly functional and participatory with applications such as Google Earth, and have made significant progress in bridging small and large scales (Goodchild 2000; Butler 2006; Grossner et al. 2008; Cozzi and Ring 2011; Summerhayes 2016). Thus time-geographies and other geovisualizations can handle a range of scales, but they also can provide powerful geographic insight into the human condition (Pred 1977). For example, Kraak's space-time cube of Napoleon's march in Russia reveals the human toll of the war displayed as a 3D graphic of lives lost over time and distance (Kraak and MacEachren 1999), and Kwan's body map display the emotional discomfort of Muslim women in certain places on their daily life paths (Kwan 2008). Such multidimensional studies help people analyze and visualize epic and mundane events at contrasting spatial and temporal scales, ranging from a continent over months to a city over a few hours (Wheatley and Gillings 2002; Kwan 1999; Kwan and Lee 2004). Like VH, however, such academic geovisualizations have had limited access and functionality beyond the laboratory, and they retain the objective Model View, rather than allow audiences the freedom to explore data in an immersive environment (Tukey 1977; Monmonier 1989; Anselin 2000; Anselin and Rey 2010).

Thus GIS technologies have enabled scholars to analyze and display a range of historic geographic phenomena at a range of scales in two, three, and even four dimensions, including rare but notable examples of Virtual Geographies (Crang and Crang 1999; Kinsley 2014; Chen and Lin 2018). Despite problems with inaccessibility, GIS research has contributed greatly to historic and geographic knowledge, including evidence of injustice and marginalization. Thus Critical and Humanities GIS research often combine qualitative and quantitative data, documenting, recording, displaying, and analyzing phenomena such as personal feelings, 
emotions, and mobility. Such intangible elements are essential in the transition from spatial analysis to a meaningful experience of place.

\subsection{Presence \& Place: Sensuous, Embodied, Experience}

In the most-cited article in the twenty-year history of MIT's VR journal Presence, Witmer and Singer suggest that the degree of presence in VR depends on involvement and immersion, which are influenced by four factors: control, sensory (sic), distraction, and realism (MIT Press Journals 2012). Immersion is a measure of the degree to which one perceives "oneself to be enveloped by, included in, and interacting with an environment" (Witmer and Singer 1998, 227). Thus immersion may be enhanced by selecting a closed system such as an HMD with responsive controls designed to be accessible to a broad range of people. Involvement is the "degree of significance or meaning" that a person attaches to a situation. Significance is also a pivotal term used in cultural heritage and likewise "meaning" has similar stature in qualitative and subjective geographies and studies of place and being. Because significance relates to the relative importance of a site, perception of significance in VH may be enhanced by providing access to an internationally important or inaccessible heritage site - one that is extremely fragile, remote, or has been completely destroyed. In the eyes of heritage professionals and other scientists, perceived significance of a $\mathrm{VH}$ project is raised by explicit adherence to international heritage praxis on accuracy, transparency, and contextualization. Geographers have long recognized "meaning" as a critical element in the human experience of place. Therefore scholarship related to place may enhance the meaning that users attach to a VH environment experience. Returning to the four factors that influence presence, the sensory factor remains unresolved. Sensory 
factors are closely related to place, and yet because VH studies give little emphasis to intangible aspects, such as sensuous, embodied, and emotional experience, these aspects of place warrant further consideration.

Many scholars in geography and other disciplines have moved beyond the objective study of space to incorporate humanistic, qualitative, and personal perspectives on place over the past five decades: first with humanistic geographers in the 1970s and 1980s and more recently through embodied social geographies, advanced most notably in feminist and gender geographies (Moss and Dyck 2003). Yi-Fu Tuan was among the forerunners to recognize the importance of the body and mind in examining the relationships of people and their perceptions of the environment and feelings about place. Tuan argued that place should be distinguished from space because the latter is sterile, while the former is imbued with feeling, memory, and meaningful experiences (Tuan 1974, 1979). Subsequent phenomenological insights into humanistic geography centered on the human body and its relationship to space and place through concepts such as lifeworld, time-space rhythms, dwelling and journey, and the emotional affect places have on people (Merleau-Ponty 1968; Relph 1976; Seamon and Buttimer 1980; Cresswell 1996). Although the work of humanistic geographers was criticized by some as nostalgic, deterministic, or overly simplistic (Massey 1994; Peet 1998; Creswell 2015), key concepts such as sense of place and time-space rhythms emerged in the mainstream of geographic thought, and others such as body, mobility, and emotion have been taken up with alacrity since the 1990s, especially by feminists in geography and other social sciences. This focus on embodiment or the body as subject, has advanced geographic knowledge of diverse people and places and the dynamics of power, mobility and constraint, emotion and fear in the varied spaces of everyday life. Recent scholarship on mobility and emotion in the body-subject may have important implications for 
presence and sense of place in $\mathrm{VH}$, but is better considered after a brief examination of the senses, and in particular the sense of hearing and sound.

Aside from vision and the visual, studies of sound were the first to emerge in recent sensuous scholarship (Ihde 1976; Shaffer 1977; Truax 1978, 1984), followed by taste, most notably on

food consumption (Farb and Armelagos 1980) and foodways (Brown and Mussell 1984). Those focused purely on smell are much less common (Corbin 1986; le Guerer 1992), though smell is often considered in concert with taste (Rodaway 1984). Likewise, studies of touch are so rare in the humanities and social sciences that a recent reviewer could boast "the first overview of the treatment of haptic knowledges in geography..." (Paterson 2009, 766). There also have been notable efforts at addressing all of the senses, and these, like Paterson, often consider sensibilities or "internal bodily sensations" such as fear in their treatments of the senses (Rodaway 1994; Corbin 1995; Classen 1993; Paterson 2009). Despite the importance of smell, taste and touch, this dissertation focuses on sound and its connection to sensation, emotion and affect, which may contribute to presence and sense of place in $\mathrm{VH}$.

\section{Soundscape \& the Sensuous Past}

Sound follows sight as the most studied sense, and together they are considered the higher, empirical, objective senses (Smith 2007; Classen 1993; Vinge 1975; Kant 1798). Sounds can be classified, objectively recorded, and described (volume, pitch, frequency, etc.), but aurality also has subjective qualities. Like humanistic geography, studies of soundscape can be traced to phenomenological philosophers of the late 1960s (Ihde 1970; Smith 1969; Slaughter 1970). 
Building upon this phenomenological literature, the World Soundscape Project (WSP) developed a methodology for recording endangered sonic elements of the environment throughout the 1970s, which may be adapted to design and develop soundscapes in a VH system (Schaffer 1977; Truax 1984).

Much as a geographer, archaeologist, or heritage delineator records the tangible components of a cultural landscape, the WSP presented a clear methodology for documenting the soundscape and ways of mapping or charting the origins, frequency, and intensity of natural and cultural sounds, and their cyclical nature. The Project introduced terms that remain useful today, including the notion of the "earwitness" (the person who heard and described the sound), "soundscape" and its main themes of "keynote" or ubiquitous background sounds, "signals" or sounds that are made purposefully to direct or warn people, and "soundmarks," which are analogous to physical landmarks (Schaffer 1994, 8-10). If as composers, the researchers were inclined to arrange and blend the sounds into an artistic composition, the WSP maintains an archive of separate audio files and recently published many of the raw materials along with documentation--the equivalent of HABS field notes--describing the parameters under which each recording was completed (World Soundscape Project 2009; Simoni and Fosdick 2010). Along with their classification schemes, Schafer and Truax emphasized power relationships, noting that some signal makers (such as churches, markets, and police) are able to break sound ordinances without repercussion, and are thus above the law (Schafer 1980). In addition to the WSP, a sensuous VH may draw upon the insights of a range of philosophers, historians, anthropologists, and geographers that have explored the sensuous past. 
Social historians have pursued related themes of power, class, and variations in sound reception by time and place, emphasizing how sound was contested during the American enlightenment (Schmidt 2000), among the people of rural France in the nineteenth century (Corbin 1998), and during the American Civil War (Smith 2005). While Smith and others examine the sonic and sensuous past as an aspect of social history (2003), environmental historians (Coates 2005) and scholars from other disciplines such as philosophy and anthropology have brought important perspectives to the subject (Ihde 1976 and 2007; Rodaway 1994; Panopoulos 2003; Feld and Brenneis 2004; Pink 2009). Sounds may be conceived as socially constructed and active and essential voices, whether emanating from animate or inanimate objects (Ihde 1976, 2007). Sound scholarship thus may contribute at least two major elements to the envisioned VH system. The World Soundscape Project provides a methodology for documenting, cataloging, and maintaining archives of historic natural and cultural sounds, referenced by temporal and spatial associations. In addition, they and other sound scholars note that sounds have an effect on people, and reflect power and other social relationships. Sound is a key intangible element of place that can expand the extent of world knowledge and reproduction fidelity in VR and VH and perhaps further the immersion of the user. As Ihde (2007) explains, sight is detached and passive, while sound is polyphonic and immersive, and thus aural elements may facilitate the transformation from passive viewer to presence in VR.

\section{Non Representational Theory, Embodiment, and Mobility}

Recent geographic and anthropological research has focused on the body and increasingly on embodiment, mobility, and emotion. In the move toward embodiment, Nigel Thrift's non- 
representational theory emphasizes the dynamic and unpredictable aspects of being human as a performance of continuous becoming (Thrift 1996, 2007; Lorimer 2005; Butcher 2012). Sensory anthropology stresses the unity of body and mind, while recognizing that at times the body operates by habit, without thinking, including connections among the sense of touch, the brain, and emotions (Classen 2005; Howes 2006). Nonrepresentational theory and embodiment emerged as important ideas in social and cultural geography late in the 1990s (Davidson and Milligan 2004; Butcher 2012), and may contribute to a VH system that seeks to explore the illusive everyday world of the distant past. Embodiment in historical geography includes studies on embodied aspects of travel (Travis 2008), gesture (Griffin 2008), and eighteenth-century household consumption (Evans 2008). Harrison suggested a focus on the relationships of the lived present and "sensible surface" of things, for "all the 'minor circumstances' of everyday life," such as "culinary practices, dress styles, the gait of bodies, the things on my desk, (and) the wear on the carpet" (Harrison 2000, 502). The phenomena that comprise the everyday life of a city or a particular street, include "the very close, the familiar, and the habitual" that are largely "unseen" and thus forgotten (Harrison 2000, 497). The rising interest in such dynamics of human experience, including emergent becomings and constant change (Wittgenstein 1988 in Harrison 2000) are reflected in recent studies of mobility, and also have clear relevance to ICH and embodied VHEs.

If virtual heritage is to become more immersive and participatory, then studies of embodiment, mobility, and emotion have important implications for the way that NPCs and players move about, experience, and interact in the virtual past. Mobility has been recognized by some as the new paradigm in the humanities and social sciences (Sheller and Urry 2006; Cresswell 2006) or even "the spirit of the age" (Franquesa 2011). Feminist studies have focused attention on the 
relative immobility of women, immigrants and other marginalized groups due to social and political constraints. Early studies examined gender differences in commuting distances (Hanson and Johnson 1985; Blumen and Kellerman 1990; Mclafferty and Preston 1991), and while such research continues (Cristaldi 2005; Cresswell and Uteng 2008; Vashro et al. 2016), it has expanded into other directions, such as low income workers (Murakami and Young 1997; Gilbert 1998) and the relationship among race, gender, and constraint on work trips (JohnsonAnumonwo 1997). Similar studies of mobility and travel behavior focused on women in the suburbs (Goddard et al. 2006), women across the twentieth century (Gossen and Purvis 2005), and other marginalized groups exploring variations in the experience of the very young (O'Brien et al. 2000), gender and the elderly (Hough et al. 2008), ethnic groups (Doyle and Taylor 2000), and immigrants (Conlon 2011), and more recently the perils of forced mobility related to war, famine, modern slavery, and sex trafficking (Parrenas 2011; Siegel 2012; Kozma 2016).

Mobility research has grappled also with emotion and fear, as seen in Mei Po Kwan's timegeographic visualizations of women, ethnicity, and fear discussed above (Kwan 2002, 2004, 2008), which built on earlier geographies of women's fear (Valentine 1989), women's fear of violence (Koskela 1999), and the racial components of women's fear of public spaces (Day 1999). Subsequent research explored safety and belonging by women (Kern 2005) and the fear of being victimized in transportation environments (Loukaitou-Sideris and Fink 2009). Recent research has examined the increased vulnerability perceived by the working class (BruntonSmith and Sturgis 2011) and by women in public spaces (McNeely and Yuan 2016). Others have linked increased perception of fear to being a previous victims of crime (Snedker 2015) and with trust of neighbors (Alper and Chappell 2012). 
Work in the emotional experience of immobility and the sense of danger builds on a burgeoning literature in emotional geographies (Anderson and Smith 2001; Davidson and Milligan 2004; Davidson et al. 2007; Smith et al. 2009; Curti et al. 2010). Embodied cognition is moving from cognitive science literature (Anderson 2003; Garbarini and Adensato 2008) into geography and "embodied cognitive geographies" serving as a parallel between the seemingly disparate research tracks of poststructural geography, geographic information science, and cognitive-behavioral geography (Butcher 2012). Embodied cognition has relevance in VR and human computer interaction (Garbarini and Adensato 2004) in haptics technologies (Saddik, et al. 2011), virtual sensation (Swink 2009) and affective computing (Scherer 2010). Thus when envisioning and designing a place-based, first-person $\mathrm{VH}$, the human and gendered experience of sensuous and subjective phenomena such as sound, emotion, and fear must be considered.

Research in Qualitative GIS, Humanities GIS, Critical GIS, and geovisualization has demonstrated that objective data can be combined with subjective data to produce new knowledge and insights into mobility, ethnicity, gender, and class in the city. The graphic display of such work, however, has been presented almost exclusively in the Plan (GIS) or Model (time-geographic) View. If the transition from time geography and multidimensional GIS to Virtual Geographies (Crang and Crang 1999; Kinsley 2014), Virtual GIS (Fisher and Unwin 2002), and Virtual Geographic Environments or VGEs (Chen and Lin 2018) is slowly emerging, an immediate solution for place-based VGEs may be found in an important class of entertainment software that has been developed for the computer and console game market over the past two decades. Game engines enable the integration of digital 3D models of historic buildings with terrain and other natural and cultural features, along with intangible elements such as sound and emotion. They also may provide a practical means of exploring historical and 
critical GIS data including qualitative data from the first-person perspective and dissemination through VR displays. In addition, related research on serious games suggests that the use of game engines may contribute to the functionality of VH for HP.

\subsection{Game Engines \& Serious Games for Virtual Heritage}

Almost from the very beginning, the best $\mathrm{VH}$ projects employed game engines to immerse people in $\mathrm{VH}$ environments and enable them to explore a model from the first-person perspective. This began with the VRND project, which demonstrated increased user mobility, access, and functionality over previous VH platforms (Denard 1999). The Enichiji Temple project showed how game engines could enable users to access metric data of VH models from within the virtual environment (Calef et al. 2002). The Sao Paolo project revealed how such tools promote collaboration among disparate interdisciplinary team members to increase accuracy and permit independent validation (Zuffo et al, 2007). Subsequent VH projects and concurrent developments in serious games suggest that nearly all of the VH challenges may be addressed using computer game engines.

Serious games use computer game engines to address real-world problems through a focus on training and teaching. Related studies in the science of teaching and learning demonstrate that analog and digital games can be powerful pedagogical tools (Egenfeldt-Nielsen 2006). VH may be enriched by tapping into the potential of games to construct knowledge, facilitate collaboration and training, for learning in higher education, and to raise empathy levels, and work for social change. Beyond this, games can provide both entertainment and motivation, 
qualities that are typically lacking in traditional $\mathrm{VH}$ projects. Advances in computer processing speeds and display capabilities have enabled the creation of immersive first-person games that approach the verisimilitude of high end VR systems at a fraction of the hardware costs, and some game engines can be exported into Virtual Reality CAVEs and the latest HMDs for an enhanced immersive experience.

Since the late 1990s, the traditional console video game market has been dominated by firstperson shooters (FPS). FPS games provide an open ended real-time adventure or quest scenario from the first-person perspective. That such games are referred to as "shooters" underscores the preponderance of war games in this genre, yet the billions of dollars invested in such games has resulted in a platform that can be adapted to produce serious real-world scenarios depicting the past, present, or future (Lin 2017). For example, the Center for Computer Games Research at IT University in Copenhagen, Denmark has turned the FPS on its head, specializing in games for peace that demonstrate it is possible to apply critical social theory to cultural and heritage gaming environment. The center's Global Conflicts and Playing History series are rarities in the history of gaming, for they address serious historical subject matter, using game environments and elements of play; they revolve around learning about injustice, rather than shooting (Buch and Egenfeldt-Nielsen 2007, Bogost 2010).

Egenfeldt-Nielsen, the leader of Denmark's Serious Games initiative challenged researchers to use control groups to measure the effectiveness games for learning against similar classes that cover the same content without games (Egenfeldt-Nielsen 2006). Since then, numerous researchers have employed control groups that demonstrate the efficacy of simulations and videogames for education and training (Owston, et al. 2009; Aldrich 2009; Salas, et al. 2009; 
Corbeil and Laveault 2008; Akinsola and Animasahun 2007; Buch and Egenfeldt-Nielsen 2007; Egenfeldt-Nielson 2005; Lieberman 2001; Squire et al. 2004; Wiebe and Martin 1994). This research provides substantial evidence that serious games produce measurable gains in learning. Digital construction games such as Railroad Tycoon, Civilization, Bridge Builder, and Making History II, proved to be engaging, fun, and as functionally useful (for teaching and learning) as they are popular (Squire 2004, 2005; Egenfeldt-Nielsen 2006; Weir and Baranowski 2008). Recent incarnations of construction games such as Second Life, Minecraft, and Roblox expand the agency of players, their ability to construct custom avatars, buildings, landscapes, and neighborhoods, and to collaborate with others online. Such games link constructivist and sociocultural learning with massively multi-player on-line role-playing games (MMORPG) and the emerging social networking class of media (Ito 2009; Corbeil and Laveault 2011; Kervin et al. 2015; Takeuchi and Valla 2014; McCall 2016).

\section{Integrating Digital Heritage Models with Serious Games}

Taken together, these examples demonstrate some of the remarkable promise of combining heritage recording and digital modeling traditions with the first-person interaction of game engines. Continued advances in processing speed, human-computer interaction, and display (Moore 1965, 1995) have calmed the zero-sum battle between functionality and photorealism; VH modelers can now choose both. Working on interdisciplinary teams, heritage professionals can combine accurate models of buildings, objects, people, vegetation, and landscapes within a game environment to immerse themselves, students, and visitors within an accessible, contextualized virtual historic place. 
Taken together, the works of Egenfeldt-Nielsen, Salen, Zimmerman, Ito, and Gee reveal several qualities that contribute to the success of game-based learning. Among the most important components - and perhaps no game can have all of them - are those of non-linearity, freedom, and the presence of a clear and attainable challenge. In addition, the power of construction and building as a means of learning has been long recognized, and the power of socio-cultural learning through collaboration with teachers and other students not only mirrors the real world, but also is pedagogically effective. Together, these developments suggest that assigning teams of students to produce digital models of historic landscape elements may not only contribute to VHEs but also enhance student learning of vernacular house types, settlement patterns, and digital heritage best practices.

\section{VR System Functionalities for Historic Preservation}

Although functionality was not listed explicitly among the principal early concerns of VR (Milgram and Kishino 1994; Witmer and Singer 1998), the success of the past two decades of VR research has rested on its ability to function as a source of entertainment and as a tool that simulates real world environments for training such as flight simulators, military simulations, and surgery, for treating PTSD and concussion diagnostics, in robotics control systems, and as a space for scientific collaboration, and commerce (www.theverge.com/a/virtual-reality/intro ). As an applied discipline, all HP efforts are tied to facilitating the sustainability of heritage resources, which includes not only the "bricks and mortar" work of stabilizing, restoring, or rehabilitating the heritage resource, but preservation planning activities such as identification, documentation and recording of heritage, and the critical communication outreach activities of education, 
training, advocacy, and interpretation (www.ncpe.us/about-ncpe/). VH technologies should be able to support any of these activities, yet as we have seen, most VH work has focused on interpreting great heritage buildings, typically in a way that is not transparent, leaving a gap between what is recorded and documented and what is communicated to students, visitors and others. The London Charter suggests that VH should focus on activities that cannot be accomplished by traditional means (Denard 2012), and several areas have been inadequately served by traditional heritage recording media and technologies. For example, reconstructing places that have been demolished while clearly representing what is known and what is conjecture is among the oldest challenges of HP. Among the most recent challenges in HP are recording and communicating knowledge about ICH and raising awareness of the importance of preserving working class heritage. $\mathrm{VH}$ offers a medium where these and other challenges may be addressed. Applications in GIS and geovisualization for cultural resource management suggest that a place-based VH system can help researchers identify and record previously undocumented heritage resources, visualize historic house types in a 3D landscape as a context for preservation planning, and support heritage education, communication, and interpretation. Furthermore, although this vision of a place-based VH system has been based largely on the principles and needs of Historic Preservation, because they have been considered in light of shared concerns of VR and Cultural Geography, it is anticipated that its design and functionalities will also have implications for those disciplines.

Thus concepts of space, landscape, and place developed in the geographic literature of the past four decades contribute to a framework that moves beyond a static, inauthentic, and impersonal VH paradigm toward a place-based VH that more closely resembles the personal, sensuous, and affective way that people experience the world. In addition, a place-based $\mathrm{VH}$ is envisioned as a 
system that functions to serve research, communication, and education in HP, but also for VR and cultural geography. In summary, the envisioned VH system supports research activities associated with inventorying, documenting and recording historic resources, while also enhancing communication, education and interpretation activities, so that knowledge of heritage, both tangible and intangible, including what is unknown and what is conjecture, may be communicated and integrated into interpretation and preservation efforts. 


\section{A Methodology for Reconstructing Place in Virtual Heritage}

To accomplish the design objectives set out in Chapter 3, the virtual heritage system must facilitate three fundamental activities: data gathering, data processing, and data integration. The system must be capable of handling accurate and measured data about the diverse components that comprise a historic cultural landscape such as structures, vegetation, the physical environment, and topography. Critical to this data gathering is the need for a comprehensive method for obtaining data about buildings that have been demolished, and accounting for the broad range of information to be incorporated into the system. The second class of components is related to the processing of the data. The system must be capable of handling the geographic mapped distribution of tangible features as well as the intangible elements of place such as sound and smell, and to do so in three dimensions. Third, the system must be capable of integrating all these elements within an immersive environment that will enable the exploration and examination of the virtual place from an interactive first-person perspective. Additionally, preservationists, planners, educators, and museum professionals must be able to access and operate the system, explore the data, and provide feedback so that the system may be implemented for a variety of educational, professional, planning, and heritage presentation needs. The system also must provide metadata and paradata that describe the elements making up the virtual environment, along with their sources and limitations. Each of these components and the inter-relationships comprise a place-based VH system, which is delineated in the schema in Figure 4.1. 


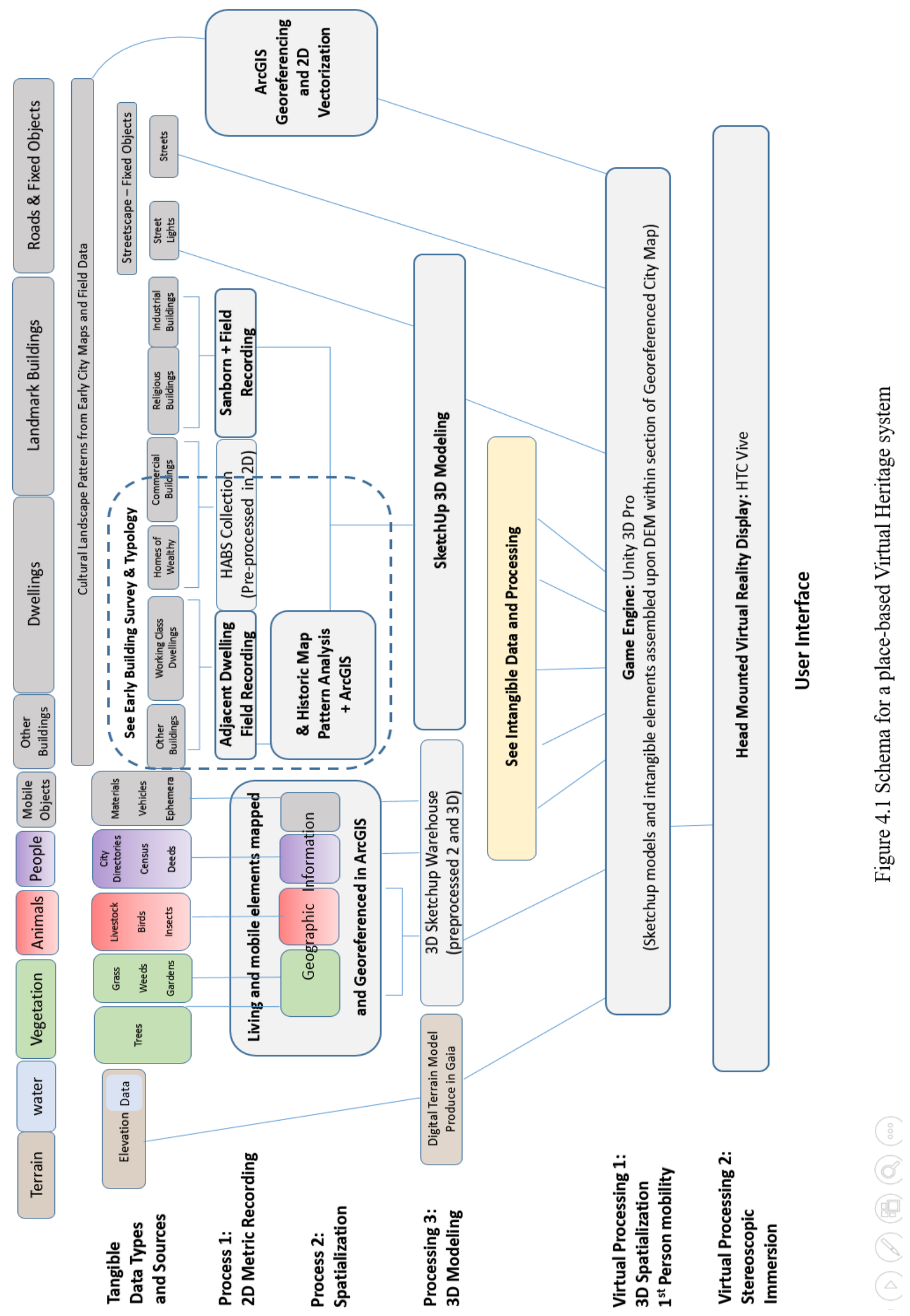




\subsection{Data Gathering \& Collation}

At the top of the schema are the vital historic data drawn from digital archives and field research. As with any $\mathrm{VH}$, particularly in western cultures, historic buildings are an important component. In this place-based approach, however, it is critical to gather data not only of the monumental structure itself, but also about the other buildings and objects that comprised the historic cultural landscape. These data include both common and high-style dwellings, industrial, commercial, public, and religious buildings in the vicinity, along with the roads and the fixed and movable objects that existed at the time. The place-based model also includes the physical topography of the landscape such as the terrain, water features, and vegetation, as well as the animals and people that inhabited the place. Intangible data must be carefully researched to represent the special meanings and characteristics associated with that place. Because undocumented conjecture is such a problem in $\mathrm{VH}$, and a taboo in heritage recording, the proposed place-based VH system includes a detailed methodology for reconstructing buildings that are no longer standing, based on the types of data that might be available for a particular time and location. These data might include historic maps, and recent and historic aerial orthophotographs, that aid in identifying extant buildings and reconstructing buildings that are otherwise undocumented. During the process of field and archival research, documentation of the sources and limitations of all the data must be gathered, stored, integrated into the system, and made accessible. 


\section{Data about the Physical Environment}

Representative data of the real-world phenomena of the past (natural, human, and cultural) and sources of knowledge about them must be gathered from existing archival resources and supplemented by field research where archival sources are lacking or unreliable (Raitz 2001). For the place-based VH system, such physical data includes terrain, hydrography, flora, fauna, and atmospherics. Historic elevation data is available from numerous clearinghouses in the form of 10-meter contours or better. Finer elevation such as 3-meter elevation data may be available from USGS 1/9 arc-second survey, and even more precise elevation data can be derived from LiDAR point cloud data where available. Ten-meter DEM data might be sufficient because additional precision would increase the polygon count substantially -- possibly to the detriment of real time navigation depending on the size of the study area. Evidence of flora and fauna may be obtained from newspapers, ordinances, deed books, historic bird's eye views, books on local botany, and contemporary literature. Atmospheric data can be derived from newspaper records, and the water levels of local streams and rivers should reflect the season and year selected for the project.
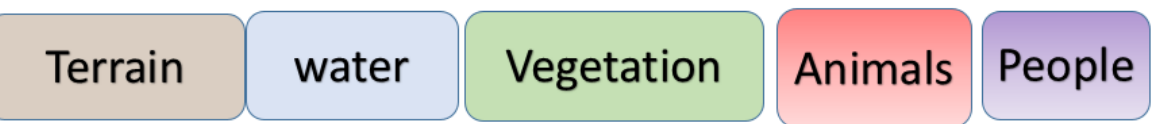

Mobile Objects
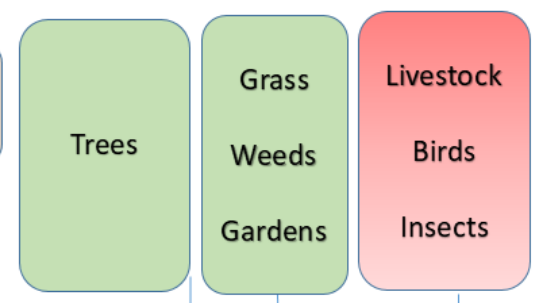

Figure 4.2 Schema detail of natural and human data types and sources 


\section{Data about Human Occupancy}

Archival sources can reveal much about the human population of a given place, and the archival record for the United States is particularly rich for the mid-nineteenth century onward. City directories, census enumerator records, property deeds, tax assessor's records, the Sanborn fire insurance maps and other early city maps provide evidence of where people lived and worked along with their demographic, social, and cultural associations. Stories, meanings, and memories attached to buildings and other locations in the study area are essential in humanizing the VH and transforming space into place. A person who lived or worked in what is now a heritage site might be identified to serve an important role as a NPC to guide users through the heritage site. This person might be a fictional character, or a real person, prominent or common, but ideally someone who left a record of their feelings or had substantial associations and interactions with the place. Such text might be incorporated into a script that introduces users to the serious game environment and the place represented, or as a supplement to the more routine historic human data from census, city directories, deeds, land books, and vital records that can be tied spatially to objects in the virtual environment. It would be highly desirable to produce numerous NPCs representing historic residents of the town, dressed in period clothing, set on appropriate daily life-paths, and possessing information that could be shared during encounters with users.

\section{Cultural Landscape Data}

Accurate data must also be gathered about the dwellings, buildings, and other essential elements in the cultural landscape. These elements include movable objects, dwellings from working 
class houses to the mansions of the wealthy, landmark buildings such as industrial, religious, and public buildings, streets, and elements of infrastructure such as street lamps. Because the placebased VH system does not rely on direct modeling from LiDAR or SfM, this data will most likely be in a two-dimensional form. Photographs, drawings, maps, and other records must be obtained from local archives and digitized as necessary, along with their metadata.

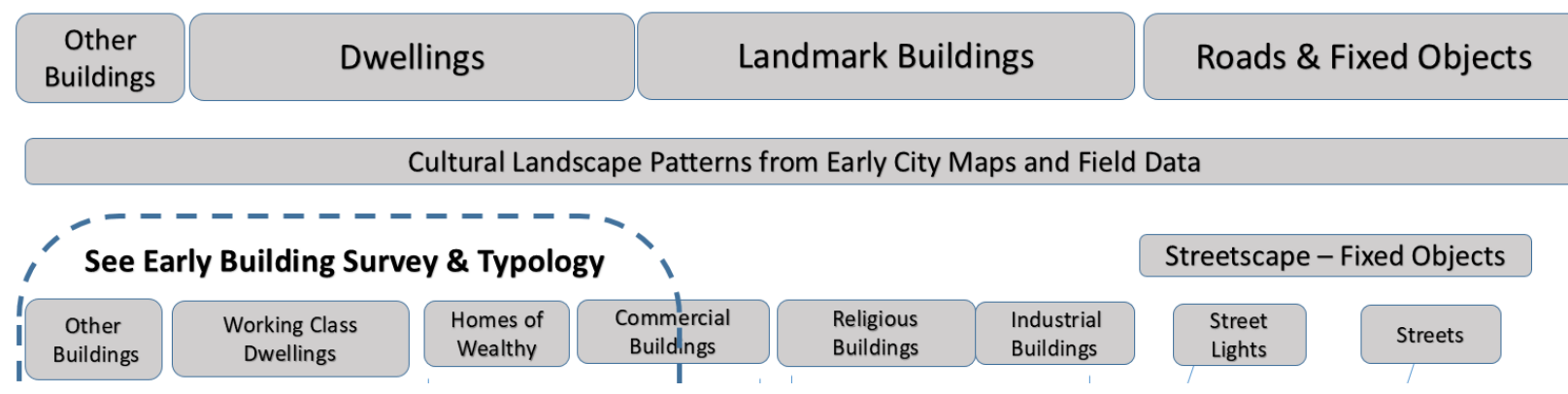

Figure 4.3 Schema detail of material cultural data types and sources

In instances where very few historic structures remain in the cultural landscape today digitally reconstructing dwellings in places is challenging. Five different means of obtaining data about historic buildings may be required, depending on the type and quality of information that is available. First, for buildings that remain standing, the structure can be recorded in a field survey by measuring and photographing each façade elevation. Second, for those structures represented in historic photographs, images of the façade(s) can be gathered and combined with building footprints obtained from the historic Sanborn maps to generate a 3D model. A third source of data concerning heritage buildings that might be incorporated into the system is existing intensive surveys, such as those of the HABS/HAER collection at the Library of Congress. As discussed in Chapter 2, HABS provides tens of thousands of as-found measured 
drawings of building forms and styles and includes an astonishing number of antebellum buildings recorded since the 1930s. These records provide an outstanding but much underutilized source for 3D heritage modeling to digitally reconstruct the recorded buildings or to act as a reference in the reconstruction of demolished houses of the same footprint, type, and style. However, in cases where the historic buildings have been demolished and no photographs, drawings, or engravings remain, a plausible reconstruction can be undertaken based on nearby contemporary structures that remain standing.

A fourth means of gathering data for constructing $3 \mathrm{D}$ building models is to conduct an intensive field survey that generates $2 \mathrm{D}$ survey data of building types to be found in the vicinity. A survey of surviving buildings in an adjacent contemporary neighborhood can provide invaluable evidence of typical facades and floor plans to assist in reconstructing demolished buildings. While exterior details (particularly ornamentation) may have changed with evolving styles, the interior form is generally subject to less change and thus load-bearing walls and the floor plan are key diagnostic elements of a dwelling's original form (Hubka 2013). Placing these sources in the context of other popular building forms and styles using the methods and scholarship drawn from vernacular architecture, material culture, and settlement geography contributes to scholarship on the house types prevalent in particular regions and cultural hearths (Lewis 1979; Noble 1984; Kniffen 1965; Carter and Cromley 2005).

In many cases, however, even nearby contemporary buildings that approximate the size, shape, and materials of buildings that have been demolished simply do not survive. This is especially so for many vernacular dwellings, industrial buildings, and outbuildings. Many industrial buildings were made to serve specific purposes and could not readily be adapted to new uses. 
Likewise, the humblest dwellings and outbuildings were not meant to last, but rather were built for expediency. Thus, remaining examples of such buildings can be extremely rare. This issue necessitates a fifth means of generating data to reconstruct the buildings of the past. In such cases, detailed 2D footprints of buildings from early city maps can be used as the primary basis for digital reconstruction (Mou 2012; Piekielek 2017). Sanborn Fire Insurance maps in the United States were drawn invariably for urban areas and are particularly helpful because they detail a building's size, shape, materials, and the number of floors along with other details. Sanborn maps can thus serve as the primary basis for digital reconstruction. In the above five instances, the method and data sources must be noted so that the source and accuracy of the digital reconstruction can be assessed.

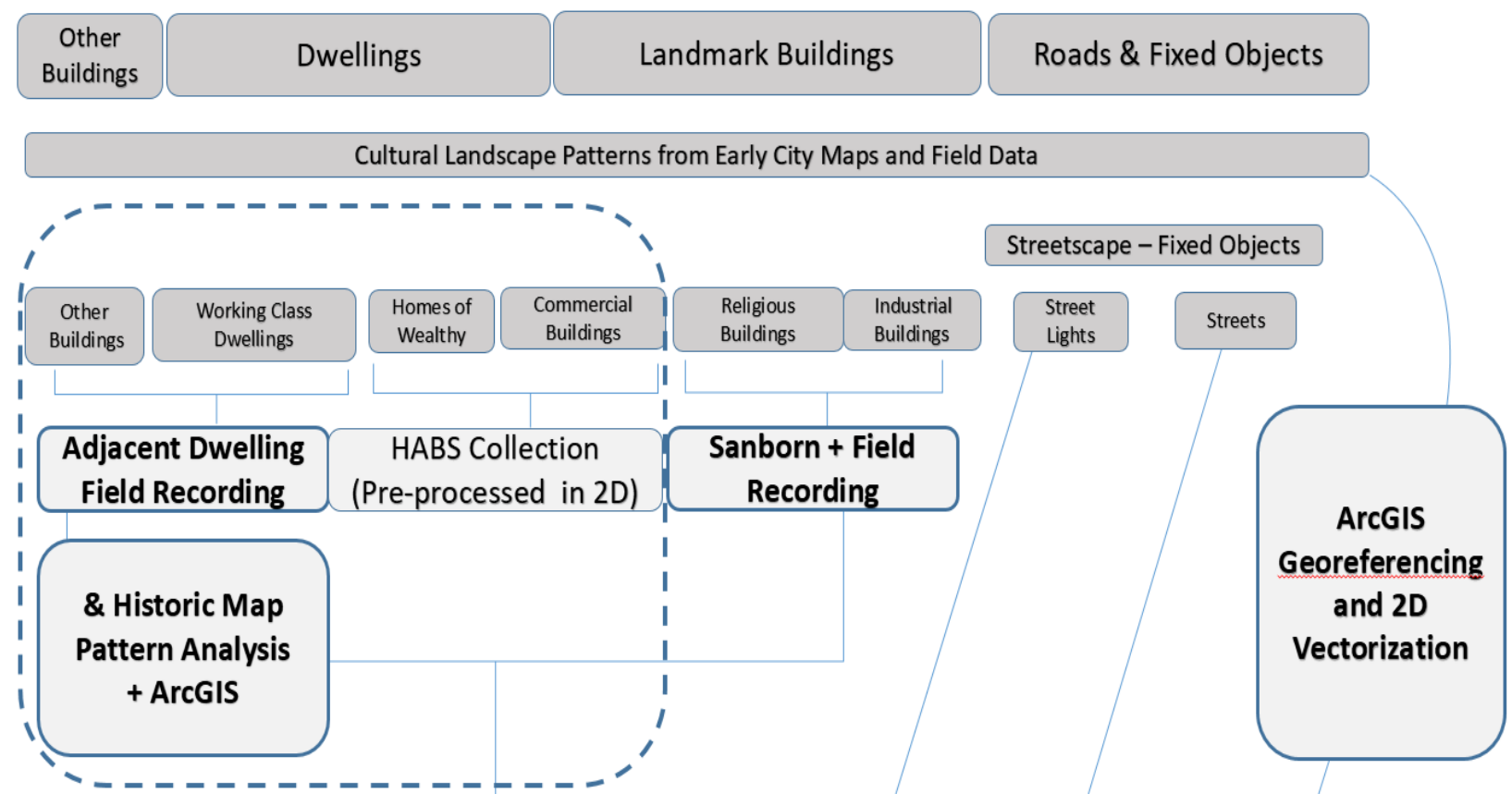

Figure 4.4 Schema detail: Immovable cultural heritage, 2D survey, and spatialization. 
Just as Sanborn maps provide remarkably accurate data about every building in an urban neighborhood, they also depict the infrastructure of the cultural landscape such as the width of streets, and the location of fire hydrants and waterlines. Many local history sources contain information on the physical infrastructure of a given city and its utility systems and street furniture such as gas, lighting, pavement, sidewalks, and signs. For a given VH project, particularly in the early stages of its development, the stationary and transient elements may be limited to a few significant representative examples that might expand in a well-resourced, longterm, place-based VH. Objects should be selected based on available data and their potential to contribute to the heritage and sense of place about the study area.

\subsection{Processing Data}

The core of the schema revolves around the digital processing of tangible and intangible phenomena whereby heritage data is converted into compatible formats for import into the game engine. This section accommodates three main types of processing. Geoprocessing reflects the geographic approach taken here to VH. An overlay of the spatial relationships of all digital assets in the study area is generated in ArcGIS, QGIS or other GIS software. A digital elevation model (DEM) provides the landform upon which is built the cultural and natural elements. The DEM in this case study is built in Gaia (www.procedural-worlds.com), a software add-on to Unity3D (https://unity3d.com) that, among other features, enables accurate real-world terrain data to be imported as height maps to create the model terrain and even add vegetation cover. The second type of processing involves 3D modeling. SketchUp, perhaps the most accessible and popular 3D modeling software currently available, is the primary means of rendering 
building structures and other tangible built components of the landscape (www.sketchup.com). SketchUp, like Unity3D, has the advantage of providing access to a digital 3D warehouse of previously rendered buildings and objects that can be utilized when appropriate (https://3dwarehouse.sketchup.com/). Third, digital intangible elements might include audio files from digital archives, but can also be generated specifically for a given $\mathrm{VH}$ project. These files must be organized and stored along with the 3D models and the paradata that describes their origins and limitations in accordance with the London Charter (Denard 2012). The following sections examine these three types of processing in greater detail.

\section{Geoprocessing}

A geographic information system (GIS) such as ArcGIS, the open source QGIS and GRASS, or EDRISI, produces accurate spatial mapped representations and stores and processes the spatial relations between objects representing the cultural, physical, and natural landscape. ArcGIS was selected for use in this system. ArcGIS (www.arcgis.com/) has long been the industry leader in GIS and provides valuable functionality necessary for processing spatial data in the virtual scenes. The GIS layers for the study are based on historic maps geo-registered to recent orthophotographs, with the location of important tangible elements (natural, human, cultural) and intangible elements delineated (Favretto 2012). The spatial primitives of point, lines, or polygons representing the data gathered during archival and field research are recorded in the GIS and imported into the game engine such that each 3D model, audio file, text file, and other asset is correctly positioned in the scene. Static features require defined locations in the scene. Because dynamic elements tax the immersive VR system's ability to display real-time, such 
aspects must be simplified and GIS can aid in this effort. Dynamic human and animal elements, if included, require that path constraints be delineated on a map and converted to a navigation mesh (nav mesh) in the game engine.

ArcGIS can be used to help identify and analyze early surviving buildings in a contemporary and spatially proximate neighborhood where building stock survives. Buildings depicted on earlier maps can be correlated to those recorded on the recent orthophotographs. This mapping should be complemented by a field survey and archival research to identify contemporary buildings by their morphology: roof type, orientation, floorplan, and fenestration (McLennan nd; Hubka 2013). This results in a typology that correlates the earliest insurance map footprints of lost buildings in the study area to similar buildings that survive from that era in an adjacent neighborhood, and thereby provides the closest approximation possible for their virtual reconstruction.

\section{D Modeling}

Three-dimensional models that populate the virtual scene can be generated directly from heritage objects via digital laser scanners or SfM devices. However, in this work where several significant buildings are no longer extant, an indirect method for 3D model generation is used that reduces the costs and hardware overhead associated with laser scanning and SfM technologies. The approach applied here is thus economically viable and saves resources and time expended on acquiring and operating costly hardware. 
There is no shortage of software options to undertake "indirect" 3D modeling. 3DS Max and Maya (www.Autodesk.com) are among the commercial leaders, and Blender (www.blender.org) is arguably the best open source option. It should be noted, however, that these software packages are complex and have a steep learning curve that creates challenges to those without expertise of the systems. Moreover, these programs are best suited for photorealism and, as discussed previously, since the place-based VH system values accuracy over precision, photorealism can become a hindrance to real time interactivity in the VH environment. Ultimately, SketchUp Pro was selected to construct the digital 3D architectural models due to its accessibility, ease of use, the availability and number of existing prefabricated models, and its compatibility with Unity3D (Fig. 4.5). However, just about any digital 3D model may be exported to file types that are compatible with Unity 3D. Such files must be optimized to reduce polygon count, organized, and stored, along with documentation of sources and limitations, on local servers and hard drives and backed up in cloud storage for added security and in the interest in future accessibility. 

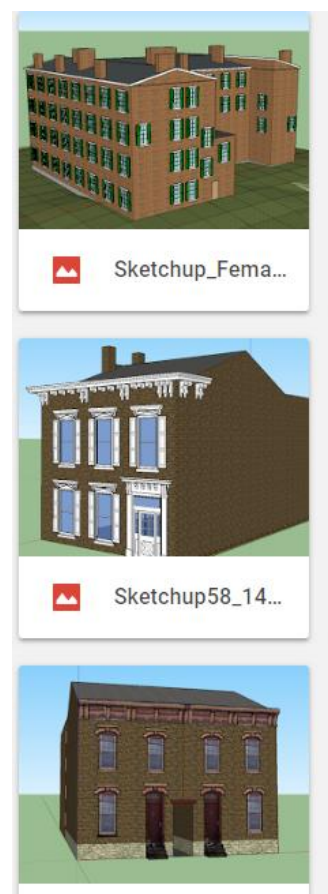

^ Sketchup726_2...

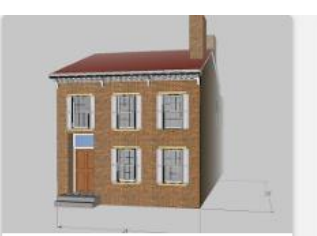

Sketchup26ish...

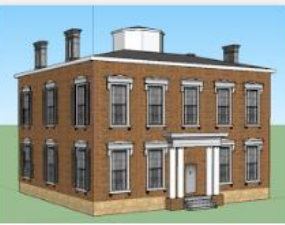

^ Sketchup100_1...

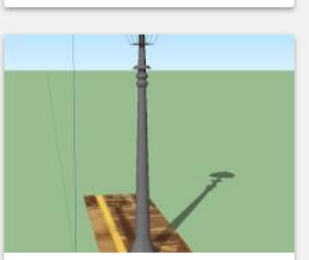

^ Sketchup1850s...

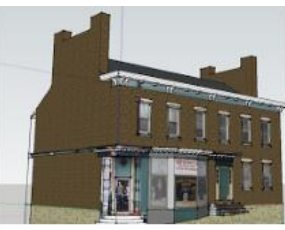

Sketchup29_31...

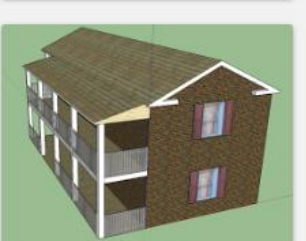

^ Sketchup629M...

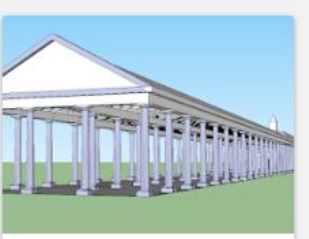

• Sketchup2200...

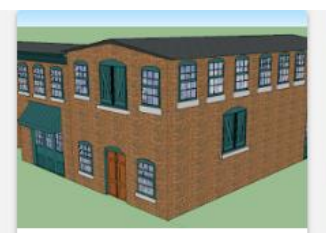

Sketchup 31 ish...

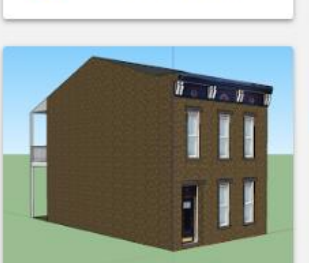

Sketchup635M...

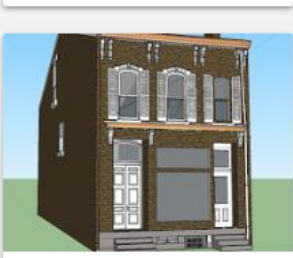

॥ Sketchup2238...

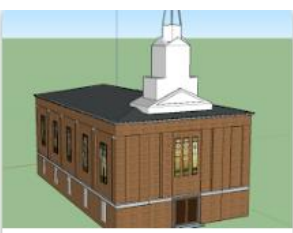

Sketchup32ish...

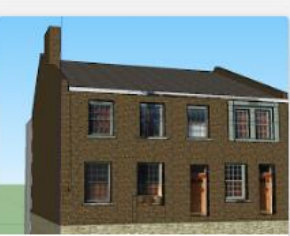

Sketchup653M...

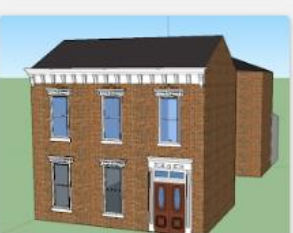

- Sketchup2305C...

Figure 4.5 SketchUp 3D models of historic structures from surveys of historic architecture in Wheeling, West Virginia (Digital HP Lab, Eastern Michigan University).

The digital 3D assets of the system include numerous models produced specifically for the Wheeling study based on the data gathered using one or more of the five different types of surveys and pre-fabricated models described above. Such "prefabs" are essential components of virtual and game environments because they save resources and are often optimized to balance realism with a lower-polygon count. A digital terrain model (DTM) is produced by importing terrain elevation data into Gaia. (www.procedural-worlds.com ). Gaia is also used to establish the water levels and to populate the terrain with vegetation based on the historic data acquired about the study area using the Speed Tree plug-in (https://store.speedtree.com). Humans and animals in the place-based VH system are represented by low-polygon models, such as those 
produced by Synty Studio (www.facebook.com/syntystudios). Although such cartoonish NPCs may distract some users (Fig. 4.6), they reflect the need to reduce polygon count for real-time display in the immersive VR environment coupled with the almost exorbitant resources required to model realistic and dynamic avatars and complications arising from the uncanny valley (Mori 1970; MacDorman and Ishiguro 2006; Bentkowska-Kafel 2013).

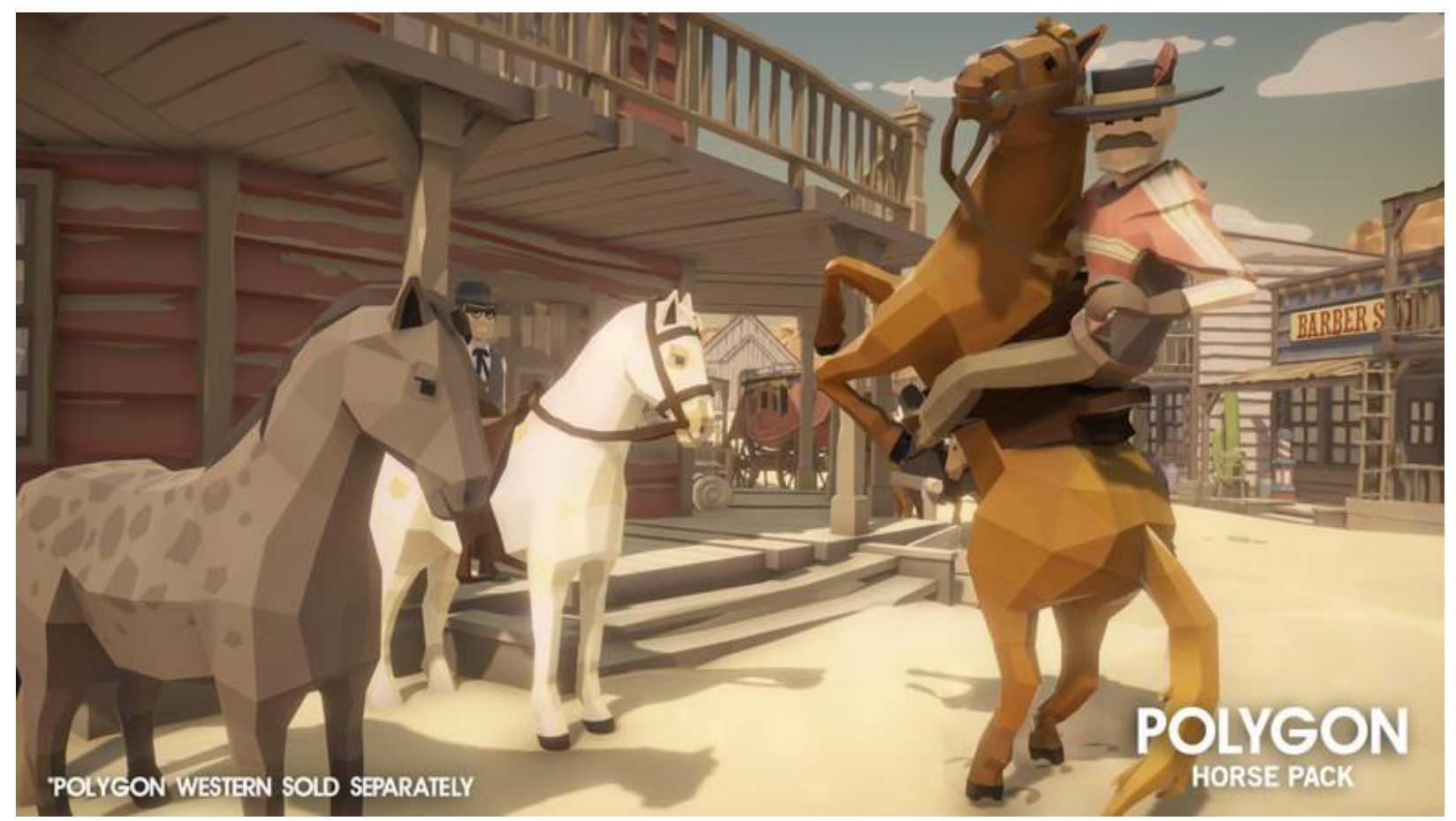

Figure 4.6 Low polygon human and animal prefab models from Synty Studio may look cartoonish, but render efficiently, enabling real time interaction in HMDs. https://assetstore.unity.com/packages/3d/characters/animals/polygon-horse-pack-112452 


\section{Intangible Data Processing}

Each of the natural, human, and cultural assets imported into the virtual environment may also have intangible characteristics. Intangible heritage, as discussed in Chapter 2, refers to the immaterial elements of culture such as sound, smell, taste, stories, rituals, emotions and affective qualities. For example, the sound of thunder or the smell of manure are intangible assets associated with a place or a scene. In the place-based VH system, all intangible elements are tied to a specific location or object. Although smell and tactile qualities have been explored in virtual environments to varying degrees of success (Ferrari 2018), the place-based system restricts the sensuous elements to only that of sound because of its dominant role among the non-visual senses and because of the resources required to implement other non-visuocentric senses into this analysis. The work of Ferrari (2018) demonstrates how smell might be incorporated within such virtual reconstructions in an immersive environment. In these early stages of development, other intangible elements are limited to a representative selection based on their ability to evoke a sense of place (Fig 4.7). Among the most important intangible aspects of place are the meanings and associations attached to them by people. Thus a key component of the place-based VH system is the audio of people sharing their perspectives and telling a story or recounting a memory about the place, people, and events. Similarly, signals and keynotes of the soundscape discussed in Chapter 2 provide the foreground and background cultural sounds generated by humans at locations in the study area, such as industrial, religious, and commercial sites, which evoke power and social relations and may enhance immersion and emotional involvement in $\mathrm{VH}$ (Revill 2016; Pietroni 2018). In addition, animal, bird, and insect sounds may seem like minutia, but they too are keynotes of a given soundscape (Schafer 1994; Truax 2001). 


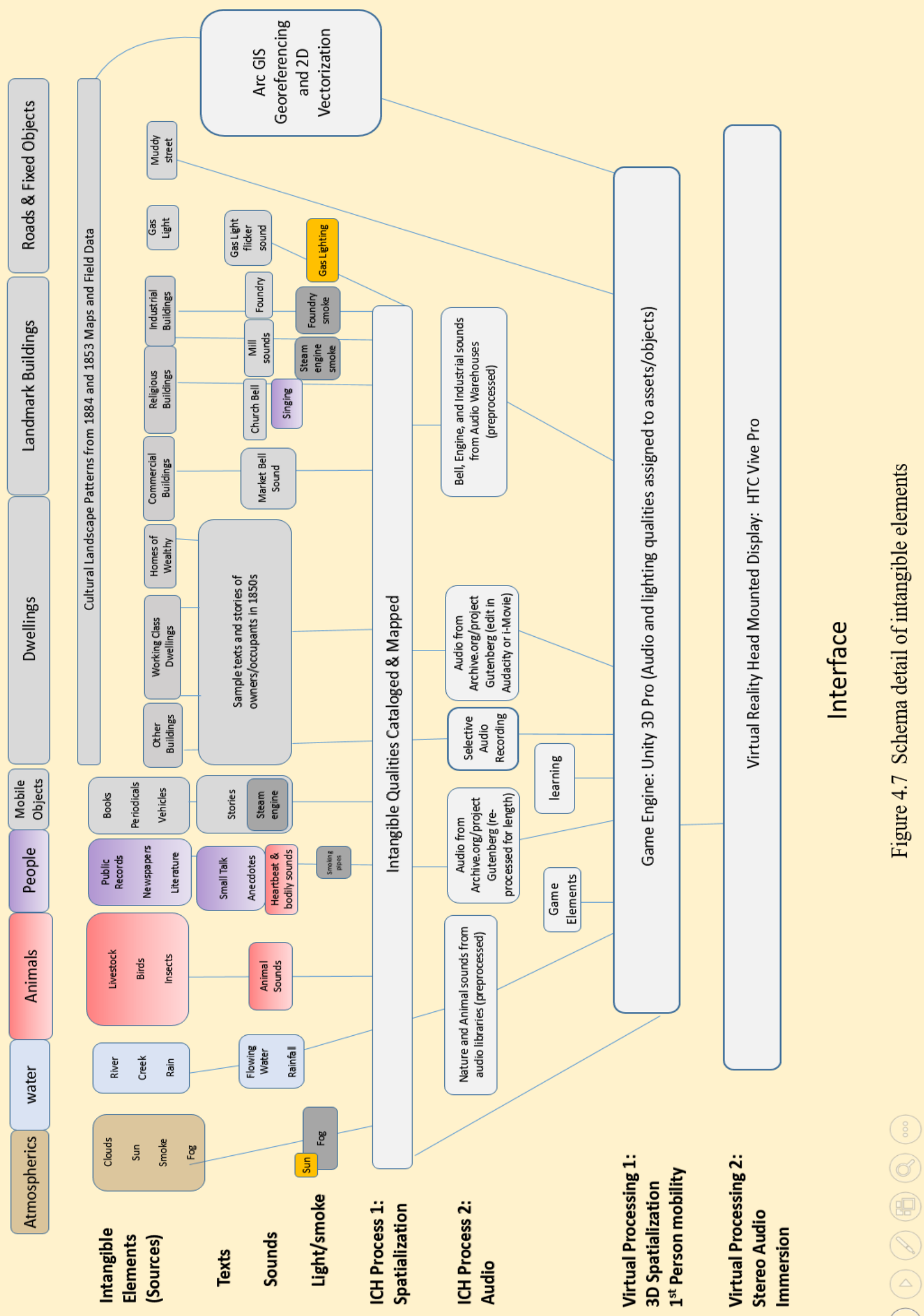


The variance of aural keynotes and signals from hour to hour and season to season may be incorporated into the place-based VH system, or a given project may choose to focus on a single time of a single day. Audio files may be obtained from the Macaulay Library at the Cornel Ornithology lab (www.birds.cornell.edu) and other digital audio warehouses. Perhaps less evocative, but no less important, is the paradata about the audio assets themselves and the historic phenomena that they represent. This paradata provides documentation of the source materials and the limitations of the audio files and processes involved in their production.

\subsection{Unity3D, Data Integration, and User Interface}

In a place-based VH system, all the elements described above are important, yet the areas of integration and interface are perhaps the keystone of the system, for this is how the user accesses the heritage project, enters the scene, and interacts within the virtual environment. The integration of the various components and the system interface have three primary technical components: the game engine and associated software that manages the 3D virtual representation and facilitates user interaction; the hardware that displays the virtual environment, stores all of the components, and processes and responds to user input; and finally the system interface that serves as a portal to the immersive environment, components, paradata, and other information about the project.

Game engines such as Unity3D (https://unity3d.com) and Unreal (https://unrealengine.com ) provide an efficient means for integrating diverse digital 3D objects into a virtual landscape and enable them to be explored in the first-person World View perspective. Unity3D emerged some 
five years ago as the serious game platform of choice among leading humanities scholars working in virtual heritage. It is among the most popular game engines for independent game development (Forte 2013; Addison et al. 2013; Guidi, et al. 2015). The Unreal game engine is equally powerful, but preference was given in this study to Unity3D due to the smaller user community and the limited support base of the Unreal engine. Another route would have been to program directly for the Vive Pro (www.vive.com/us/product/vive-pro/) in Open VR (https://github.com/ValveSoftware/openvr) or SteamVR (https://steamcommunity.com/steamvr). Bypassing the stable Unity3D gaming platform, however would add unnecessary overhead to the project and limit the extensibility of the platform to other projects areas. Unity3D provides maximum future accessibility because it has the flexibility to export to virtually any gaming or VR platform, such as Xbox, PC, Mac, mobile devices, Oculus Rift, HTC Vive, along with Windows MR (mixed reality) devices and others (www.youtube.com/watch?v=cmRSkHl-Gv0).

The Unity3D game engine is freely available to the education community and possesses an intuitive graphical user interface, support, and flexibility. It is designed, as its name suggests, to facilitate the import and manipulation of digital objects from various digital modeling software, and its products can be exported to a CAVE or HMD, Mac or PC, the web, or a range of console games and mobile devices. Thus, the engine can be used to accurately reconstruct the material components of historic landscapes, incorporate intangible elements, and enable users to explore and interact with the virtual heritage from the first-person perspective in a serious game or highly immersive VR environment. Unity 3D offers maximum distribution and accessibility in the short term and the best potential for long-term stability. 
Preparing Unity3D for a $\mathrm{VH}$ project requires importing a number of plugins and assets, such as the Unity standard environment and character assets, Gaia, SteamVR, and Virtual Reality Tool Kit (www.vrtk.io). Next, 3D models are imported into Unity3D beginning with the DTM and vegetation generated directly in Unity3D using the Gaia plugin. Once the basic system is functioning, maps are imported that depict the spatial location of each cultural, natural, and human element to be incorporated into the scene. Digital 3D models of the buildings are imported, scaled, rotated, and placed in the scene. Associated data is assigned to each asset, and audio files are imported and assigned to assets as appropriate. Each audio asset should be assigned a trigger so that, for example, a sound is played at an appropriate time or place. Each sound may have a buffer zone that is triggered based on some event or action and a bell curve that defines how it is heard. Keynote sounds such as bird calls may loop constantly in the background with buffers that provide some variation. The movement of NPCs may be directed within navigation meshes, which can be accomplished in Unity3D through C\# scripts or directed using COTS plug-ins such as the NPC Populator for Unity developed by Clockwork Games (www.clockworks-games.com).

Public expectations of Virtual Reality have been heightened by Hollywood fiction, from the holodeck of Star Trek: The Next Generation (1987) to Spielberg's Ready Player One (2018). There are three basic display options for a VH system: CAVEs, HMDs, and first-person video games (Fig 4.8). Cave-Automatic Virtual Environments (CAVEs) have been perceived as the most desirable VR platform because of their size and resolution, stereo imagery, frame rates, accessibility to multiple users simultaneously, and response to user input, all of which promote an unmatched sense of presence. However, the cost and complexity of CAVE systems make them inaccessible outside of major research universities, federal agencies, and corporations, and 
even there, use is limited to a small number of people. With advances in display technology, processing speed, and hand-held controllers, HMDs have emerged in the past few years as serious alternatives to CAVEs. The HTC Vive and Oculus Rift HMDs in particular offer immersive, stereoscopic, and real-time experiences of virtual environments at a fraction of the cost. The Vive is the industry leader, with a slight edge over its rival the Oculus Rift, due to the superior resolution of its optical display, its early adoption of hand-held controllers, and its ability to offer a virtual room-sized VR experience, rather than a stationary and desk-bound system. Other HMD systems are available and range in cost and complexity from the Google Cardboard to the Microsoft Hololens. At least a dozen companies are targeting curious consumers with mid-range VR and Mixed Reality devices at costs similar to a basic computer or minimal low-end devices that sell for less than $\$ 100$.
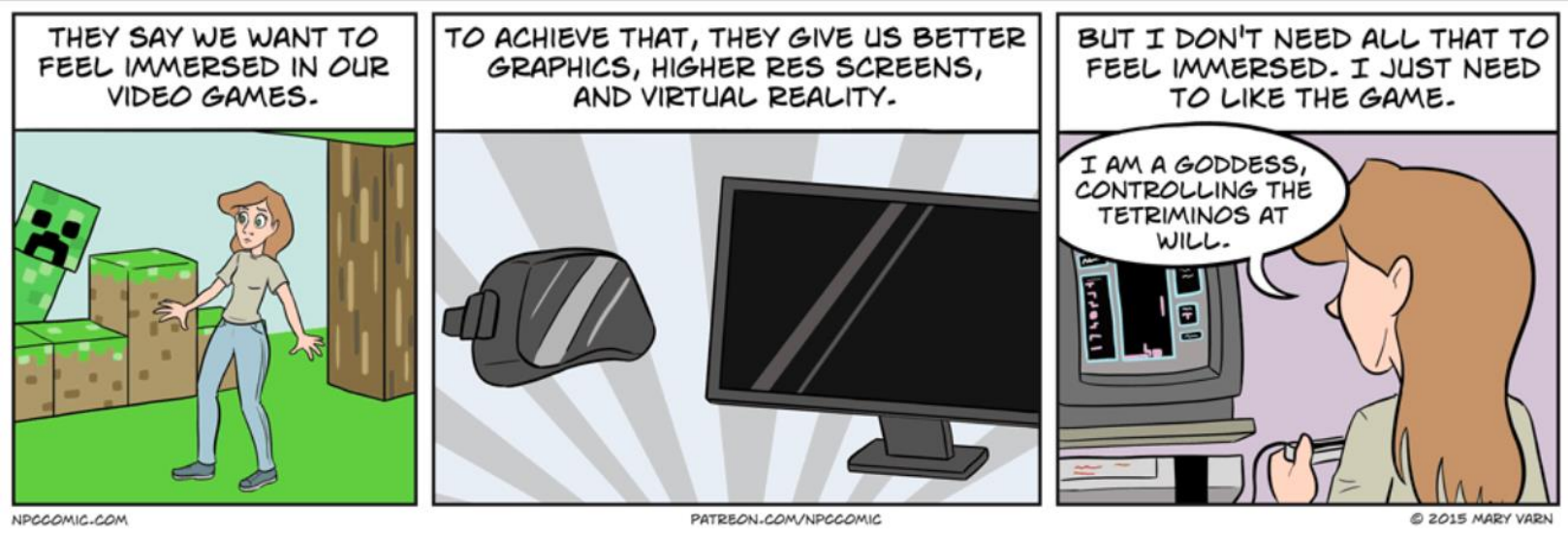

Figure 4.8 “Game Immersion” NPC Comic. Mary Varn, 2015. http://www.npccomic.com/comic/2015/10/09/game-immersion/

Even the best HMDs have limitations that affect the sense of presence, reproduction fidelity and extent of world knowledge. Despite tremendous advances in computer graphics cards and 
computer processors (interestingly largely driven by developments in the video game industry) the polygon count of the scenes targeted for VR often need to be reduced drastically to produce the frame rates necessary to avoid display lag and nausea. Even under optimal conditions, VR fatigue typically occurs within 10-15 minutes. Furthermore, mobility in such environments is limited, because HMD users must virtually "teleport" from one station to another, from which they may roam further as if on a virtual leash, before teleporting to the next station. This unnatural point to point experience may adversely affect the sense of presence and stands in contrast to the experience of first person video game environments in which users move freely which adds to the sense of immersion and presence.

The place-based VH system, as designed, can use any of the three VH options, but targets the HMD as the most accessible fully-immersive platform. The ease of access to the system also serves well as an extensible base for a wide range of applications and locations. To facilitate sustainable access to the system and its components, a web portal is recommended to provide access to background information about the project, allow users to download the $\mathrm{VH}$ environment, launch a scene, access an introductory video, review the paradata, evaluate the project, and provide feedback.

The place-based VH system developed here was optimized for the HTC Vive Pro (Fig 4.9) but can readily be exported for access via a traditional first-person PC video game, which offers superior processing speeds over Mac and Web-based options. Compared to HMD platforms, first-person gaming on PC or console does not produce the same level of immersion or sense of presence, but does offer real-time interactivity, the support of a much broader network of independent developers, and unrivaled mobility and accessibility. In contrast, the HTC Vive 
platform enables the system and its users to experience aspects of place enabled by a deeply immersive VR. That the demonstration version of the place-based VH can be designed for the HMD, yet is still compatible with the PC-gaming platform used by millions of potential users is a great advantage, particularly during the early stages of development, where user feedback is critical.

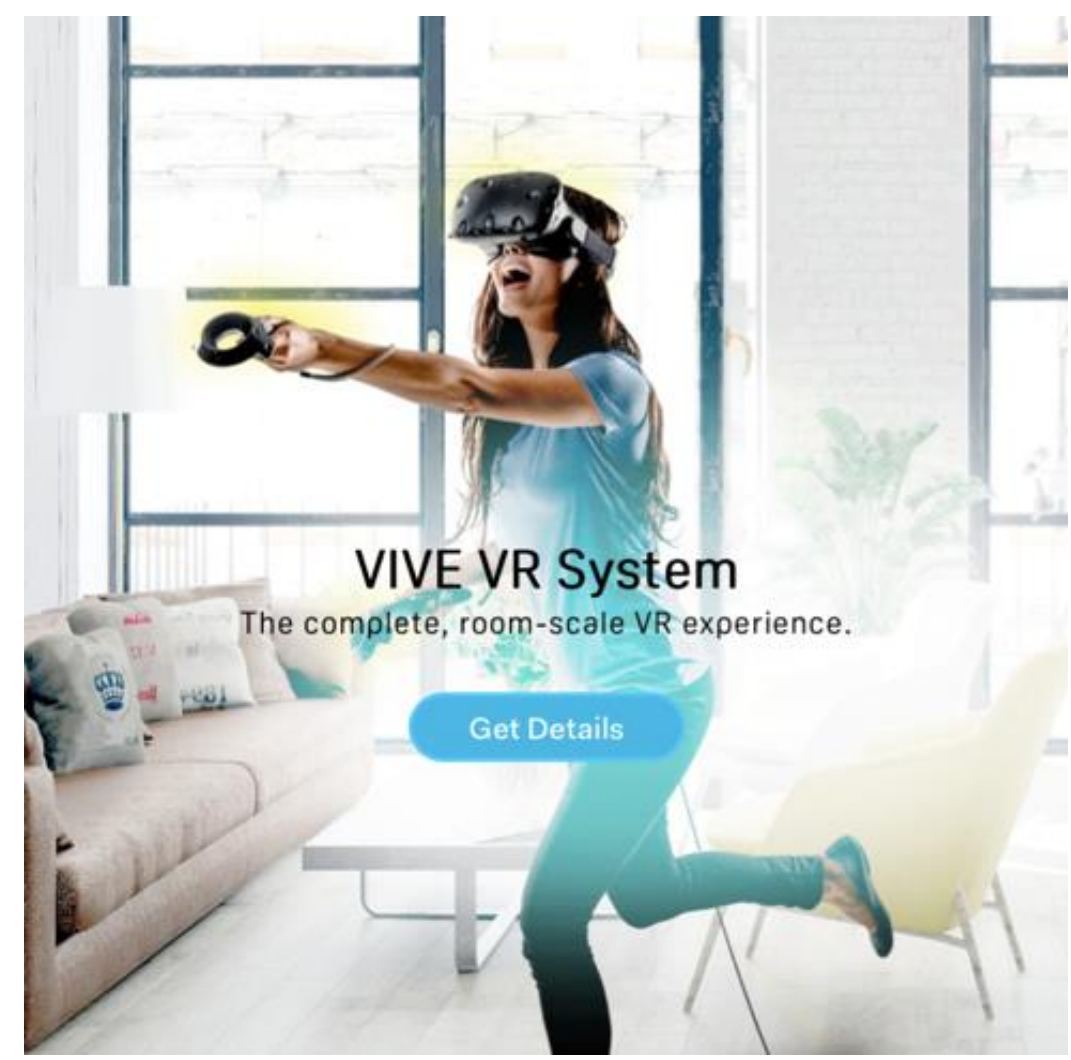

Figure 4.9 Vive HMD Virtual Reality System (https://www.vive.com/us/).

\section{The User Interface}

A critical but oft-neglected component of $\mathrm{VH}$ systems is the user interface that provides access to the system, data, models, paradata, and the immersive experience (Fanini and Pagano 2015). In early stages of development, a knowledgeable user provides access and orients users to the 
place-based VH system. However, as such projects mature, place-based VH developers must design elements that introduce and facilitate user access to the system and subject matter, such as cut scenes, game elements, NPC guides, and website. A cut scene is a short video that orients users to the heritage area and its significance. Such cut scenes are common in commercial and serious games and may be created in Unity3D using Pegasus, a COTS plug-in produced by Procedural Worlds (https://discordapp.com/invite/rtKn8rw). Cut scenes follow a story board and provide background information about the place being explored, along with guidance on tasks and objectives to achieve in the introductory scene. Game elements should be limited at the introductory level, and focus on tasks that orient heritage managers, preservationists, interpreters and other users to the system and its features. Users may be guided by a local historical figure as an avatar and encouraged to explore the reconstructed place and evaluate data about buildings, people, and events associated with the study area. Cut scenes, games elements, and NPCs can help prepare users navigate the place-based $\mathrm{VH}$, examine it as a heritage recording, and experience a sensuous and emotional reconstruction of heritage place. A website can serve as a portal that enhances access to the entire place-based VH system and its components, including the paradata about the archival sources, 3D models, and other elements of the digital reconstruction. 


\section{Gathering \& Processing Data: A Place-based Virtual Heritage Case Study}

Wheeling, Virginia (now West Virginia) in the 1850s was selected as the setting for a case study to test and evaluate the place-based VH system for two reasons. First, on Wheeling's Webster Street in the 1850s stood the home of literary realism pioneer Rebecca Harding Davis who emerged in the early 1860s as a leading author of stories that exposed the social costs of unbridled industrialization on the poor and vulnerable sections of society. She wrote her earliest works, such as Life in the Iron Mills (1861), Margaret Howth (1862), and David Gaunt (1862), based on her hometown of Wheeling, Virginia (http://rebeccahardingdaviscompleteworks.com). Despite numerous studies exploring the importance of the author and her works, scholars have devoted little attention to this period of the author's life or to the place where Rebecca Harding lived in the years prior to her 1863 marriage to Clarke Davis. Significantly for this study, Harding's evocative writing provides vivid insight into Wheeling as a place, the everyday experience of people in the industrializing city, and an opportunity to re-examine scholarly knowledge of the author, her early works, and her neighborhood (Knowles 2004). Harding's embrace of a radically honest realism contributes important placial elements that previously have been lacking in virtual heritage. These include intangible elements, such as her sensuous, emotional, and personal writing that helps transform space into place. Her writings provide a basis for reconstructing a $\mathrm{VH}$ that explores the everyday, commonplace, and the margins of the city. Her literary honesty complements a place-based $\mathrm{VH}$. The opening words of Life in the Iron Mills reveal powerful insight into Wheeling at the time: "A cloudy day: do you know what that is in a town of iron-works? ... (The) idiosyncrasy of this town is smoke. It rolls sullenly in 
slow folds from the great chimneys of the iron-foundries, and settles down in black, slimy pools on the muddy streets. Smoke on the wharves, smoke on the dingy boats, on the yellow river, -clinging in a coating of greasy soot to the house-front, the two faded poplars, the faces of the passers-by." Rebecca Harding thus provides an intimate knowledge of the people and the built environment, a sense of the profound impact that industrialization was having on common people in this place (Harding 1861), and an opportunity to explore her personal perspective in VH (Knowles 2004).

The second reason that Wheeling was selected for the case study is that its cultural heritage is nationally significant, and historic resources abound in local archives and on the landscape. The city's stock of urban antebellum dwellings is among the most remarkable and diverse in the United States (Bonenberger et al. 2018). Furthermore, many of these buildings have been recorded with drawings, photographs, and histories that can be used as the basis for virtually reconstructing the cultural and historic landscape elements of its neighborhoods. Together, with the wealth of field and archival data about 1850s Wheeling, the writings, stories, and perspective of Rebecca Harding Davis make her neighborhood an ideal choice for a case study for placebased VH. Drawing upon these and other sources described above, one can see how a more complete model of Harding's neighborhood can be formed and might take shape that includes the Harding home and property, the surrounding buildings and streets delineated from heritage sources, and populated with the movable objects of everyday life. Moreover, all these aspects are supplemented by extensive public records about the buildings and the people associated with them gathered from deed books, tax records, plat maps, census records, and city directories. 
In contrast to the city as a whole, unfortunately, the historic resources related to Rebecca Harding's former home and street are almost non-existent. Only one structure that stood on Webster Street in the 1850 s remains standing today and only one early image of the street survives. Even that image is limited because it was taken at an extreme angle and more than fifty years after Harding lived there. Thus preserving and interpreting the legacy of Rebecca Harding Davis in Wheeling provides a challenge to traditional historic preservation and virtual heritage alike. The case study that follows is focused on her home and street which can serve to fill a deep gap in public and academic knowledge and provides an opportunity to test the $\mathrm{VH}$ system's ability to digitally reconstruct a place-based virtual heritage representation of the past that has been all but completely vanquished and to represent it with a sense of the place in which it was situated.

\section{Rebecca Harding's Wheeling: A Place-Based VH}

This place-based VH system elevates the heritage components to a status equal in standing with its virtual components and the principles of access, authenticity, and context are given the highest priority. This situates the place-based $\mathrm{VH}$ system in contrast to a traditional $\mathrm{VH}$ approach, which would seek to produce a photorealistic 3D building with minimal if any attention to environmental surroundings, documentation of sources, procedures, uncertainty, conjecture, and the intangibles of place.

The case study recreates the historic spaces in which Rebecca Harding lived, documenting and digitally reconstructing the heritage of her time including former structures and other elements of 
the 1850 s streetscape. Specifically, the area of focus for this study is within a neighborhood delineated by Wheeling Creek, the Ohio River, and the Crescent Iron Works. The study incorporates intangible elements of this place in the area immediately surrounding her home on Webster Street between Market and Main Streets where, Harding had an intimate outlook on the "slow stream of human life creeping past, night and morning, to the great mills" (Harding 1861). In her work Harding drew upon her neighborhood to portray a story of the working class in a familiar, impassioned, and often emotional narrative that had not been encountered previously in American literature (Harris 1991). Just as Harding's subject matter challenged the writing conventions of her day, a placed-based VH system challenges conventional historic preservation and heritage recording techniques.

Reconstructing places such as Webster (now $20^{\text {th }}$ ) Street in Wheeling constitute a tremendous challenge to traditional heritage recording and for $\mathrm{VH}$ alike. The street has been drastically altered by urban development and redevelopment over the past 160 years. Only one building standing on Webster Street in the 1850s survives, and even the foundation of Harding's home is hidden below layers of soil and covered with a paved parking lot. Unlike the many World Heritage sites modeled in VH, no intensive archaeological or above ground survey has been conducted at the site of Rebecca Harding's house, so there is little data upon which to base even a traditional heritage recording let alone a $\mathrm{VH}$ reconstruction.

Conventional heritage recording of significant sites in the United States follow the Standards and Guidelines of the Historic American Buildings Survey (HABS). As discussed in Chapter 2, HABS guidelines call for precise documentation of existing physical conditions. Reconstruction drawings are strictly forbidden and any conjecture must be clearly noted (Vogel 1983). Thus 
recording the existing conditions of the Harding House ruins would require consent of the property owner to carefully remove the parking lot, conduct an archaeological dig, and produce measured drawings delineating the foundation walls in plan-view and elevation to the nearest $1 / 8$ inch. The Historic American Landscape Survey (HALS), a sister organization to HABS founded in 2000, provides an alternative approach to recording heritage and the existing remains of past landscapes. However, HALS has focused largely on professionally designed gardens, estates, parks, and cemeteries, so its methods do not translate well to the lost urban landscape experienced by Rebecca Harding in the 1850s. Such lost historic sites simply run counter to the approach of the federal heritage documentation programs which reflect the architectural mindset of their founders and a long-standing aversion to the act of reconstruction. Because the place's significance is largely tied to what happened there, rather than its tangible remains, the traditional HABS/HAER/HALS approach cannot live up to HABS Standard 1: "Documentation shall adequately explicate and illustrate what is significant about the...site" (Vogel 1983).

As such, traditional heritage interpretation at the former site of the Harding House would draw upon archival and archeological research to determine the house's dimensions, footprint, and façade. If Rebecca Harding had been sufficiently famous in the 1930s-50s, the city might have physically "reconstructed" the townhouse following the tradition of Colonial Williamsburg. But this practice fell out of fashion with the heritage community due to the Venice Charter and National Historic Preservation Act of 1966, which both emphasize authenticity and integrity. If the property were acquired today, preservationists might represent the shape and dimensions of the home via a simple steel superstructure like Venturi and Rauch's 1976 design for the site of the 1763 Benjamin Franklin House in Philadelphia (Fig. 5.1) to provide some sense of the lived space (Matero 2010). Alternatively, and less intrusive, the footprint of the Harding House might 
be outlined with brick or stone pavers, coupled with interpretive signage or a kiosk that provides an overview of Harding, her writings and their significance, and how her work reflects life among the working immigrants of Wheeling in the 1850s (Tyler et al. 2018). While either approach could prove a valuable aid for site interpretation, today it is increasingly likely that the effort would include a digital, if not 3D component. As we have seen, however, such projects run the danger of repeating mistakes that are typical of the route $\mathrm{VH}$ has taken.

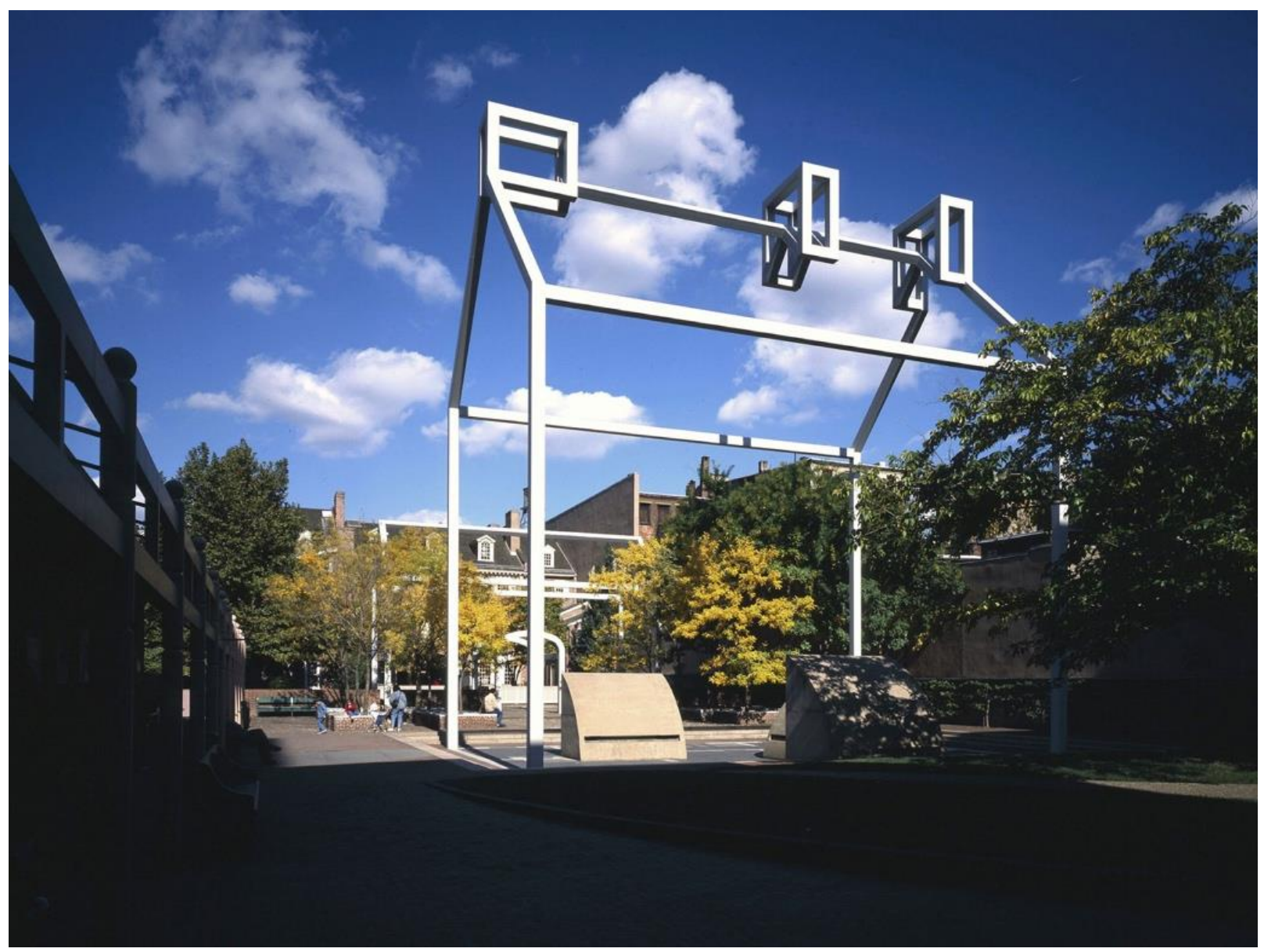

Figure 5.1 Venturi and Rauch's 1976 "Ghost Structure” at Franklin Court (Independence National Historic Park; https://www.nps.gov/npgallery/GetAsset/3D00C6B9-155D-451F67CBCDFA110DC69E). 
Unlike conventional heritage recording and site interpretation, a typical $\mathrm{VH}$ approach would have no qualms about reconstructing the Harding House based on the best available data. The project would draw upon field and archaeological data if available and include the archival resources of public history research, such as historic maps, photographs, engravings, and other visual, textual, and statistical records. The one incomplete and later image of Harding's house (Fig 5.2) reveals a series of three-bay townhouses, a form that was popular among the wellheeled of the nineteenth century, and which remains as a prominent house type in Wheeling today (Bonenberger et al. 2018). Following the traditional VH approach, a 3D virtual heritage model of the house would be constructed based on the footprint depicted on the 1" $=50$ ' Sanborn Insurance map. The VH model would be rendered in great detail with period materials, decorations, and colors to enhance the photorealism of the model. However, with so little data available, the tendency of VH toward hyperrealism, the non-disclosure of any model conjecture, and the absence of paradata would lack intellectual transparency, and be of limited use in documenting, analyzing, interpreting, communicating, or advancing knowledge of Rebecca Harding's heritage. Moreover, the model would lack the geographic context of its surrounding cultural and placial landscape. 

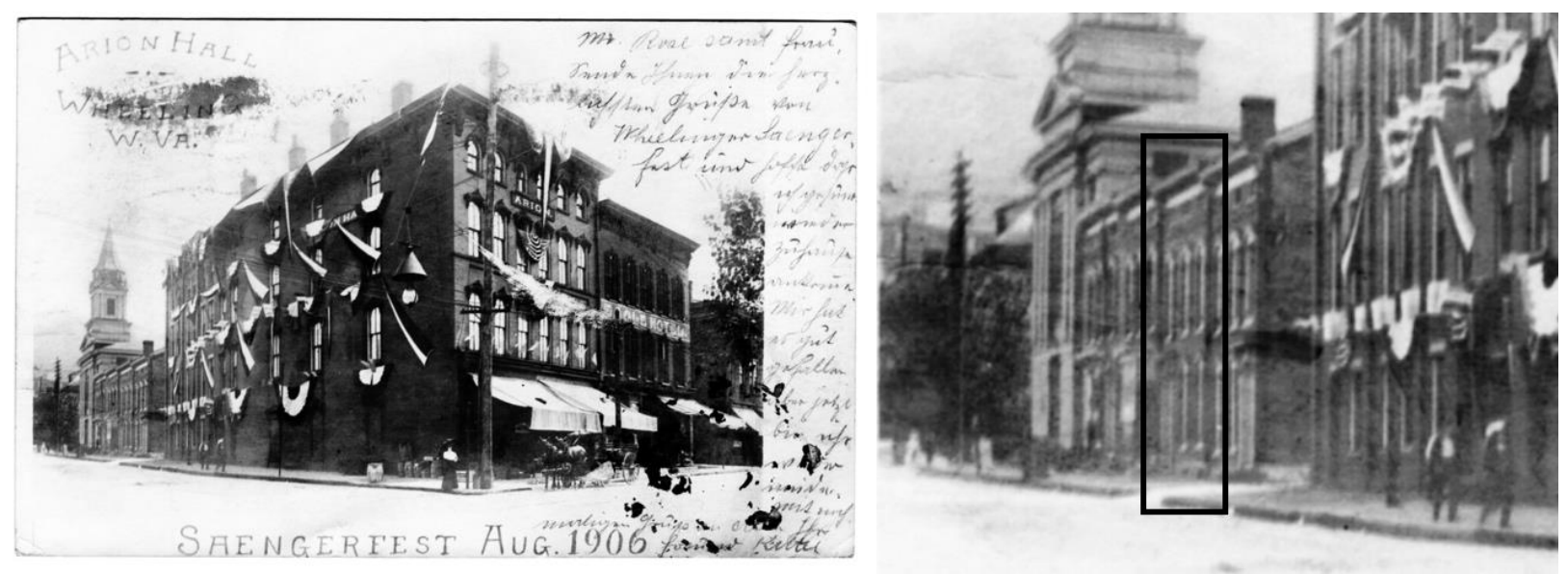

Figure 5.2 The Harding House depicted in a 1906 photograph (Left). In detail at right, it is the third townhouse to the right of the Presbyterian Church; second to the left of the alley (Ohio County Public Library).

Implementing a place-based approach to $\mathrm{VH}$ began in much the same way as a traditional heritage recording project or conventional $\mathrm{VH}$ project, by gathering the best available data about the Harding House through archival and field research in addition to gathering data that revealed the dwelling's geographic context and the placial context of her house in 1850s Wheeling. To determine the nature of the demolished buildings and to digitally model them in $3 \mathrm{D}$, a number of sources were consulted and tasks undertaken. These resources and tasks included linking georeferenced historic maps to recent orthophotographs; undertaking an intensive survey of nearby contemporary dwellings; producing a series of 3D digital models using SketchUp; and visually reflecting the quality of data available in each $3 \mathrm{D}$ model. In addition, implementing a place-based $\mathrm{VH}$ system required gathering and processing the intangible elements of heritage in the study area, including the words and stories of Rebecca Harding, along with the natural and cultural soundscape. Throughout the process, data sources and paradata describing the process 
were documented that included the limitations and levels of uncertainty represented in the individual elements. The 3D objects are located on a digital terrain model in a serious game environment that was subsequently exported to a HMD and made available online along with additional resources (Fig 5.3).

\subsection{Data Gathering, Storage, and Access}

All project files, including original archival sources, field data, and digital assets gathered and produced for the project, and paradata are stored on local hard drives and backed up on servers and in cloud storage with access provided via a shared Google Drive (Fig 5.3). An intuitive digital file structure facilitates access to the project data. The first component of this online repository comprises written materials describing the goals, research questions, planning and design of the model and the demonstration project, most of which are included in the chapters of this dissertation. The second component contains the archival and field data gathered for the project. The third component of the system contains the processed data and paradata, including the 3D models, GIS files, and audio elements that were gathered or produced for the case study. The fourth component of the project is the Unity3D scene, which can be downloaded for HTC Vive. 


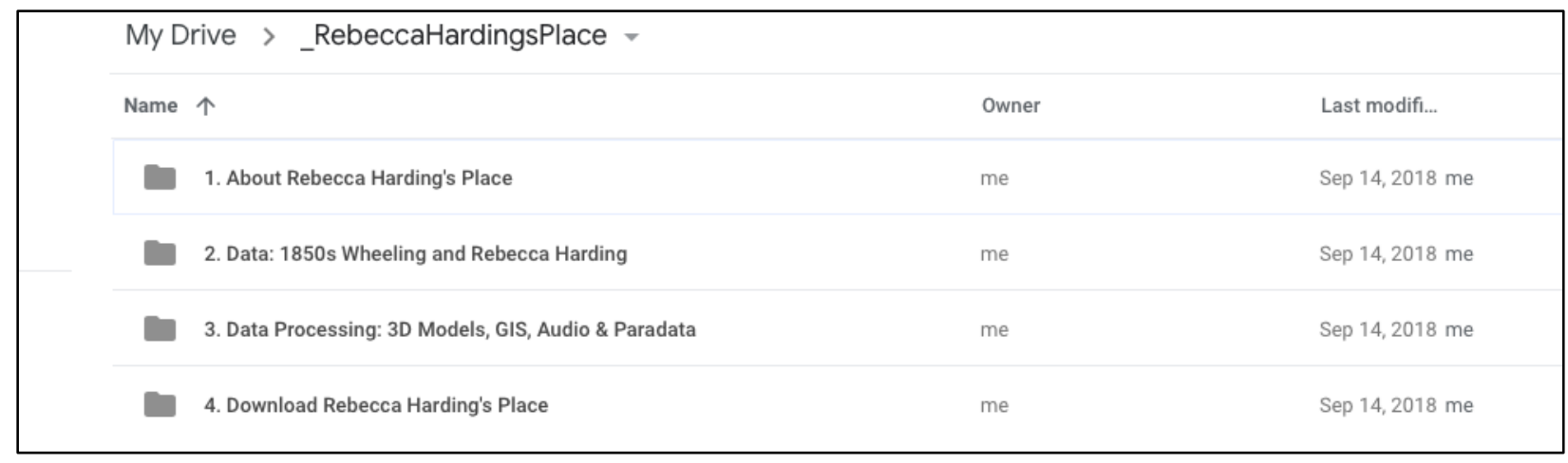

Figure 5.3 Component folders of the Place-based VH Case Study.

The digital data resources include those related to Rebecca Harding and those related to Wheeling in the mid-nineteenth century. Historic resources on Wheeling in the mid-nineteenth century are further subdivided into two main areas. "Recent surveys and scholarship" contains heritage surveys conducted over the past decade, National Register of Historic Places surveys of the 1980s and 90s, and urban renewal surveys of the 1960s and 70s. The "Archival sources" file is divided into folders entitled images, maps, records, and texts. These files contain all of the digital primary sources gathered or produced for the case study, such as the city maps that depict the houses on Webster Street in 1853 and 1884 (Fig 5.4). Another file contains data related to Rebecca Harding (Davis), including selections of her writings, data related to her life in Wheeling, and scholarship about her and the works that she wrote in and about Wheeling. These files include sources from original research, public domain, and copyright materials. Although it would be ideal to allow unrestricted access to all the materials, only public domain, open source, and original research can be shared freely. In addition to the archival data gathered for the project, an intensive survey was conducted by the author of this dissertation to record buildings that survive from the antebellum period (Bonenberger et al. 2018). This survey used traditional 
architectural and historical surveying methods combined with a historical GIS that enabled the identification of early buildings in North Wheeling, a contemporary neighborhood with similar dwellings and demographics to Center Wheeling, where the Harding's lived in the 1850s. The survey was conducted to assist in determining the likely form of antebellum buildings along Webster Street that have since been demolished.

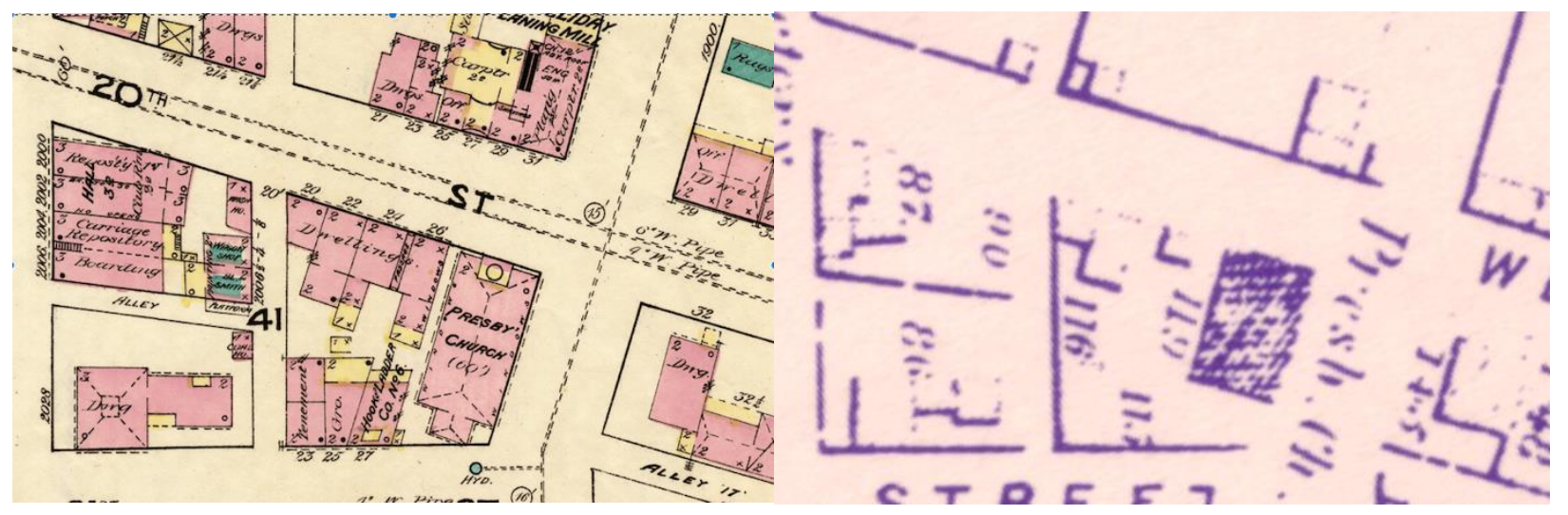

Figure 5.4 Side-by-side comparison of Harding House at 22 Webster Street as depicted on 1884 Sanborn Sheet 9 (Left), and 1853 Manfred and Simpson map (Right).

\subsection{Historic Buildings Survey \& GIS Components}

Architectural surveys of Center Wheeling, where Harding lived in the 1850s, and the adjacent central business district, reveal that very few structures remain from the antebellum era (Kleyle 1978; Fluty 1984), yet a remarkable percentage of the antebellum building stock survives in sections of adjacent neighborhoods, particularly in North Wheeling (Marshall 1988;

Bonenberger et al. 2018). Thus an intensive field and archival survey of the oldest surviving homes of North Wheeling was designed and undertaken to identify early vernacular homes in the city and document their history and architectural characteristics. The resulting typology of early 
dwellings in North Wheeling provided critical information to assist in the virtual reconstruction of the demolished dwellings along Webster Street. Matching the survey data to the building footprints documented in early city maps enables a virtual 3D reconstruction to be made that is considerably more credible than using imagination and artistic license. A historical GIS was designed to help identify pre-1853 dwellings, organize the research findings, and provide a spatial foundation for reconstructing the urban landscape in the Unity3D game engine and HTC Vive (Bonenberger et al. 2018, Balletti and Guerra 2016, Baletti 2014).

The first step in the intensive building survey that was undertaken was to geo-register high resolution digital copies of the earliest city maps with the one-foot resolution orthophotographs of the study area obtained from the West Virginia GIS Technical Center (WVGISTC). Polygonal layers of the 1853, 1871, and 1890 buildings were produced, along with a layer of potential buildings surviving since1890 based on the correlation between the 1890 map and current buildings depicted on the 2006 orthophotograph. A side-by-side comparison of the three maps was completed for each block in the study area, and it revealed 51 surviving dwellings that appear on both the 1853 map and the 1890 map. These dwellings warranted additional field and archival research (Fig 5.5). 


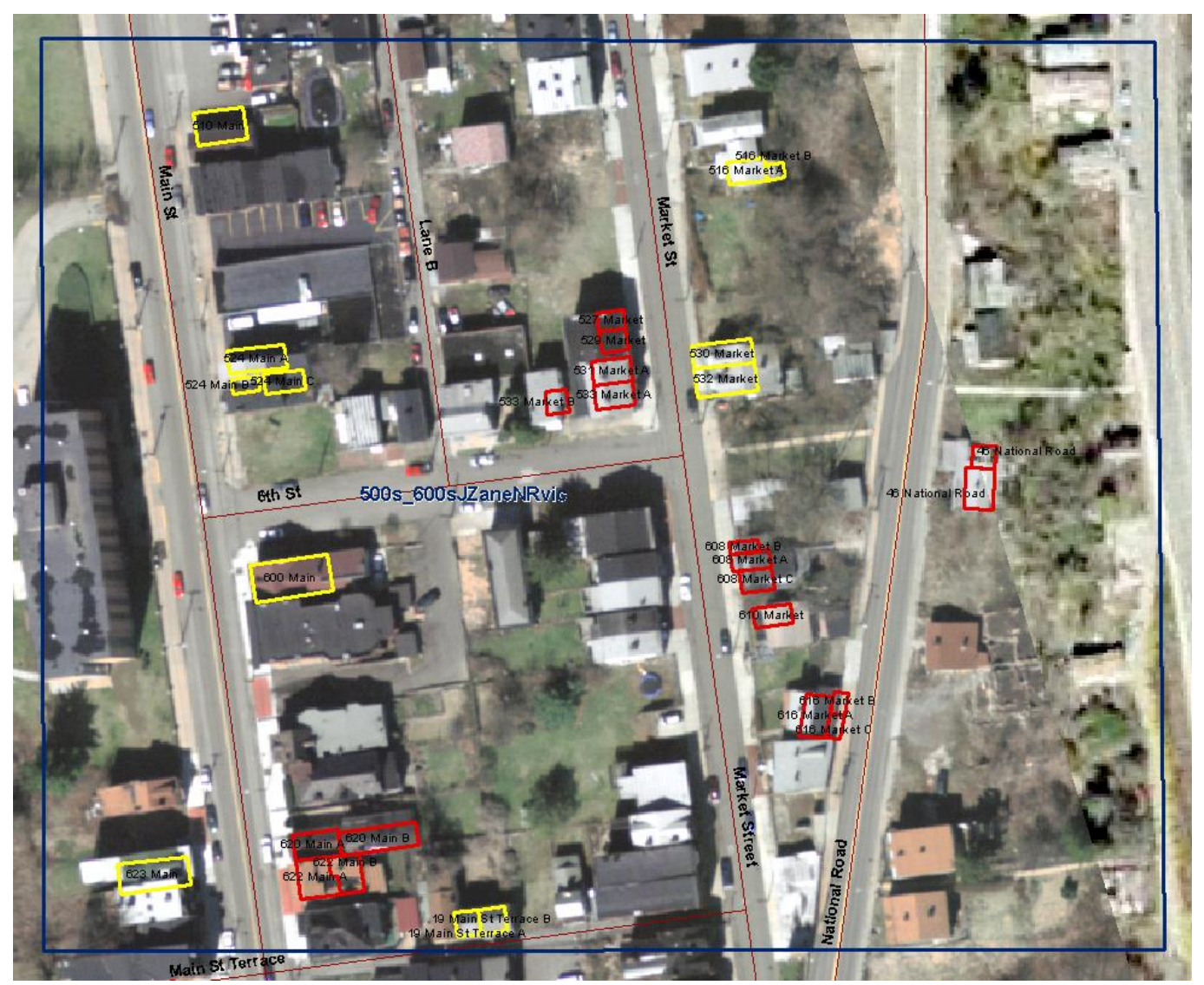

Figure 5.5 North Wheeling Historical GIS detail showing the area north of the intersection of Market Street and National Road in Jonathan Zane's Addition with 1890s footprints of likely (red) and possible (yellow) surviving pre-1853 dwellings depicted on 2006 orthophotograph, viewed here at a scale of $1 "=$ approximately 120 feet (Bonenberger et al. 2018).

Due to resource limitations, only twenty-four of these early dwellings were intensively surveyed with field measurements and photography and their histories were documented from city directories, census records, deed books, and the oldest tax assessor's valuations dating back to 1845. The date of construction was determined for each building, the chain of ownership was documented, the façade widths measured, and the floor plans recorded where accessible. The façade widths were compared with measurements delineated from the earliest Sanborn maps. 
The Sanborn footprints of 13 of the 17 examples (76\%) deviated by less than 10\% from the field survey measurements (Fig 5.6). Three footprints were off by about $15 \%$ and one clearly was measured incorrectly. These findings confirm general knowledge that these insurance maps provide an invaluable understanding of the scale, shape, height, and materials forming the building even though their precision may be somewhat limited. The Sanborn fire insurance maps remain the best source of information about most demolished urban buildings across the United States in the mid- to late-nineteenth century.

\begin{tabular}{|c|c|c|c|c|}
\hline \multirow{2}{*}{$\begin{array}{l}3 \\
4\end{array}$} & \multirow[b]{2}{*}{ Address } & \multirow[b]{2}{*}{ Plan or House Type } & Sanborn 1890 & NWhg17 \\
\hline & & & Width & width \\
\hline 5 & 635 Main & SPP & 23 & 25 \\
\hline 6 & 711 Main & SPP & 26 & 27.5 \\
\hline 7 & 722/724 Main: 722 & SPP & 20 & 22 \\
\hline 8 & 722/724 Main: 724 & SPP & 22 & 22.5 \\
\hline 9 & 727 Main & SPP & 24 & 28 \\
\hline 10 & 314 West (Core Block) & $2 / 31$-House & 21 & 24 \\
\hline 11 & 416 Main CB & SPP Com & 27.5 & 32 \\
\hline 12 & 422 Main CB & SPP Com & 24 & 24 \\
\hline 13 & 424 Main CB & 2over2 & 18 & 16 \\
\hline 14 & 444 Kenney CB & GP & 38.5 & 40 \\
\hline 15 & 29 Pike CB & 4-bay H/P & 29.5 & 31 \\
\hline 16 & 620 Main CB & HP & 18 & 18.5 \\
\hline 17 & 629 Main CB & CP 2over2 & 23 & $18 / 25.5$ \\
\hline 18 & 652 Main & 2over2 & 16 & 17 \\
\hline 19 & 653 Main CB & SPP +2 & 39.5 & 35 \\
\hline 20 & 655 Main CB & SPP & 43.5 & 30 \\
\hline 21 & 659 Main CB & 2over2 & 21 & 19 \\
\hline 22 & DJB Core Block (CB) 1890 & & & \\
\hline 23 & from full-size & & & \\
\hline 24 & $1 \mathrm{~cm}=20.2(9.9 \mathrm{~cm}=200 \mathrm{ft})$ & & & \\
\hline
\end{tabular}

Figure 5.6 Width of dwelling facades (in feet) from insurance maps (Sanborn 1890) compared with field measurements (NWhg17) recorded during the Early Dwellings of North Wheeling survey (Bonenberger et al. 2018).

To complete a typology of dwelling types in early Wheeling based on the Sanborn footprints, additional antebellum façade widths were measured in Center and North Wheeling in March 2018. The total of thirty-four dwellings surveyed varied in width from 16'-0" to 40'-6." Each of 
the thirty-four buildings followed a strict typology and provided critical information needed to correlate the buildings depicted on Center Wheeling's Sanborn maps with the extant contemporary buildings of North Wheeling (Fig. 5.7). All those buildings that measured 19 feet or less along the front facade were two bays wide with two windows or door openings on each story. Those facades that measured 20-28 feet wide were three bay buildings and those between 30 and 34 feet wide were four bays wide. Those buildings that measured over 35 feet were five bays wide. Although multiple house types are associated with each division of width, almost all of these variations are clarified by their depiction on the Sanborn maps. As a result of this survey, clear protocol was established for reconstructing the demolished dwellings of Rebecca Harding's neighborhood.

\begin{tabular}{|c|c|}
\hline \multicolumn{2}{|c|}{$\begin{array}{l}\text { Antebellum Building Widths in Wheeling, West Virginia } \\
\text { From DJB Field Measurements March } 2018\end{array}$} \\
\hline 2 Bay (10 examples) & $15-19$ feet \\
\hline 2 Bay + Porch (3) & $16-18+$ Porch of $6-7.5$ \\
\hline Gable Fronters(3) & $16-18.5$ \\
\hline 3 Bay (14) & $20-28$ feet \\
\hline Commercial (4) & $20-25.5$ \\
\hline 2/3-I House (1) & 24 \\
\hline SPP (9) & $22-28$ \\
\hline 4-Bay ((6) & 30-33.5 feet \\
\hline $2 / 2 D(2)$ & $30-33.5$ \\
\hline$H / P$ & 31 \\
\hline I-House & 30.5 \\
\hline 5-Bay (4) & $35-40.5$ feet \\
\hline Georgian Plan & 40 \\
\hline Completed 2/3G & 40.5 \\
\hline $\mathrm{SPP}+2 / 2$ & 35 \\
\hline I-House & 35 \\
\hline
\end{tabular}

Figure 5.7 Dwelling width correlated with the number of bays across the façade. Vernacular house types are abbreviated as follows: $2 / 2 \mathrm{D}=$ two-over-two dwelling; $\mathrm{H} / \mathrm{P}=\mathrm{Hall}$ and Parlor; Completed $2 / 3 \mathrm{G}=$ Two-thirds Georgian plan house with two bay addition. $\mathrm{SPP}+2 / 2=$ Duplex comprising a side passage townhouse and a two-over-two dwelling. 
To create a base map of buildings on Webster Street in 1853, Historical GIS layers were developed in a manner similar to that of the North Wheeling Study (Bonenberger et al. 2018). Buildings depicted on the earliest city map at 1" $=100$ ' (Manfred and Simpson 1853) were compared to those delineated at $1 "=50$ ' on the earliest insurance map of Wheeling (Sanborn 1884). Because most of the buildings from 1853 were still standing in 1884, the Sanborn map provides an important additional level of detail beyond the 1853 footprint (Fig. 5.4), which is reflected in how such buildings were modeled and rendered in 3D (Sauder 1980).

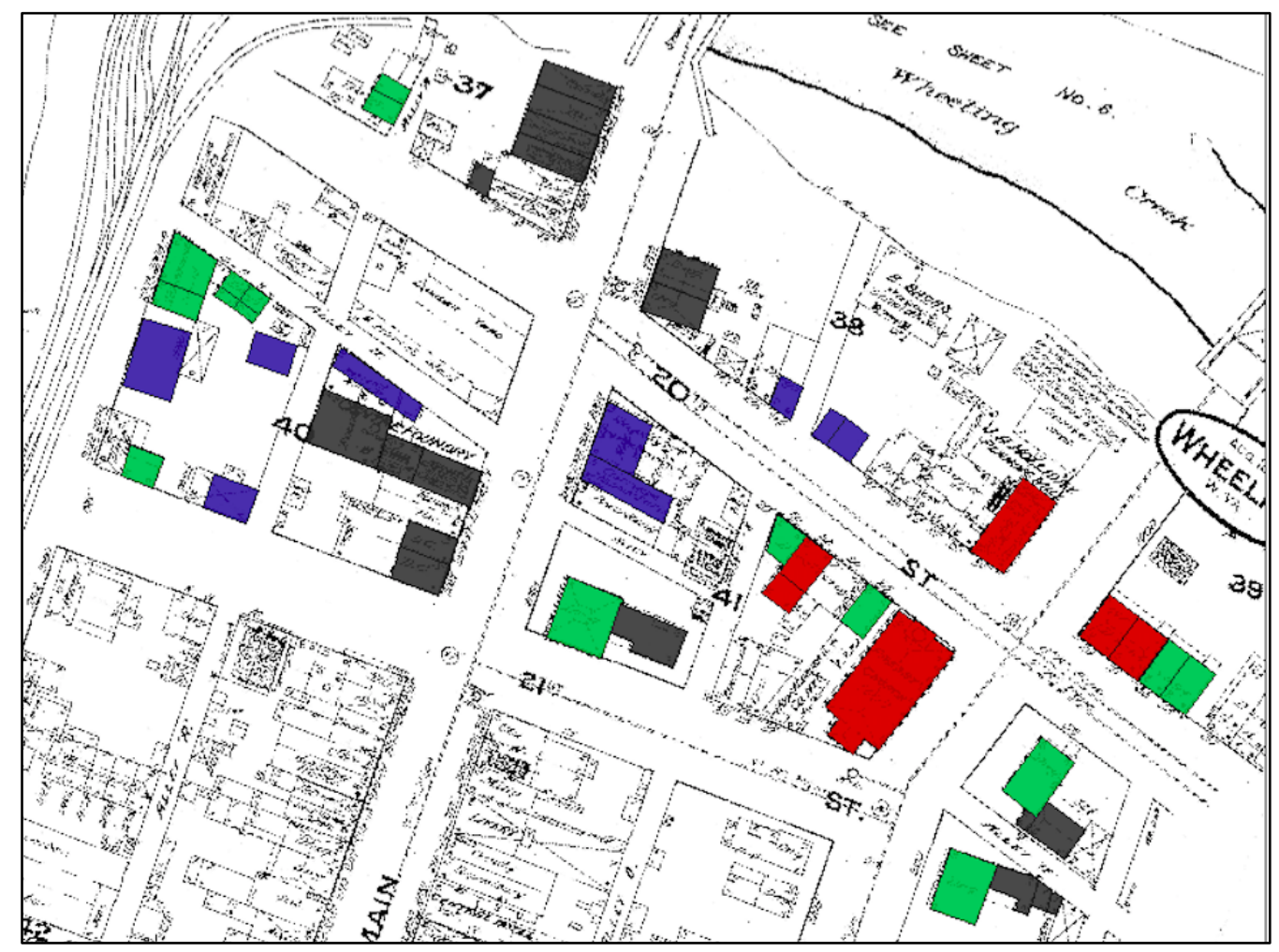

Figure 5.8 Historical GIS revealing Webster Street buildings from the 1853 city map correlated with the 1884 Sanborn map showing the quality of data sources: Level 1 models (Blue) based solely on 1853 map; Level 2 (Black) based on the correlation between 1853 and 1884 maps; Level 3 (Green) based on the 1853 and 1884 maps with local intensive survey; and Level 4 (Red) extant and/or based on photographic documentation (Steffany Wood). 


\subsection{Data Processing: 3D Models, Geoprocessing, and Representing Uncertainty:}

A range of structures were modeled in SketchUp including landmark buildings, prominent houses, vernacular dwellings, and other buildings. In order to avoid undocumented conjecture, each building model was rendered in a way that reflects the specific level of information that was available. These levels fall into four basic categories (Fig. 5.8 and 5.9). At the primary level, those buildings that appeared only on the 1853 map were rendered as simple massed models based solely on their footprint. At the second level, those buildings depicted on the 1853 and 1884 map were rendered with the correct number of stories, building material, and roof type. Those buildings on the 1884 map that strongly correlated with the surveyed local vernacular building types underwent a third level of rendering that included façade arrangement and chimney placement. Finally, buildings that remain standing or were documented in photographs were made as photorealistic as possible appropriate with the quality of available evidence.

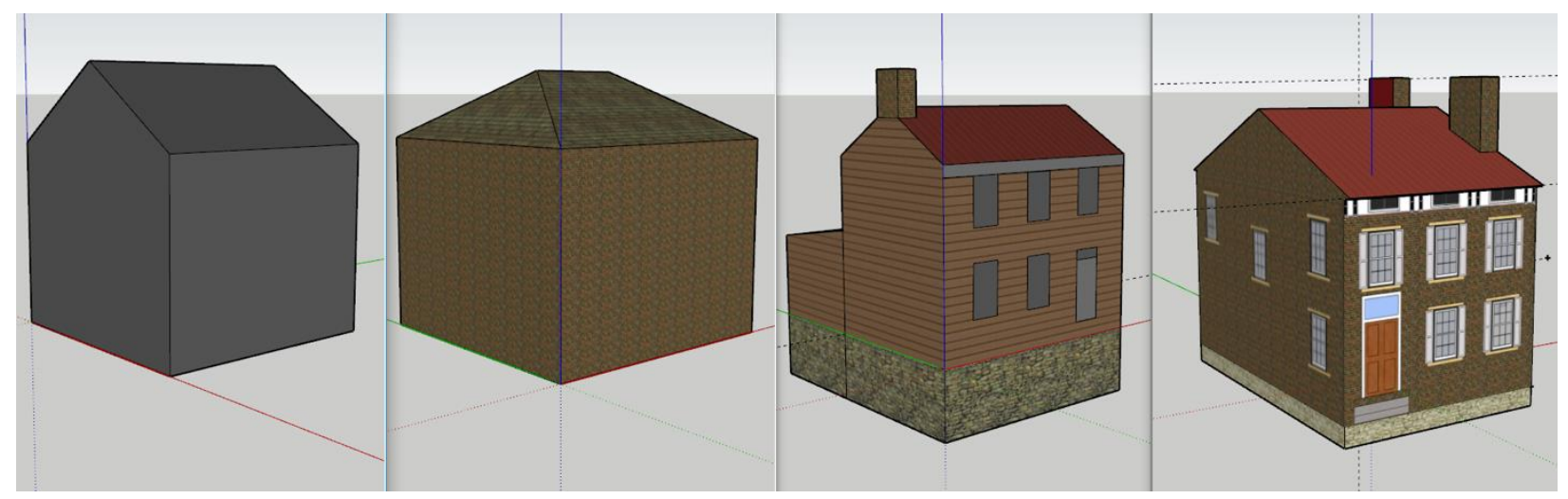

Figure 5.9 The rendering hierarchy of low-polygon 3D models based on the four classes of data available (Left to Right): Level 1 model used for all buildings only depicted on 1853 map; example of Level 2 (1853 and 1884) model used for brick buildings with hip roof indicated on 1884 Sanborn; example of Level 3 based on intensive survey correlation with 1884 Sanborn (the model of 314 West Street that was adapted for 71/4 Webster Street); and Level 4 with photographic record where this example is the Harding House. 
Thus the system and case study sought to carefully avoid the performativity and undocumented conjecture typical of $\mathrm{VH}$, and instead represent the present state of heritage knowledge about each building on Wester Street. Only two of the three landmark buildings were rendered as photorealistic models while the third was rendered to a level two. The Second Presbyterian church that stood adjacent to the Harding House was modeled based on the Sanborn footprint, while its elevations were rendered from field photographs taken prior to its roof collapse and demolition in 2016. To accommodate the polygon limits of fully immersive VR, the elevations of a higher polygon version of the model were captured to serve as textures for a low polygon version (Fig. 10). The church's spire was modeled based on the Sanborn maps, supplemented by its depiction in historic photographs (Fig. 5.2). The Holiday Planing Mill was one of many mills and factories that once dominated the industrial landscape along Wheeling Creek and the Ohio River. The saw mill stood across the street from the Harding House and represents a demolished building with little photographic evidence. In this case the digital 3D model of the mill reflects the massing, material, and smokestack depicted in the Sanborn map. Only parts of the east and south elevations of the mill are rendered based on the one surviving photograph of a partial rear oblique view taken from the northeast in the 1910s. Finally, with no evidence beyond the 1853 and 1884 maps, the Center Foundry is represented as a simple massed model colored red (indicating per the Sanborn convention that it is built of brick). 


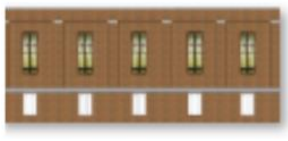

PresbyEfacade

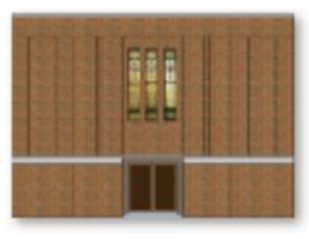

PresbyNFacade

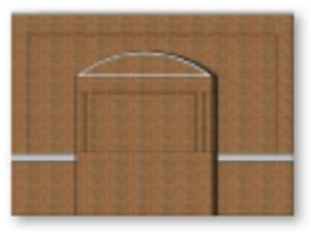

PresbySFacade

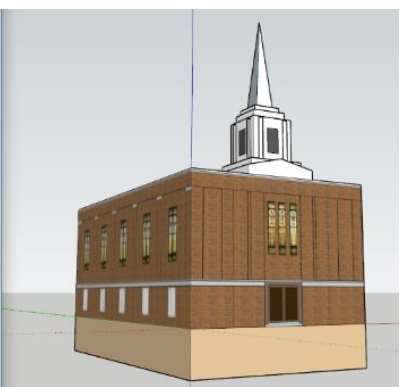

Figure 5.10 Elevation textures (Left) of high resolution model of Second Presbyterian imported to create high fidelity, low-polygon model (Right) compatible with VR.

In addition to the landmark buildings, numerous dwellings and other structures were modeled in SketchUp. Two models represent the highest level of rendering and information while eight buildings are at the third level, and sixteen buildings were rendered at the lowest two levels. The only antebellum dwelling still standing on Webster St. was rendered with the greatest detail. The Rebecca Harding House was rendered in slightly less detail because only the façade was visible on the 1906 photograph. The photograph confirmed the side passage townhouse form (and 2/3 Georgian Plan) that correlates with the Sanborn footprint, so the form, roof type, and chimney placement of the dwelling were rendered as well. Like the other Level 4 buildings, high fidelity was achieved by creating elevation textures from very detailed 3D models with high polygon counts and draping these on low-polygon models (Bentkowska-Kafel 2013). Importantly, the dimensions of eight demolished dwellings delineated on the Sanborn maps for this area strongly correlated with numerous surviving buildings measured during the intensive field surveys. In addition to their exterior dimensions, the survey produced photographs and many floor plans and provided a sound basis for modeling a variety of dwellings, from those of the wealthy to the humbler homes of the poor and working class. Thus these eight dwellings on, or near, Webster 
Street were modeled according to the house types recorded in the local intensive surveys. Five of these building reconstructions were based on data gathered in the North Wheeling Early Dwellings Survey, one building from an extant HABS record, and two buildings were based on the measurement of a working-class stack house in Center Wheeling.

The eight demolished homes included a range of high style and vernacular houses, such as the grand Italianate mansion with belvedere that stood at 2028 Market, the two-thirds Georgian at 32 Market Street, working class dwellings near the railroad tracks, a two-thirds I-House at 71/4 Webster Street, and two stack houses on Alley 17 (Fig. 5.11). The 3D models were subsequently exported from SketchUp in obj, dae, and fbx file formats and archived along with paradata in preparation for import into the Unity3D scene.

Address Width Bays Type

6 Alley $17 \quad 16, \quad 2 \quad$ Stack House

8 Alley $17 \quad 16$ ' 2 Stack House

71/4 Webster 24' 3 2/3 I-House

32 Webster 28, $32 / 3$ Georgian Plan

33 Webster 17, 2 Two-over-Two

35 Webster 20' 3 2/3 Georgian Plan

2028 Main 44' 5 Italianate Cube

2100 Market 44' 5 Georgian Plan

\section{Local Intensive Survey Basis}

2231 Lane E, Center Wheeling

2231 Lane E, Center Wheeling

314 West St., North Wheeling

727 Main St., North Wheeling, and others

424 Main St., North Wheeling, and others

722 Main St., North Wheeling, and others

$10012^{\text {th }}$ St., Wheeling from HABS

444 Kenney St., North Wheeling

Figure 5.11 Street address and type of each demolished dwelling that was modeled for the case study at level 3, based on correlation of the 1853 and 1884 building footprints with the local intensive survey data. 


\section{Commonplace Objects}

In addition to the 3D models of buildings, Wheeling's early gas streetlamps were modeled in SketchUp specifically for this project, and numerous prefabricated 3D models were obtained from the Unity Asset Store to efficiently populate the landscape with common street objects of the time period. The style of gas streetlamps placed throughout Wheeling during the 1850s was accidentally recorded at the edge of a stereographic pair of photographs dating to the 1860s. Although the exact placement of these lamps is not known, the image shows that the lamps doubled as street signs on the southwest and northeast corners of the intersection. For the demonstration project, a streetlamp was modeled in SketchUp based on the stereo pair and placed in the Unity3D scene at the intersection of Market and Webster streets. Street names were not rendered in the model but could be included as an accurate and intuitive navigational feature in future iterations of the project. Another prominent feature of the 1850s Wheeling streetscape were the Lombardi Poplar trees mentioned by Rebecca Harding Davis in her seminal work (1861) and her memoir (1904). Prefabricated 3D models of Lombardi Poplar were purchased from SpeedTree via the Unity Asset Store, and included low polygon count versions designed specifically for VR and mobile games. SpeedTree also provided 3D models of other trees and types of vegetation. Additional prefabricated objects obtained for the project included wooden barrels, a carriage, steam locomotive, and railroad cars (Poly Source). 


\section{People \& Animals}

Perhaps the greatest challenge associated with building a VH based on the opening scene to Life in the Iron Mills is in recreating the streets teaming with animals and "crowded human beings... streaming forth night and morning from the great mills" (Harding 1961). Such a dynamic scene is beyond the present capabilities of real-time navigation in a fully-immersive virtual environment. The human elements are limited to the "crowd of drunken Irishmen" (Harding 1961) loitering near the intersection of Main and Webster and a few shadowy figures that can be seen through the smog on the path toward the Crescent Iron Works. Keeping with the necessary low polygon count used in the trees and most buildings, cartoonish NPCs were obtained from the Unity Asset Store (Fig 4.6). In future iterations of the project, the avatars of these NPCs could represent actual people that lived or worked in the neighborhood with artificial intelligence and animation based on appropriate daily life paths for characters of different classes, occupations, and social status. Interaction with these avatars could include dialog based on current events of the 1850 s and stories about Wheeling's past. Animals common to Wheeling and the neighborhood were obtained from the Unity Asset Store and could be added to the scene in future iterations, along with appropriate audio tracks and navigation meshes. 


\section{Constructing Landscape and Place in Unity3D and the HTC Vive}

To establish the height map representation of the study area in Unity3D a digital terrain map was created from the National Map (https://viewer.nationalmap.gov/basic/) and the West Virginia GIS Technical Center (WVGISTC) http://wvgis.wvu.edu/data/data.php. Although 2014 LiDAR point cloud data was available for the study area, it likely would be too precise and interfere with

real-time navigation in the VH system and was not used. Three-meter DEM data (SAMB 2003) was acquired from WVGISTC from the 1/9 arc-second dataset and 10-meter DEM data (USGS NED 10m) was retrieved from the National Map. Using Photoshop, the lower resolution $10 \mathrm{~m}$ data was clipped to $512 \times 512 \mathrm{~m}$ and converted to the RAW file format for Gaia before using the Gaia plug-in to import the height map into Unity3D. Gaia automatically defaults to a $1024 \times 1024$ meter area for Virtual Reality and mobile platforms, but given the actual distance on Webster Street from the Ohio River to the Crescent Iron Mill, the more conservative 512x512 meter area was selected to reduce the file size and polygon count by approximately $75 \%$ (Fig 6.1). 


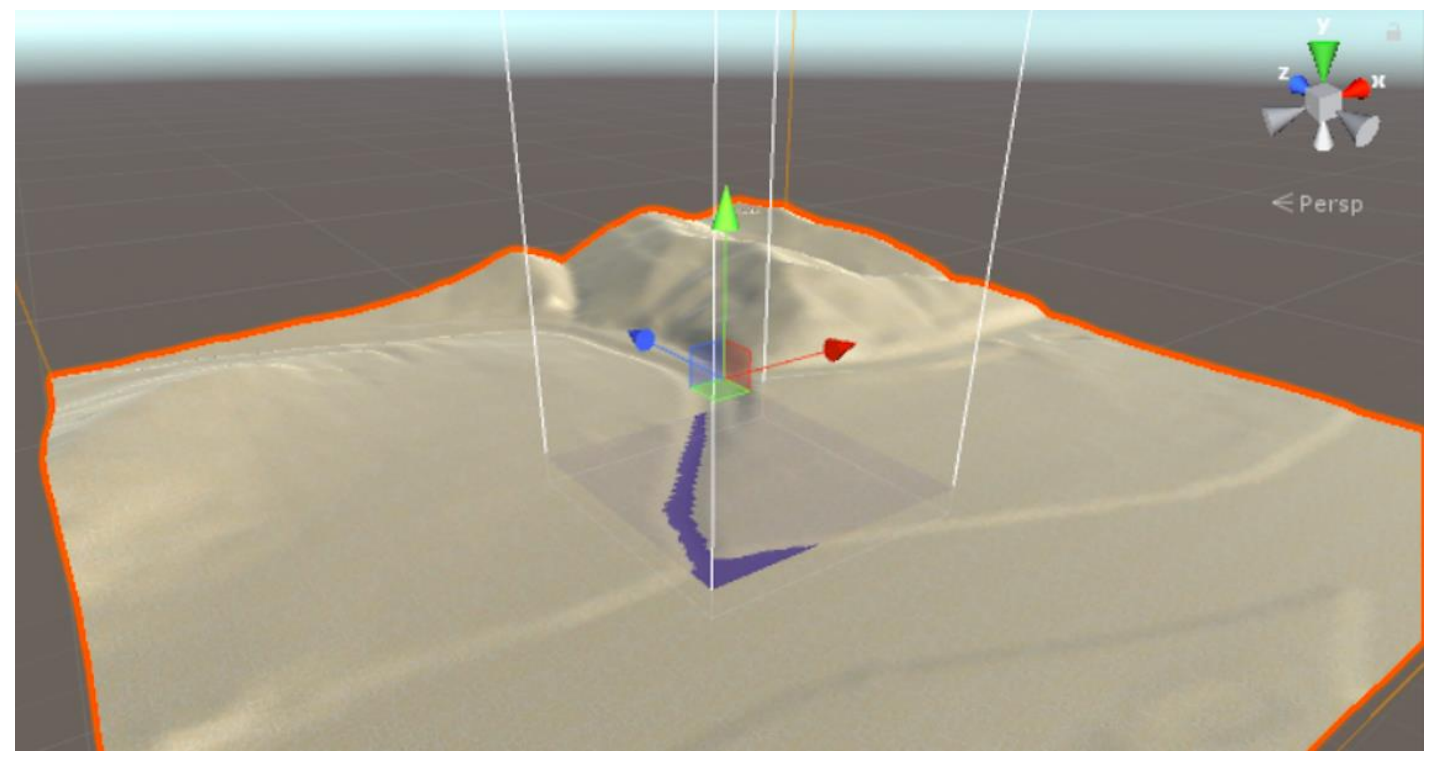

Figure 6.1 Digital Terrain Model of Wheeling near the mouth of Wheeling Creek. Bird's-eye view from northwest, with $512 \times 512$ meter Webster Street study area about to be stamped using Gaia plugin.

The 512x512-meter terrain model was stamped in Gaia and imported into the project scene along with standard character and environmental assets and the SpeedTree plug-in and Lombardi Poplar files. In Gaia, the terrain was textured and natural features such as rocks, grasses and trees were spawned using low-polygon assets to facilitate real-time interaction in VR. Although the terrain texture is less realistic and the trees and plants have a cartoon-like aesthetic, this compromise presents an honest representation of the current limitations of VR rendering and effective usage. The water resources in the study area were rendered to approximate the level and appearance of Wheeling Creek and the Ohio River during the spring thaw. The 1884 Sanborn base map depicts the spatial location of mid-nineteenth century buildings (Fig 5.8) and was imported as a texture into the Unity3D project to help guide the accurate spatial placement of digital assets within the Webster Street scene. The Virtual Reality Tool Kit was added to the 
project to provide means for exporting the Unity3D project into the HTC Vive and for emulating that platform during the build-out process and play-testing that occurred regularly as assets and textures were added. Finally, atmospheric and lighting effects were added to simulate a smoggy early spring morning before dawn, and the first-person controllers were added to the scene.

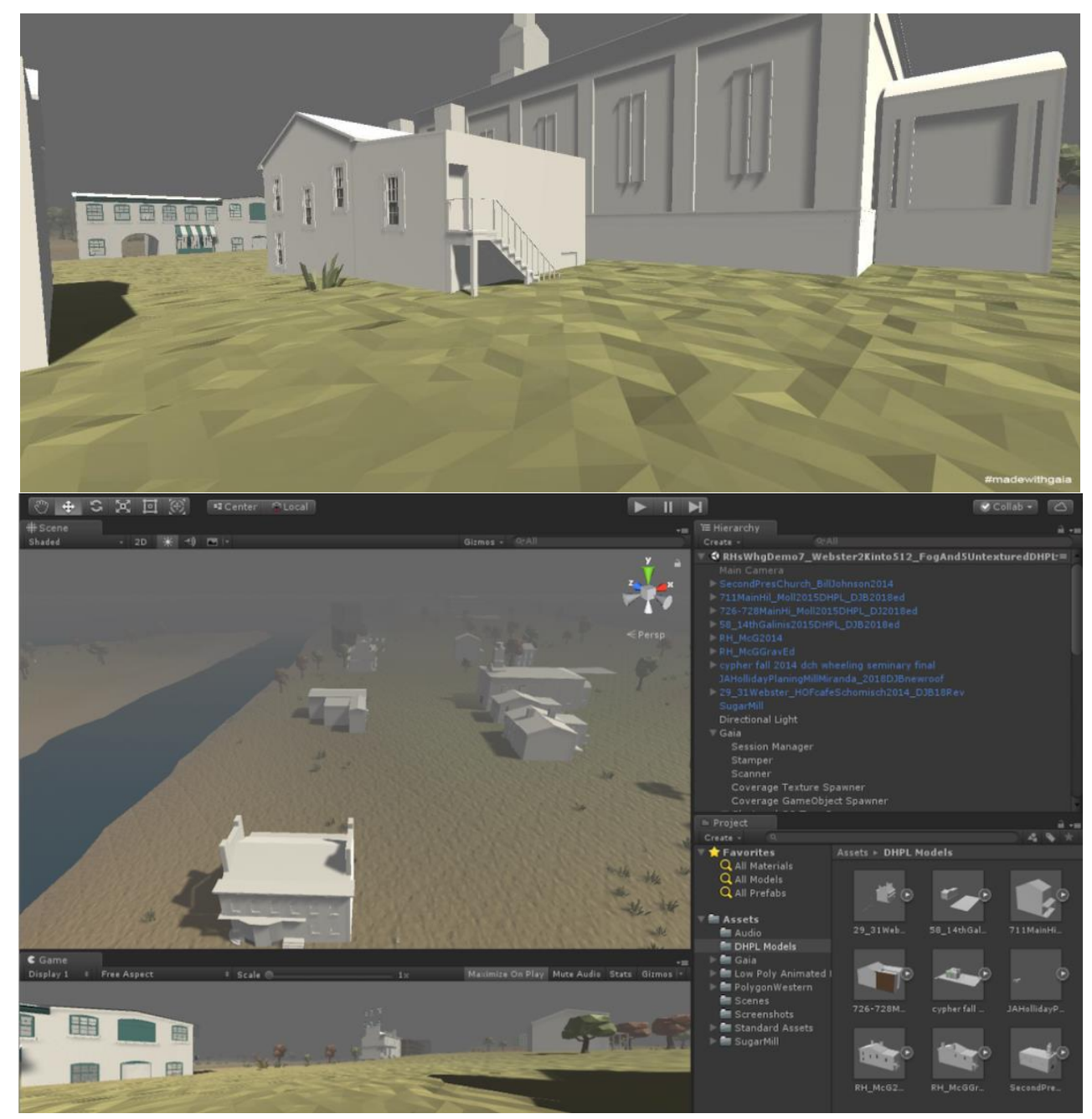

Figure 6.2 Early trial showing the height map rendered with water, vegetation, fog, and 3D building models with high polygon count. The high-polygon models functioned well in the game environment but caused the system to crash in VR. 
The nascent Unity3D scene was play tested through several trials, and the scale was calibrated using standard reference objects, and the settings were fine-tuned in the lighting and inspector windows (Fig 6.2). The resulting height map provided an accurate representation of the topography from near the mouth of Wheeling Creek to the narrowing of the flood plain where Webster Street is constrained by Chapline's Hill as it enters the property of the Crescent Mill. The 3D building models were imported into the Unity 3D scene, and were scaled to the appropriate height and located on the height map. Several trials importing various 3D file types into Unity revealed that dae files provided the best results rather than the obj or fbx types because they imported with the appropriate colors and included surfaces for draping textures onto the detailed level 4 models (Fig 6.3). Finally, the 3D models of street lamps, trees, people, animals, and other objects were imported into the streetscape, and selected audio files were added to the scene.

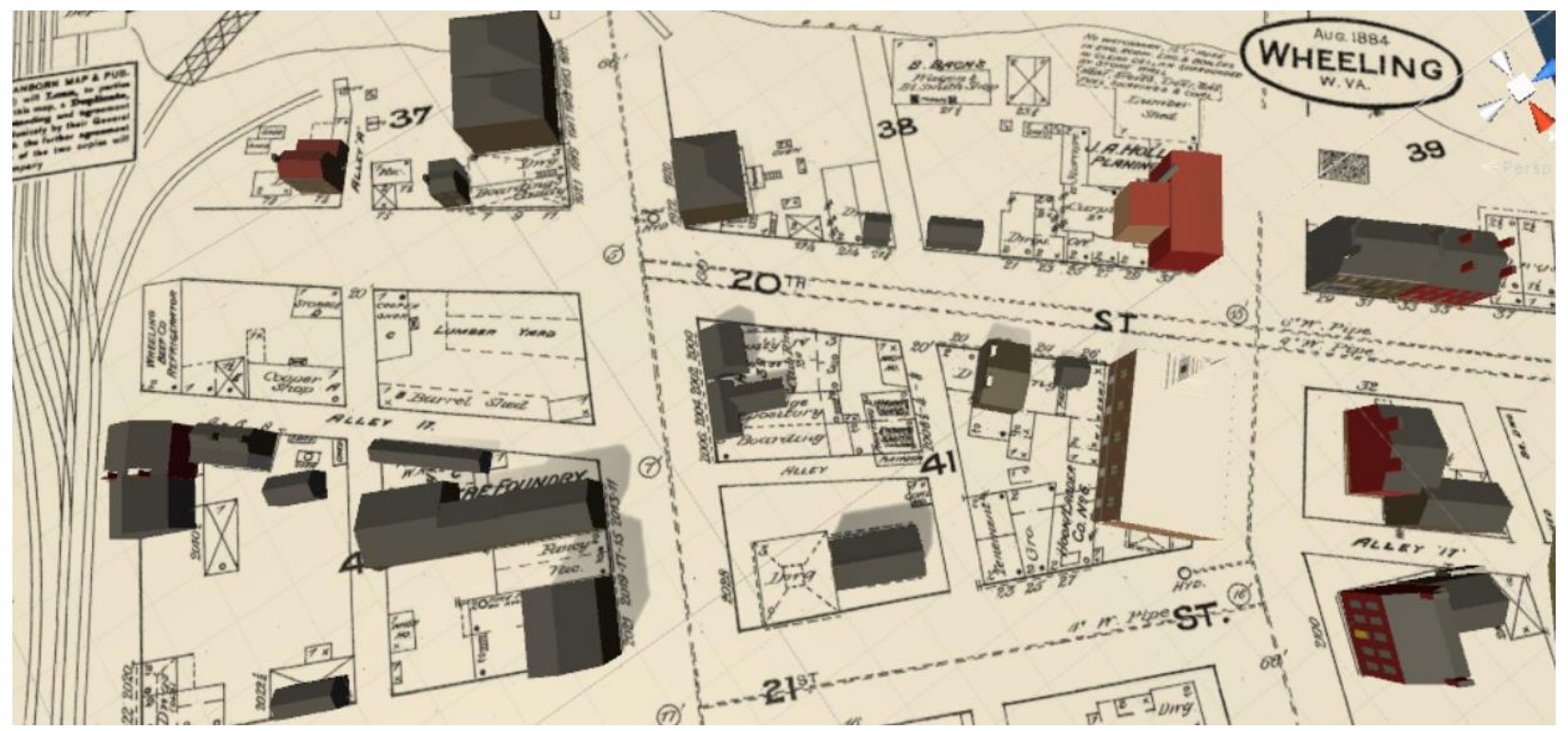

Figure 6.3 Bird's eye view of Unity3D scene view showing the 1853 building models of all four levels on the 1884 map base layer. 
The digital audio files were placed in the virtual environment to create a soundscape that evokes a sense of Rebecca Harding's neighborhood in the 1850s. The first sounds encountered by users are the clips from an audio recording of Life in the Iron Mills. Several short excerpts from Elizabeth Klett's 2010 Audiovox reading were downloaded from Archive.org, selected, and edited in Audacity for length to provide an introduction to Harding's work. Within the Unity3D scene, several sound files are linked to particular spatial locations (Fig 6.4). A block south of the Harding House, a bell rings the familiar E note of the hourly Westminster bells, indicating that dawn is near and the Centre Market house is open for business (City of Wheeling 1855). Among the keynote industrial sounds represented is a locomotive leaving the B\&O Station and crossing Wheeling Creek into Centre Wheeling (Soundfellas). The song of a canary mentioned in Life in the Iron Mills was selected as a representative animal sound, but the sounds of hogs, chickens, cows, and horses were obtained for future iterations of the project (Cornell Ornithology Lab). Among the human sounds are a "crowd of drunken Irishmen," recorded specifically for this project (McElroy) and the sound of a heartbeat (Soundsnap). These latter sounds may evoke a sense of foreboding and danger that can be experienced in places where one feels uncomfortable. The audio effects were limited to intangible representative examples of human, natural, and industrial sounds heard along Webster Street. The open source and public domain audio sources are available for users to play or download, along with their metadata and internet links to the original sources. 


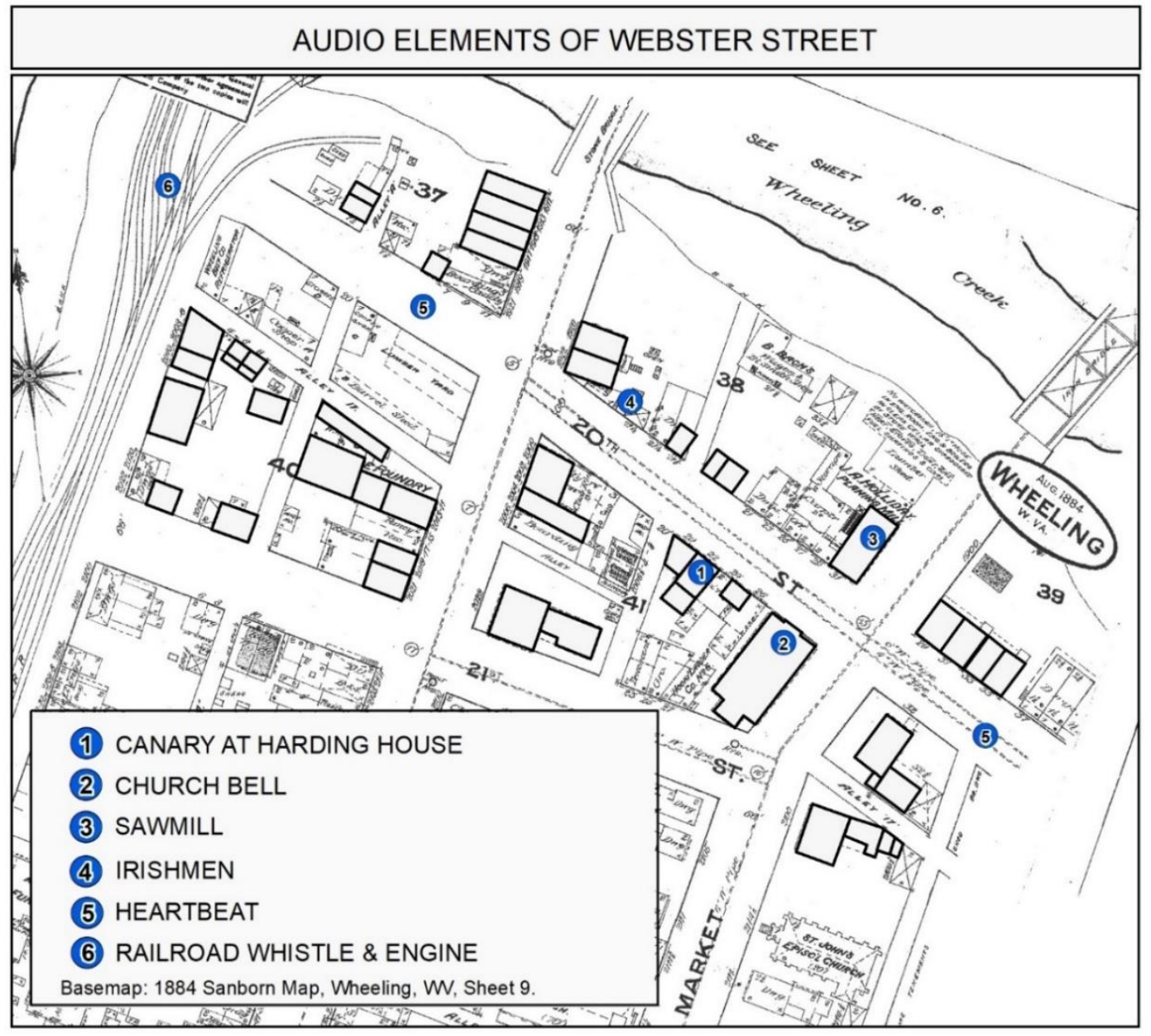

Figure 6.4 Audio elements selected for Case Study (Steffany Wood).

\subsection{Rebecca Harding's Place, VR Demonstration Scene}

The case study explores elements of place by combining data about historic Webster Street and the heritage reconstructions of buildings and landscape with the mood and feeling inspired by the setting of Harding's Life in the Iron Mills. The VR scene also connects users with the sounds, associations, and emotion experienced in this heritage place. As the scene concludes loading, a bell strikes in the distance, signaling that the city market has opened. The user is standing on the south side of Webster Street between Market and Main Streets and in front of Rebecca Harding's 
House. The user is fully immersed in the reconstructed environment of Wheeling as it appeared in the 1850s. The façade of the townhouse where the Harding's lived is rendered at the highest level of detail, revealing it as a three-bay side passage plan and indicating that this representation is based on the best documentary evidence. From this point, one can explore the mix of residential, commercial, religious, and industrial buildings that comprise the neighborhood. The Presbyterian Church next door and the business opposite are likewise rendered at the highest level, however, looking up and down Webster Street, the user sees a range of building models rendered at varying levels of detail, but most stand one or two stories high with a side gable or hip roof that characterize the Upper Ohio Valley. The homes here, near the top of Market Street, reflect the house types popular among the middle and upper classes, but a venture around the neighborhood reveals different housing types of the poor and working class (Fig 6.5).

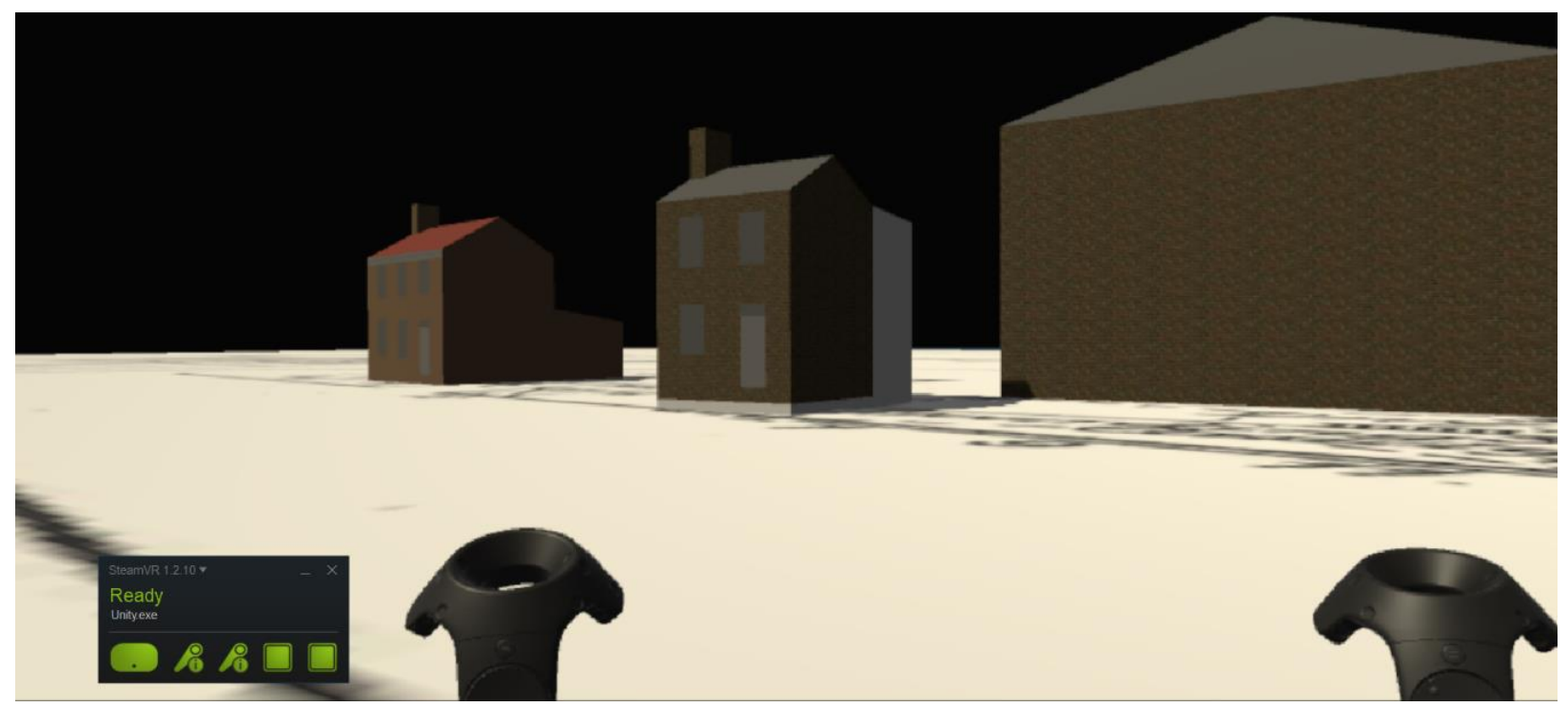

Figure 6.5 Vernacular working class dwellings at the foot of Webster Street viewed in the HTC Vive were based on extant examples surveyed nearby: 2/3 I-House (Left) and Stack House (Center), which correlated strongly with building footprints on the earliest maps. 
The user notes the sounds of the locomotive, representing the industrial noises of the factories, mills, and foundries heard around the clock (Fig 6.6). In the foreground, some fifty feet to the west, one can hear chatter from the "crowd of drunken Irishmen" that have not yet found their way home, but they are obscured by the "nightmare fog" of the industrial city (Harding 1861). The user has two options: turn to the left (west) toward the drunken crowd, or turn to the right and head eastward up the slight hill toward Market Street. As one ventures beyond the fine houses and gas street lamps on Market Street, however, the sound of human voices dwindles and the noise of the factories along the creek increase. Continuation along a narrow passage between the creek and hillside leads to the great Crescent Mill -- the "Iron Mill" that provides the title to Harding's seminal work. Here the background sound of her heartbeat intensifies, signaling an emotional response that she is "out of place" and uncomfortable in her environment. If one returns toward Main Street and the industrial area along with the Ohio River, where the poor and transient people of the working class live in stack houses and tenements along the railroad tracks, another evocative experience awaits. From the corner of Main and Webster Street, the sounds of the drunken Irishmen again emerge. Venturing further west to the base of Water Street and the crowded immigrant industrial district near the river, the intensification of the beating heart sound is triggered once again. Together these elements of the soundscape provide users with a sensuous and affective experience, not only hearing the keynote sounds reminiscent of Harding's writings about Wheeling but perhaps the subconscious affective sense of topo phobia when venturing “out of place” (Tuan 1979; Cresswell 1996; Kwan 2002). 


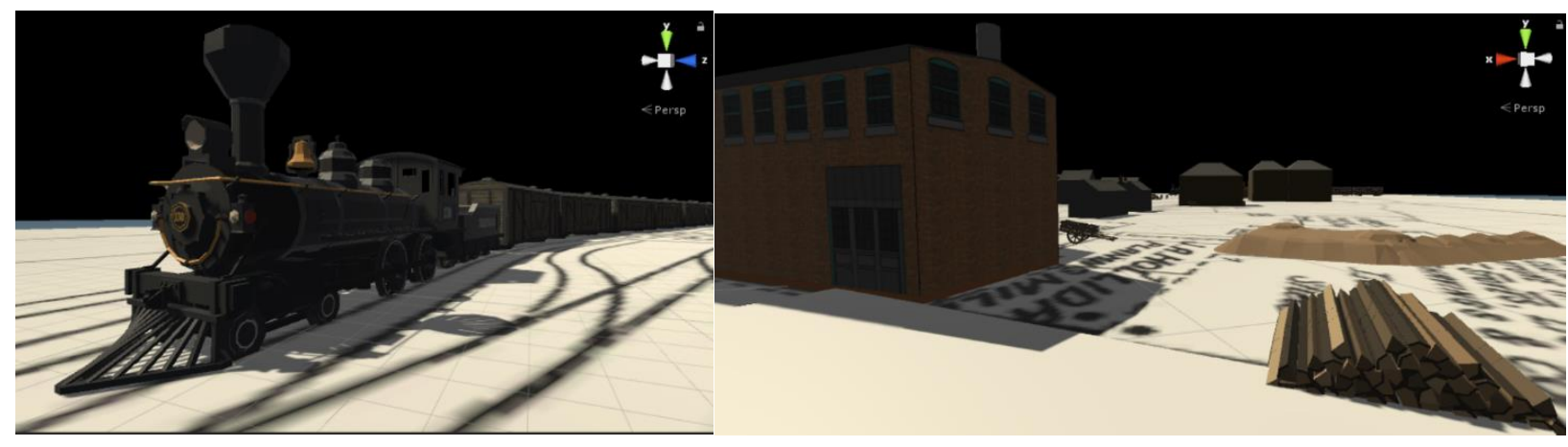

Figure 6.6 Steam Locomotive (Left) and Planing mill (Right) with its lumber yard and tailings.

This demonstration of a place-based VH system enables users to experience the virtually reconstructed landscape of Center Wheeling on two levels. First, and importantly, they explore the accurate heritage recording represented in the dwellings and other buildings of the 1850s that are based on archival and field research. Within the virtual environment in the HTC Vive, each 3D building is rendered at one of four levels of detail according to the quality and detail of the heritage information available (Fig 6.7). Beyond this extensive experience of the scene as a record of data and empirical knowledge about the heritage landscape, the user also experiences the intangible aspects of heritage through a scenario designed to evoke a sensuous and emotional reaction to the place, and inspired by the writings of Rebecca Harding Davis. The scene is but one component of a place-based virtual heritage system that combines best heritage management practices demanded of heritage recording along with its metadata documentation made available for independent verification and validation. To this end, additional resources enable users to explore and examine not only the "end product," but also the components of the system, the historical data, and the paradata that describes how they were produced. 


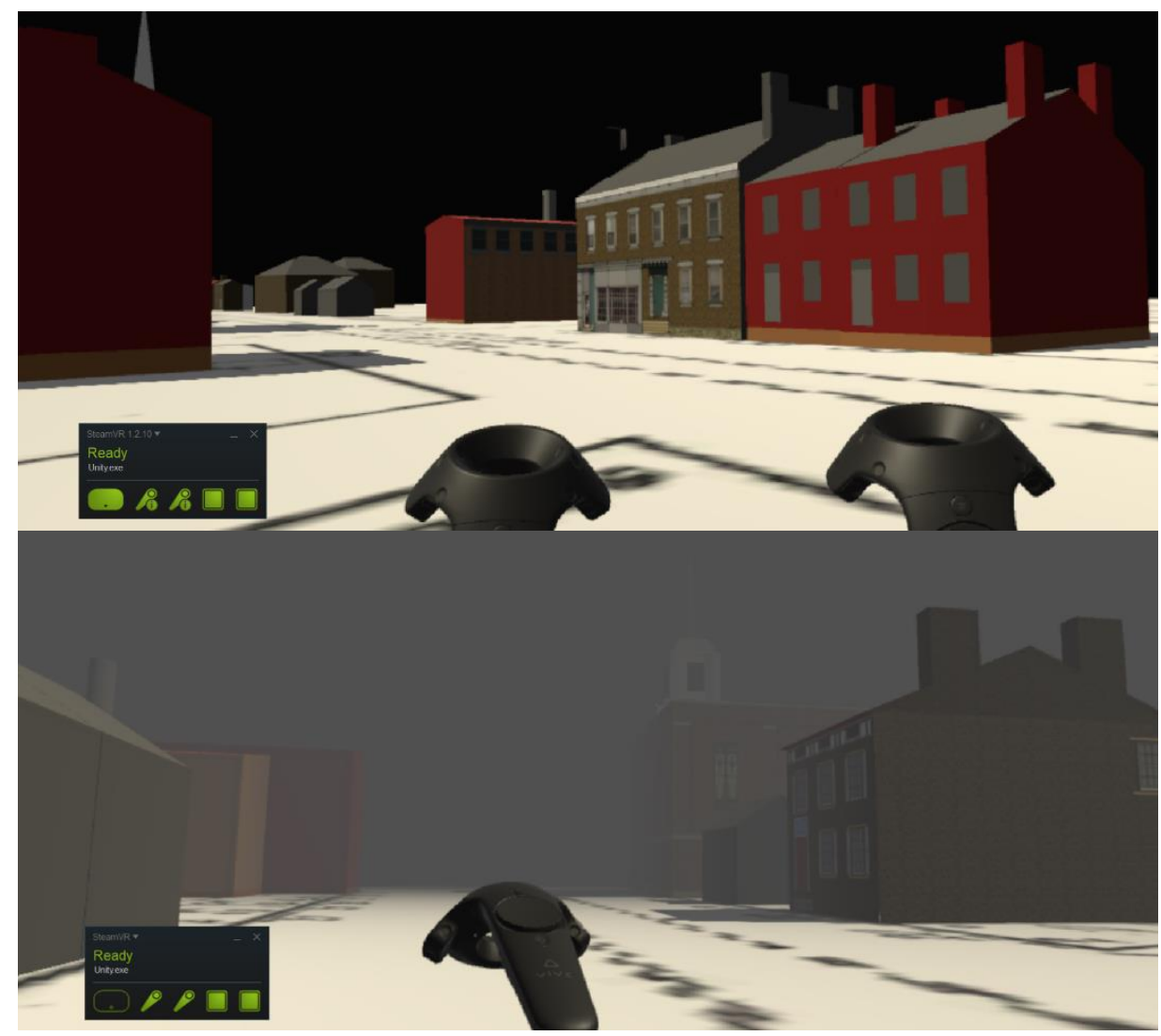

Figure 6.7 Rebecca Harding's Wheeling explored in the HTC Vive. Images reveal the variation in house types and rendering methods (above) and contrast in atmospherics with fog (Below).

In summary, this place-based heritage project provides immediate access to field and archival data, and to documentation on the various 3D models and other assets assembled, along with the transparency and authenticity expected of heritage recording efforts. This access enables users to further examine the vernacular and landscape contexts of Webster Street, and the project's living and functional components. To this end, when a user exits the virtual environment, they return to the main menu and are encouraged to further explore the place-based VH system, its components, and the evidence upon which its heritage is based. 


\section{Evaluating the Place-Based Virtual Heritage System}

The system and demonstration project may be evaluated in the context of ongoing research in historic preservation, virtual reality, and cultural geography, the three fields that were integrated into the design, with historic preservation at the forefront. The system is designed to involve preservation planners, heritage recording, museum and interpretation specialists, virtual heritage, virtual reality, serious game designers, and cultural geographers. The system demonstrated here achieved several of the specifications set out in the HP principles explored in Chapter 2. These principles are embedded in this system and include accessibility, transparency, sustainability, authenticity, geographic contextualization, the ability to handle intangible cultural heritage, and functionality. Ultimately, the place-based VH system must be evaluated not only in terms of HP but also in relation to the VR principles examined in Chapter 3 comprising the extent of world knowledge, reproduction fidelity, and presence (Andreoli 2017).

\section{Accessibility}

If the typical $\mathrm{VH}$ project is accessed primarily through conference papers and perhaps the distribution of still images or flythrough videos of a VH model, this place-based system and case study is accessible at numerous levels. The case study can be downloaded for the HTC Vive Head-Mounted Display (HMD) and is compatible with PC. Furthermore, the 3D models, sounds, GIS, Unity3D files, paradata, and digitized archival sources are available for closer examination via a shared Google Drive and backed up on a server at the Digital Heritage 
Preservation Lab of Eastern Michigan University. From the VR product, to the 3D components, down to the data upon which they were built, the place-based VH system is designed for enhanced access.

There are obvious limitations to system access. The platform exists across the digital spectrum requiring access to the internet and a personal computer along with the ability operate the WASD first-person gaming controls on the keyboard. The digital demands are more pronounced in immersive VR, yet HMDs such as HTC Vive are increasingly available, cost effective, and significantly more accessible than CAVEs. Although most of the system was built using open source or free software and/or assets, even some of the commercial software such as ArcGIS have open source alternatives, such as QGIS. In addition, although most of the digital archival sources, audio sources, and 3D models are available to download, other sources are proprietary, and may not be shared freely. In addition, paradata and metadata are not automatically embedded in each file and asset. Finally, despite the efforts taken to provide access throughout the system from data to the virtual environment, the long-term accessibility of these elements are not guaranteed.

These current limitations, however, may be viewed also as opportunities for future enhancements to such systems. Because of the system's use of the Unity3D platform, export to Apple's Mac computers, video game consoles such as XboxOne and Play Station 4, other HMDs such as the Oculus Rift and Samsung, and other Windows Mixed Reality platforms would require relatively little effort. Accessibility also may be enhanced via digital archival management software such as Collective Access and discussions have occurred regarding the curation of the case study and other projects of the DHPL in the Historic Preservation collection at the EMU archives. Long- 
term funding is required to guarantee sustainable access and to further develop the system (Gerth et al. 2017; Seifert et al 2017).

\section{Accuracy \& Transparency}

The spatial accuracy of the heritage assets was maintained geographically by building the digital elevation model upon USGS data and rectifying early maps with high resolution orthophotographs. The GIS and historical map analysis components of the system successfully supported the identification and modeling of early buildings and their correlation with dwelling types in the historic cultural landscape of the study area that had been demolished long ago, and significantly, this enabled an accurate reconstruction of the 1850s urban landscape, three decades before the first Sanborn insurance maps of the city were produced. The accuracy of the heritage 3D models was achieved by following HABS standards, and using primary sources, paradata, and documentation of the data source and methods associated with individual models. The 3D models were built at four levels of detail, reflecting the type and quality of data that was available and the uncertainty associated with each. The four buildings that survived or were documented with photographs are rendered with the greatest degree of detail. Eight demolished dwellings are rendered with the appropriate number of bays, chimneys, roof type, and building material based on extant house types recorded in an intensive survey of early vernacular architecture in Wheeling. Those buildings recorded only on Sanborn maps and the 1853 city map are represented as simple massed models using color coding according to the 1884 Sanborn map for wood or brick buildings and roof type. Finally, those buildings that were depicted only 
on the 1853 map of Wheeling were represented as dark grey massed models with simple gable roofs, but no chimneys, bays, or other details.

Providing detailed paradata on the individual models within the actual virtual environment would be preferable in supporting transparency, and fidelity but this was not achieved due to resource constraints. Because the present iteration of the project focused foremost on conspicuously displaying uncertainty and sources of data, the existing models serve as a foundation to be updated as increased knowledge becomes available for the local vernacular architecture of the antebellum period, and the people of Rebecca Harding's neighborhood. Thus, the system's means of documenting sources and organizing the data, models, and paradata into an intuitive file structure not only supports the production of accurate models, but continues to serve the principle of transparency.

\section{Level of Precision}

The challenge of precision is addressed in the system by acknowledging the zero sum game at play in Virtual Reality in which the level of detail is sacrificed to achieve real time navigation, maintain frame rate, and enable functional capabilities within the game/VR environment. This challenge was addressed in the case study by a) choosing a discrete study area, b) occluding information through the endemic smog prevailing in Wheeling c) optimizing the number of assets and polygon count associated with each 3D model, and d) minimizing movement.

However, this work has demonstrated that one could reduce precision while maintaining accuracy. There remains an unachievable expectation of photorealism in serious games and VR. 
Because this environment was built in Unity3D, the implicit desire to add detail and precision was heightened because the serious game platform allows greater precision and more photorealism - warranted or not. Thus, the case study comprised a constant reflexive effort to let go of the desire to include more elements and greater levels of detail, given the precision permitted by the data. This level of precision may be improved in two ways. First, through additional resources one may take advantage of advanced methods for VR rendering such as baked lighting and texture mapping (Fig 5.11) that trick the user into believing that the models themselves are more detailed and realistic (Benkowski-Kafel 2013; Christensen 2017). Additional polygons can be added strategically where they would be most conspicuous and have the greatest impact on user experience and perception. In addition, because game consoles allow for a greater number of polygons and detailed rendering buildings, landscape, and water and movement of environmental effects and NPCs, a more detailed and precise alternative version of the case study may be produced to distribute on traditional FPS gaming platforms while a different version is developed to disseminate via HMD.

\section{Geographic Context}

The project focused beyond the Harding House to examine the geographical context of the 1850s cultural landscape of Wheeling's Webster Street. Where many VH projects have focused on a single great building, this project placed the home of Rebecca Harding Davis in the context of an industrial mixed-use neighborhood. Thus the Harding House can be seen as a component of the cultural landscape of her time and situated among many fine homes standing in the desirable area 
between the Main and Market Streets, and the smaller working class dwellings to the west of Main Street in the less desirable margins of the city near the railroad and along the Ohio River.

The project provides multiple ways for users to examine and explore the vernacular architecture associated with the working class and wealthy of Rebecca Harding's neighborhood by accurately representing the broad range of dwellings and enabling users to explore and experience them in the first person. Users can "virtually" walk along Webster Street and explore examples of popular house types in the context of the neighborhood. Users may also access the intensive survey data gathered to more deeply evaluate the range of dwellings common in Wheeling during the mid-nineteenth century. In addition, users may examine individual 3D models and data describing actual buildings that were surveyed and modeled along with additional information such as floor plans, the history of residents, and of course access paradata about the vernacular models sources and limitations.

The vernacular elements of the study were limited due to the small sample size but also in the types of buildings that survive. Small wooden dwellings, outbuildings, tenements, and the earliest and humblest dwellings remain something of a mystery. As with the working class tenements and less permanent house types, many of the outbuildings and industrial landscape elements are inadequately understood, so their representation leaves much to be desired. Vernacular knowledge may be improved by the intensive survey of early dwellings in Wheeling and other nearby towns. Such surveys are needed to better understand the dwelling spaces and places of the poor and working class, both locally and across the country (Hubka 2013). In addition to further research on the urban working class and industrial landscape, the contextualization of places like Webster Street may be enhanced by linking information and 
spatial stories about the owners, residents, and workers to places in the VH environment. Another important geographic context to be explored are the interior features of dwellings, and the furnishings and use of space by those who inhabited these. For example, the interior of the Harding House could be furnished based on her memory of "the old house" from her memoir (Davis 1910) and an inventory that was entered in the official Ohio County record (Deed Book 24 1840, 209). This could contrast a typical two room dwelling of the poor, such as that occupied by the Wolfes described by Harding in Life in the Iron Mills.

\section{Living \& Intangible Heritage}

Living and intangible elements were among the elements deemed to be typically lacking in $\mathrm{VH}$ and which this project sought to address. The case study drew upon Rebecca Harding's early evocative writings on Wheeling, in addition to local research to identify the human, cultural, and industrial elements historically situated along Webster Street. The aural qualities associated with places, objects, and people were incorporated into the system, including the spoken word of Rebecca Harding's Life in the Iron Mills, the people, and other sounds of an industrial city. Emotion and affect are important intangible aspects of life, and sound was employed to reinforce the sense of presence in the scene and the experiential. Emotion was embedded into the system through the use of the heartbeat to enhance an affective response when experiencing the virtual scene.

Living and intangible elements were deliberately limited in order not to exceed the resource scope of this study. The living elements lacked any dynamic movement for these can be 
extremely complex and taxing on the processing system and in immersive VR and if not undertaken carefully can look quirky and odd and break any illusion pertaining to the scene as being representative of a situated reality. The resources required to ensure that the motions of avatars appears natural exceeded this project. The type and number of NPC people, animals, and audio elements were reduced to only a few examples whereas the streets historically would have been bustling and full of movement, life, and sound. Finally, sensuous elements were limited to sound and affect, and yet there are opportunities to explore other senses such as touch through the tactile capacities of current handheld devices, and olfactory qualities.

Additional sounds that enhance the sense of place might be desirable, such as falling rain on rooftops, horse's hoofs, and footsteps in the mud. The regional dialect that Harding employed in her fiction and local color writing (Harris 2018) could add to the sense of presence. Groups of workmen huddled in conversation and speaking German or the sound of the German choir emanating from the Presbyterian church or local singing society would reinforce the immigrant basis of the neighborhood where the German population grew dramatically during the1850s. Additional off-screen sounds would reinforce the sense of place described by Harding and the character of the neighborhood in which the scene was situated. NPCs could tell of recent news or recount stories of Wheeling's past, furthering the engagement between the virtually immersed user and the historical record. Time, money, and expertise must be sought through partnerships with other institutions and scholars to research and explore the sensuous, dynamic, social, and other intangible elements of life in the 1850s city and advance how they are presented in VH. 


\section{Functionality and Potential Applications}

Significantly, this system demonstrated its use as a preservation planning and heritage interpretive tool. The system represented early dwellings in Wheeling through the generation of accurate models reflecting the level of confidence that could be placed in the respective models. The historical GIS proved to be of great significance as an aid in identifying surviving early dwellings in North Wheeling and added to the efficiency and precision of the intensive survey and base building typology. The GIS also functioned to help place the location of each of the building in the Unity3D scene along with other objects, and sound assets

The system not only provided a means by which to envision and explore a now largely demolished urban environment of the 1850s but also to demonstrate how heritage data and sources, may be made available for examination. The system and case study, even in the nascent demonstration stage, provides an engaging means for preservation educators to teach about common vernacular houses and other dwelling types of the time and place and to place these structures in their geographical, social and cultural contexts. Likewise, because 1850s Webster Street can be explored in the first person perspective, it can serve as a planning tool, providing the means of communicating the scale and feel of Wheeling's built environment to city managers and developers who seek to produce new infill construction in the Wheeling National Heritage Area. Making known the look of the neighborhood will help them appreciate the materials, scale, and forms and style that are compatible with the period. 


\section{Virtual Reality}

In this study the traditional focus of Virtual Reality was deliberately sacrificed in order to purposefully prioritize the important historic preservation principles above all others.

Nevertheless, in the context of world knowledge, reproduction fidelity and sense of presence, the system fares remarkably well. By design there was diversity in the types and depth of heritage data presented in the place-based VH system. The case study presented not just Rebecca Harding's house, but a number of great and humble dwellings, commercial, religious, and industrial buildings scattered along Webster Street. The extent of world knowledge was expanded beyond the confines of the virtual environment since the system provides open access to a substantial digital archive of data sources, documentation, system components through a shared Google Drive. Compared to a traditional VH project, the system is capable of representing an unusual diversity of world knowledge. Because the case study was deliberately designed as a small but extensible demonstration of a place-based VH system, the study area was confined geographically to a space of about 100 meters by 500 meters. For the same reason, the cultural, natural, and sensuous data were somewhat limited but as exemplars were representative of the types and classes of tangible objects and sensuous elements present in 1850s Wheeling.

The reproduction fidelity of the case study deliberately fell short of the photorealism to be found in traditional VR projects because the rendering was based on extensive research and portrayed the level of confidence that could be brought to bear on the model construction. The limiting polygon count did impact buildings having the highest level of detail though three of the render typologies proved to be a great success and the system operated flawlessly in real time without any frame rate problems. The true disclosure of the uncertainty associated with each model 
outweighed any desire to reproduce a false photorealism and the HP principles of accuracy, authenticity, and transparency, and fidelity were fully disclosed, displayed, and documented. On this foundation of fidelity, future iterations of the project may explore open and honest conjecture as to the representation of Harding's Webster Street neighborhood.

If any VR quality was sacrificed in deference to HP principles, it was that of presence. The directive to put accuracy, honesty, and authenticity at the forefront of any heritage recording project superseded any tendency or inclination to create a photorealistic representation of Webster Street. Such a reconstruction remains desirable and would be a valuable tool for research into Rebecca Harding Davis and the world in which she lived. However, because so little survives of her street and so little was known previously about this place, the first step that had to occur was a thorough and honest recording of the building heritage. Without this baseline knowledge, any effort to enhance the sense of presence through more detailed rendering would have required undocumented conjecture. An alternative VH scene however, could be created that explores possible renderings and detail as the basis for informed discussion among heritage preservationists.

\section{User Evaluation}

The system and its methodology was shared with leaders of the Friends of Wheeling (a local preservation society), the Wheeling National Heritage Area, Historic Landmarks Preservation Commission, the survey coordinator of the State Historic Preservation Office, and students of the graduate Historic Preservation Program at Eastern Michigan University. Respondents uniformly 
remarked with enthusiasm their fascination with the project and potential as an interpretive tool and to foster awareness of the importance of historic preservation. Students of historic preservation that used the system in the DHPL completed a qualitative survey. Most students remarked on the power of being immersed in the reconstructed landscape and valued how the reconstructed landscape displayed the level of knowledge about each building. As one explained, "It is one thing to be told and read about something, but it's totally different to see and experience it." A second student noted "It was valuable to experience a place in which traditional HP methods don't work because so few buildings exist today." The pedagogical potential of the systems struck another, who stated "I can see how amazing a teaching and learning tool this will be." Despite this anecdotal external evidence of success and satisfaction, the system and case study would benefit in future from formal external evaluation by members of these and other organizations involved with heritage planning, preservation, and interpretation, along with other scholars in digital heritage, serious game design, geovisualization, VR, and digital humanities. Evaluating the Place-based VH system and the case study in light of HP and VR principles has clarified a number of areas where the system can be improved and research directions that should be undertaken, and a formal survey for external evaluation is among the highest priorities for future research. 


\section{Conclusion}

This study aimed to design and produce a virtual heritage system that serves the interests of both historic preservation and Virtual Reality based on the foundation established thorough a century of heritage recording and historic preservation praxis. This potential was examined through the design and development of a place-based VH system, which drew upon the geographic concepts of space, landscape, and place to find common ground among the concerns of VR and the principles of HP. To this end, the system accounted for accessibility, accuracy, transparency, geographic context, intangible heritage and functionality as key elements of HP praxis, while acknowledging that VR concerns for reproduction fidelity, extent of world knowledge, and presence also must be addressed in the system. The place-based system was designed and built using free or widely available and accessible commercial off the shelf software and hardware. The system was evaluated through the production of a case study that involved reconstructing an urban landscape of the 1850s in a location where only one building and few historic photographs survive.

The system is valuable in several principal ways. The system places access, accuracy and transparency at the forefront, scientific elements that have too often been sacrificed by $\mathrm{VH}$ in deference to the desire to promote presence in VR. The system successfully expanded the focus of VH from one great building to include its cultural landscape context, and in the process, provided a methodology for identifying forgotten buildings from the early- to mid-1800s, and incorporating them into a typology to serve as accurate references for virtually reconstructing a demolished cultural landscape including a range of vernacular dwellings, from the poorest to the 
grandest, previously known in the study area only by their footprints on 1880s insurance maps.

The system provides a means of integrating sensuous and affective elements of intangible cultural heritage, based largely on the power of sound combined with a scenario that, inspired by the words and life of Rebecca Harding Davis, immerses users in a situation where they may feel out of place, alone and vulnerable in a dangerous margin of the neighborhood on a dark dingy, smoggy, rainy spring day just before dawn. The system demonstrated its ability to function as a means of producing, accessing, evaluating, and communicating knowledge about a significant demolished house in one of the earliest United States National Heritage Areas, a place about which remarkably little had been previously known. Finally, although the case study involved an urban antebellum cultural landscape, the system may be employed to produce VH models of virtually any place, whether urban or rural, from the recent or distant past.

The use of proven commercial off-the-shelf components expedited the development of the system and supports its accessibility and potential for future dissemination. In addition to SketchUp Pro for 3D modeling, the system uses ArcGIS for geoprocessing, Google Drive for cloud storage and accessibility, Gaia for creating and rendering Digital Terrain Models, Audacity and i-Movie for editing digital audio files, Unity3D for the integrating diverse elements into a 3D landscape, and Virtual Reality Toolkit for exporting the Unity3D scene for use in the HTC Vive immersive Head-Mounted VR display (HMD). An Asus laptop and Alienware desktop were used for the production, testing, and editing of nearly all of the digital files and models, and the hard drives of these personal computers served as the principle storage devices, which were regularly uploaded onto a Google Drive and remote server at EMU's Digital Heritage Preservation Lab. To maximize accessibility, the system was designed to export not only to a HMD, but also to standard personal computers, and may with some reformatting also be 
exported to any range of platforms from mobile devices, video game consoles, and even VR CAVEs.

Despite these successes, a number of challenges and limitations were encountered during the system development and testing. The VH products of the case study were accessible to download for PC and Vive, as were many of the digital components, paradata and digital archival sources. However, for practical purposes, the system was not "plug and play," but rather required an expert to guide users through the setup and operation of the system including the launch of the case study and navigation through it. The architectural models of the case study were accurate and open regarding limitations and sources, and the case study was also spatially accurate, including the built-out area of Webster Street and the broader cultural landscape extent of the digital terrain model. Vive users can recognize the four levels of data upon which the 3D models of buildings were based, but they must exit the system in order to examine and review detailed paradata regarding the sources and limitations of each model. In addition, because the use of Gaia in VR is in its infancy, Gaia tutorials and user's guides are optimized for FPS gaming environments, and likewise, guidelines for VR development were not found that address the use of real elevation data, let alone the Gaia plug-in. Thus, the exact synchronization of the buildings and terrain remained a challenge; since the historic map layer could not be draped as a texture on the DEM, it was instead projected on a plane that was then positioned at ground level for placement of each 3D model in the landscape. In addition, settings for collision detection and controls were not perfected during the production of the case study, resulting in a $\mathrm{VH}$ experience where navigation remains level on the $\mathrm{Z}$ plane, rather than adjusting with terrain in the HTC Vive. Additional limitations relate to the extent of world knowledge, experience of presence and place, and the tapping into the potential of serious games 
as a pedagogical tool. Fortunately, many of these limitations are related to a lack of resources, and given the successes and promise of the system and case study, there is ample opportunity to pursue research and resources that will overcome these difficulties. The first step toward this end has been to define the most important challenges that remain and to begin the envisioning and evaluation of potential solutions.

Initial challenges relate to the accessibility of the system and its components, design of the next iteration of the system and Rebecca Harding's Place, evaluation of the experience of users of the system, and involvement of students in its development via a constructivist socio-cultural learning environment. Accessibility is one of the principal areas that the system can be improved in the short term. Although the digital files are accessible via a Google Drive, a conventional digital archive management system such as Collective Access would enhance the ability of people to find and use the system. Designing and producing a website for Rebecca Harding's Place would provide a stable if not sustainable way for people to access and evaluate the virtual environment and ancillary materials without requiring an invite to a Google Drive. This would also provide a stable place to introduce people to the project and its goals, provide support to users, and to solicit and gather feedback on how people access, use, respond to and evaluate the system and case study.

One of the principal shortcomings of the project was the inability to provide a thorough introduction to the system and case study for potential users that would prepare them to fully access and experience it. In the nascent demonstration version of place based VH system and case study completed for this dissertation, most users experienced a personal one-on-one introduction to the project, its goals, and design, and it was possible to provide real time trouble- 
shooting and advice to users as they explored the virtual environment and experienced the reconstructed landscape of Webster Street for the first time. Among the highest priorities for improving the system is to provide a brief user-friendly video introduction to the system and case study, so that people are guided through a logical progression of introductory materials about Rebecca Harding Davis, the reconstruction of her neighborhood, the Place-based VH system, and how to navigate through it. Such an introduction may follow established conventions in the commercial video game industry as well as serious game scholarship. Introductory materials currently available via the G-Drive would be revised and made available on a project website, along with a cut scene that provides an audiovisual introduction to the project.

Video game cut scenes are typically $60-90$ seconds in length, with a narrative introduction accompanying a fly-through or walkthrough of one or more scenes so that the user begins the game with some guidance about where they are, and what they are about to experience. In the case of Rebecca Harding's Place, this would involve audio excerpts of the introduction to Harding's Life in the Iron Mills, which is already available on the Google drive, accompanying a flyover of the Webster Street scene generated in Pegasus that orients users to the basic layout of the neighborhood. Such animated cut scenes are often followed by a basic tutorial level, where the user becomes familiar with the controls and can customize some settings to the personal preferences, experience, and abilities of each user. During such a tutorial session, users may be further debriefed on the goal and objectives of the scene or level and given further instructions on how to operate the system and proceed in a rational manner through the first scene or "level" of the virtual or first-person gaming environment (Swink 2009; Fullerton 2014). 
Among the key objectives envisioned for the future iterations of the system is to further investigate its capacity as a platform for exploring the geographic concept of place, including elements of vernacular landscapes, and interpreting intangible elements of cultural heritage, such as the particular meanings that individuals and social groups associate with specific locations. The experience of space and place may be enhanced by enabling users to toggle back and forth between a fully restored photorealistic virtual cultural landscape and a hierarchical representation that fully discloses known information about individual buildings, such as was presented in the case study. Aspects of place can be further pursued by integrating historical data about particular dwellings and other places, along with the stories and meanings attached to them in historic newspapers and recollections of early settlers, immigrants, and storytellers. Integrating such data with individual dwellings would provide an important link between intangible heritage and material culture studies, which is another potential trajectory for research in the place-based VH system.

The experience of being inside historic dwellings has a long tradition in heritage tourism and museum studies. Modeling the rooms and furnishings of typical dwellings inhabited by people of various social classes and ethnicities would serve purposes similar to those of Rebecca Harding Davis, who succeeded in making the stories of the poor and marginalized "a real thing" to her audience (Harding 1861). A VH of the two room hovel of Deborah, Harding's Life in the Iron Mills protagonist, for example, would enable users to explore that space in contrast to the living spaces of the Harding family and could provide a powerful VH experience. Moreover, developing such an embodied experience of place may further our ability to understand the geography of Rebecca Harding's world (Knowles 2004). In addition, the lonely experience of the case study stands in stark contrast to the opening scene of her Life in the Iron Mills, which 
describes a dense crowd of people and animals moving through that narrow muddy smoke-filled street. Producing a crowded scene in VR is currently a challenge even to the largest commercial VR producers, because it requires intense processing speed and optimization, since the computer must render every surface of each 3D asset twice (once for each eye), along with light and shadow at sixty or more frames per second while the user navigates the environment. However, the demonstration project succeeded in providing an accurate and accessible foundation upon which to build such a dynamic and lively scene that may enhance the immersion and sense of presence and place.

Another objective was to pursue the potential of serious games as a pedagogical tool for students of historic preservation, geography, VR, animation, and gaming in the process of producing future iterations of the system and project. As discussed in Chapter 3, the scholarship on constructivism and game-based learning has demonstrated efficacy as a teaching and training tool, which extends to higher education (Tierney et al. 2014; Carnes 2014). Students at Eastern Michigan University have participated in several elements of the Place-based VH system, from intensive architectural surveys, to digital 3D modeling of historic houses, and historical GIS. It is a logical step for them to collaborate more formally on refining the system and contributing to future iterations of the system as well as other projects built using the place-based VH system. For example, students of digital heritage and vernacular architecture may contribute to a warehouse of 3D models of house types and textures based on HABS measured drawings and other intensive surveys. Students of museum studies may contribute to historic furnishings plans and interpretive plans for individual dwellings, which might be rendered by students of video gaming and VR. GIS and geovisualization students might work on macro elements to populate and analyze the larger cultural landscape with procedural methods in City Engine as such 
platforms seek to move from the objective Model View to the first-person World View in coming years. These potentialities also provide opportunities for collaboration with faculty and professionals in these and other disciplines.

Finally, among the short range objectives are web-based mechanisms to evaluate the system and the experience of various users. Among the obvious means of evaluation is to design a questionnaire for users to reflect on the strengths and weaknesses of the system. This basic model could be enhanced via a $\mathrm{C}++$ or $\mathrm{C \#}$-based scripts so that answers are entered into a web form and data is sent to a database. The evaluation could be further customized by asking users to self-identify as preservationist, public planner, serious games specialist, geographer, virtual reality, museum specialist, heritage tourist, etc., and then be provided with a customized set of questions that reflect particular expertise and characteristics of users. Additional self-reporting questions may identify concerns or issues related to age, gender, ethnicity, or other demographic factors.

Beyond the analysis of such questionnaires, there are mechanisms for tracking how visitors to the website behave. For example, data may be gathered on the percentage of users who click on various links and how much time they spend on various pages. Further, it is also possible to track the behavior of users in video gaming or virtual environments so that patterns may be evaluated in where they look, when they reach various check points, how long it takes them to accomplish particular objectives, or how long particular people spend in a VR versus a video game session. Conducting and analyzing the results of such a survey and other evaluation mechanisms could provide critical data for enhancing the system and identifying and prioritizing future research efforts. 
Despite its limitations, the case study has demonstrated the enormous potential of a place-based VH system not only as a conduit for HP recording, planning, and interpretation, but also to enhance the way in which VR and geovisualization systems are designed, accessed, and experienced. This study has demonstrated that HP principles can be followed while pursuing VR in heritage projects in the context of an open and honest heritage interpretation. Presence and authenticity are not mutually exclusive. The development and testing of this place-based virtual heritage system has demonstrated that Virtual Reality and historic preservation can coexist despite seemingly irreconcilable differences. 


\section{References}

Adams, Ernest. 2004. Postmodernism and the three types of immersion. Gamasutra. July 9 , 2004. http://designersnotebook.com/Columns/063_Postmodernism/063_postmodernism.htm.

Addison, Alonzo C., Gabriele Guidi, Livio De Luca, and Sofia Pescarin, eds. 2013. Proceedings of the First Digital Heritage International Congress. 2 Vols. Oct 28 - Nov 1, 2013, Marseille, France. IEEE Press.

Addison, Alonzo. 2010. Keynote. Paper presented at "Heritage Recording and Information Management in the Digital Age," the final RecorDIM Initiative Conference, Philadelphia, Pennsylvania, November 20, 2010.

2008. The vanishing virtual: Safeguarding heritage's endangered digital record. In New heritage: New media and cultural heritage, eds. Yehuda E. Kalay, Thomas Kvan and Janice Affleck. London: Taylor \& Francis.

Agugiaro, Giorgio and Fabio Remondino. 2014. 3D GIS for cultural heritage sites: The QueryArch3D prototype. In Stefano Campana and Fabio Remondino, eds. 3D modeling in archaeology and cultural heritage theory and best practices. BAR International Series 2598. Oxford: Archaeopress,

Aitken, Stuart and James Craine. 2006. Affective geovisualizations. Directions Magazine 7: February.

Alivizatou, Marilena. 2012. Intangible heritage and the museum: New perspectives on cultural preservation. 8. Walnut Creek, Califorina: Left Coast Press.

American Living History Farms and Museums. 2018. Accessed November 12, 2018. www.ALHFAM.com

Andreoli, Roberto, et al. 2017. A framework to design, develop, and evaluate immersive and collaborative serious games in cultural heritage. ACM Journal of Computing in Cultural Heritage 11(1).

Anselin, Luc and Sergio J. Rey, eds. 2010. Perspectives on spatial data analysis. Berlin: Springer Verlag.

Anselin, Luc. 2000. Computing environments for spatial data analysis. Journal of Geographical Systems 2(3):201-20. 
Aplin, Graeme. 2002. Heritage: identification, conservation, and management. South Melbourne, Australia: Oxford University Press.

Apollonio, Fabrizio. 2016. Classification schemes for visualization of uncertainty in digital hypothetical reconstruction. In Sander Münster, et al., eds. 3D research challenges in cultural heritage II. How to manage data and knowledge related to interpretative digital 3D reconstructions of cultural heritage, 173-197. New York: Springer. Accessed February 12, 2017. http://link.springer.com/chapter/10.1007/978-3-319-47647-6_9

Apollonio, Fabrizio, Federico Fallavollita, Elisabetta Caterina Giovannini, Riccardo Foschi, and Salvatore Corso. 2017. The reconstruction of drawn architecture. Studies in Digital Heritage $1(2): 380-95$.

Apollonio, Fabrizio, M. Gaiani, and Z. Sun. 2013. In 3D modeling and data enrichment in digital reconstruction of architectural heritage. International Archives of the Photogrammetry, Remote Sensing and Spatial Information Sciences, 43-48. XXIV International CIPA Symposium, Strasbourg, September 2-6.

Athens Conference. 1931. Athens Charter for the Restoration of Historic Monuments. Athens, Greece: 21-30 October 1931. Accessed November 12, 2018.

https://www.icomos.org/en/resources/charters-and-texts

Balletti, Caterina and Francesco Guerra. 2016. Historical maps for 3D digital city's history. Cartographica 51(3):115-26.

Balletti, Catrina. 2014. Georeference in the analysis of the geometric content of early maps. ePerimetron 1(1):32-42.

Barceló, Juan A. 2000. Visualizing what might be: An introduction to Virtual Reality techniques in archaeology. In Juan A. Barceló, Maurizio Forte, and Donald H. Sanders, eds. Virtual Reality in archaeology. Oxford: Archaeopress.

Beacham, Richard, Hugh Denard, and Franco Niccolucci. 2006. An introduction to the London Charter. In Marinos Ioannides, et al., eds. The e-volution of information communication and technology in cultural heritage, Proceedings of VAST 2006, 263-69. Budapest, Hungary.

Bearman, David and Jennifer Trant, eds. 1999. Cultural heritage informatics: Selected papers from ICHIM. International Cultural Heritage Informatics Meeting. Washington, D.C., September 22-26, 1999. http://www.dlib.org/dlib/november99/ichim99 introduction.html

Bentkowska-Kafel, Anna. 2013. "I bought a piece of Roman furniture on the Internet. It's quite good but low on polygons" - Digital visualization of cultural heritage and its scholarly value in art history. An International Journal of Documentation, Visual Resources, Special Issue on Digital Art History 29(1):38-46. 
Bentkowska-Kafel, Anna, Hugh Denard, and Drew Baker. 2012. Paradata and transparency in Virtual Heritage. London: Routledge.

Beveridge, A. A. 2002. Immigration, ethnicity and race in metropolitan New York, 1900-2000. In Anne Knowles, ed. Past time, past place: GIS for history, 65-78. Redlands, California: ESRI Press.

Birnbaum, Charles A. 1994. Protecting cultural landscapes: Planning, treatment, and management of historic landscapes. Preservation Brief 35. Washington, D.C.: National Park Service.

Björk, Staffan and Jussi Holopainen. 2004. Patterns in game design. Boston: Charles River Media.

Blascovich, Jim and Jeremy Bailenson. 2011. Infinite reality: Avatars, eternal life, new worlds, and the dawn of the virtual revolution. New York: Harper Collins.

Bodenhamer David J., Corrigan J. and Harris T.M., eds. 2015. Deep maps and spatial narratives. Bloomington: Indiana University Press.

. 2010. The spatial humanities: GIS and the future of humanities scholarship.

Bloomington: Indiana University Press.

Bogost, Ian. 2010. Persuasive games: The expressive power of video games. Cambridge, Massachusetts: MIT Press.

Bonenberger, Dan, Melissa Milton-Pung, and Jessica Flores. 2018. Early Dwellings of North Wheeling. Charleston, W.Va.: West Virginia State Historic Preservation Office.

and Trevor M. Harris. 2013. Placing Virtual Heritage: Reconciling virtual and cultural heritage with the spatial turn. Proceedings of the First Digital Heritage International Congress. Vol 2. Oct 28 - Nov 1, 2013, Marseille, France. IEEE Press.

and Trevor M. Harris. 2010. Recording and exploring historic places with serious gaming engines and geographic information systems. Poster presented at Heritage Recording and Information Management in the Digital Age. November 20. Philadelphia, Pennsylvania. . 2008. Computer applications in historic preservation: Panacea or pandemic? Paper presented at the National Preservation Conference, Tulsa, Oklahoma.

Bonn, Maria, Lori Kendall, and Jerome McDonough. 2016. Preserving intangible heritage: Defining a research agenda. Proceedings of the Association for Information Science and Technology 53(1):1-5.

Brown, Emily and Paul Cairns. 2004. A grounded investigation of game immersion. CHI 2004, Vienna, Austria, April 24-29. Association for Computing Machinery. http://complexworld.pbworks.com/f/Brown+and+Cairns+(2004).pdf 
Brown, Michael and Larry Knopp. 2008. Queering the map: The productive tensions of colliding epistemologies. Annals of the American Association of Geographers 98(1):40-58.

2006. Places or polygons? Governmentality, scale and the census in the gay and lesbian atlas. Population, Space and Place 12:223-42.

Bryan, Paul, Bill Blake, and Jon Bedford. 2009. Metric survey specifications for cultural heritage. London: English Heritage. http://www.bill-

blake.co.uk/files/Download/English\%20Heritage\%20Metric\%20Survey\%20Spec\%202nd\%20Ed ition\%20Email\%20version_01en.pdf

Buch, T. \& S. Egenfeldt-Nielsen. 2007. The learning effects of Global Conflicts. Media@ Terra, Conference Proceedings, Athens.

Buckle, Caitlin. 2018. Home is where the heart is: Using Google Earth and feminist GIS to create residential histories. Paper presented to the Association of American Geographers. April 14. Washington, D.C.

Burns, John A. 2004. Recording historic structures. 2nd ed. New York: Wiley.

Butler, Declan. 2006. Virtual globes: The web-wide world. Nature 439(7078):776-778.

Calef, Chris, Turlif Vilbrant, Carl Vilbrandt, Janet Goodwin, and James Goodwin. 2002. Making it realtime: Exploring the use of optimized realtime environments for historical simulation and education. Archives \& Museum Informatics. Accessed August 7, 2017. http://www.museumsandtheweb.com/mw2002/papers/calef/calef.html

Cameron, Fiona and Sarah Kenderdine, eds. 2007. Theorizing digital cultural heritage: A critical discourse. Cambridge, Mass.: MIT Press.

Carnes, Mark. 2014. Minds on fire: How role-immersion games transform college. Harvard University Press.

Carroon, Jean. 2010. Sustainable preservation: Greening existing buildings. New York: Wiley.

Carter, Thomas and Elizabeth Cromley. 2005. Invitation to vernacular architecture. Knoxville: University of Tennessee Press.

Chen, Min and Hui Lin. 2018. Virtual geographic environments (VGEs): Originating from or beyond virtual reality (VR)? International Journal of Digital Earth 11(4):329-333.

Christen, Jonas. 2017. Reconstructing Vindonissa as a living document - A case-study of digital reconstruction for output to pre-rendered and real-time applications Studies in Digital Heritage 2:396-408. Accessed November 17, 2018. https://scholarworks.iu.edu/journals/index.php/sdh/article/view/23280 
Corbeil, P. And D. Laveault. 2011. Validity of a simulation game as a method for history teaching. Simulation \& Gaming 42(4):462-475.

Cosgrove, Denis. 1984. Social formation and symbolic landscape. Madison: University of Wisconsin Press.

Cozzani, G., F. Pozzi, F. M. Dagnino, A. V. Katos, and E. F. Katsouli. 2017. Innovative technologies for intangible cultural heritage education and preservation: The case of i-treasures. Personal and Ubiquitous Computing 21(2):253-65.

Cozzi, Patrick and Kevin Ring. 2011. 3D engine design for virtual globes. Natick, Mass: AK Peters.

Craig W., T. Harris, and D Weiner, eds. 2002. Community participation and Geographic Information Systems. London: Taylor and Francis.

Crang, Mike and Phil Crang. 1999. Virtual geographies. London: Routledge.

Cresswell, Tim. 2015. Place: An introduction. New York: John Wiley and Sons. 1996. In place/Out of place: Geography, ideology and transgression. Minneapolis: University of Minnesota Press.

Cunfer, G. 2002. Causes of the dust bowl. In Anne Knowles, ed. Past time, past place: GIS for history, 93-104. Redlands, California: ESRI Press.

Danielova, M. 2014. Visual reconstruction of archaeological data of the Sanctuary of Diana at Nemi, Italy. Master's Thesis, Techniche Universitaet Muenchen.

Davidson, Joyce, Liz Bondi, and Mick Smith, eds. 2007. Emotional geographies. Burlington, Vermont: Ashgate.

Davidson, Lisa Pfueller and Martin Perschler. 2003. The Historic American Buildings Survey during the New Deal era: Documenting "a complete resume of the builders' art." CRM: A Journal of Heritage Stewardship 1. Accessed November 12, 2018. https://home1.nps.gov/CRMJournal/Fall2003/article1.html

Davis, Rebecca Harding. 1904. Bits of gossip. Boston: Houghton Mifflin and Company. DeLeon, V. 1999. VRND: Notre-Dame cathedral, a globally accessible multi-user real-time virtual reconstruction. Proceedings of an International Conference on Virtual Systems and Multimedia (VSMM'99), 484-491. Dundee, Scotland, September.

Dell'Unto, Nicoló, et al. 2016. Experiencing ancient buildings from a 3D GIS perspective: A case drawn from the Swedish Pompeii project. Journal of Archaeological Method and Theory 23(1):73-94. 
Denard, Hugh. 2012. A new introduction to the London Charter. In A. Bentkowska-Kafel, D. Baker, and H. Denard, eds. Paradata and transparency in Virtual Heritage digital research, 5771. Burlington, Vermont: Ashgate.

http://www.londoncharter.org/fileadmin/templates/main/docs/ch6_denard.pdf 2002. Virtuality and performativity: Recreating Rome's Theatre of Pompey. PAJ: A Journal of Performance and Art 24(1):25-43.

der Manuelian, Peter. 2013. Giza 3D: Digital archaeology and scholarly access to the Giza Pyramids: The Giza Project at Harvard University. In Proceedings of the First Digital Heritage International Congress. Vol. 2, 727-34. Oct 28 - Nov 1, 2013, Marseille, France. IEEE Press. Accessed November 15, 2018. https://dash.harvard.edu/handle/1/12560998

Douglas, J. Yellowlees and Andrew Hargadon. 2001. The pleasures of immersion and engagement: Schemas, scripts, and the fifth business. Digital Creativity 12(3):153-166.

Dykes, J., A. M. MacEachren, and M. J. Kraak. 2005. Exploring geovisualization. Amsterdam: Elsevier.

Elsevier. 2019. Sharing Research Data. Accessed October 21, 2018. https://www.elsevier.com/authors/author-services/research-data

Entrikin, J. N. and J. Nicholas. 1991. The betweenness of place. Baltimore: Johns Hopkins University Press.

Eppich, Rand. 2007. Recording, Documentation, and Information Management for the conservation of heritage places. Vol 2. Illustrated examples. Los Angeles: Getty Conservation Institute.

Erdman, Kimball and Angela Payne. 2018. Applying the United States Secretary of the Interior's guidelines for the treatment of cultural landscapes to digital landscape reconstructions. Preservation Education and Research 10:75-93.

Fanini, Bruno and Alfonsina Pagano. 2015. Interface design for serious game visual strategies: the case study of Imago Bononiae. In Proceedings of the $2^{\text {nd }}$ Digital Heritage International Congress, Granada, Spain. Sep 28 - Oct 2, 2015, IEEE Press.

Faust, N. L. 1995. The Virtual Reality of GIS. Environment and Planning B: Planning and Design 22:257-68.

Favretto, A. 2012. Georeferencing historical cartography: A quality-control method. Cartographica 47(3):161-167.

Ferrari, A. 2018. Exploring the geosensory in geography: Examining olfaction and geo-virtual immersion as contributors to a sense of place and embodiment. Master's Thesis, West Virginia University. 
Fidler, John. 2007. Overview of diagnostic indirect tools for conservation. In Rand Eppich and Amel Chabbi, eds. Recording, Documentation, and Information Management for the conservation of heritage places. Vol 2. Illustrated examples. Los Angeles: Getty Conservation Institute.

Fisher, Peter and David Unwin, eds. 2002. Virtual Reality in geography. London: Taylor \& Francis.

Fluty, Beverly. 1984. Center Wheeling (W.Va.) National Register of Historic Places District Nomination. Washington, D.C.: National Park Service.

Flynn, Bernadette. 2013. V-embodiment for cultural heritage. In Proceedings of the First Digital Heritage International Congress. Vol. 2. Oct 28 - Nov 1, 2013, Marseille, France. IEEE Press.

Forte, Maurizio. 2010. Communicating heritage: Collaborative research, education and interpretation. Paper presented at "Heritage Recording and Information Management in the Digital Age," the final RecorDIM Initiative Conference, Philadelphia, Pennsylvania, November 20, 2010.

2000. About Virtual Archaeology: Disorders, cognitive interactions and virtuality. In Juan Barcelo, et al., eds. Virtual Reality in archaeology. Oxford: ArcheoPress.

Francou, Jerome. 1997. Historic Structure Reports in France: A history of guidelines and a case study. APT Bulletin: The Journal of Preservation Technology 28(1):23-28.

Frischer, B., J. Pollini, G. Capriotti, D. Dearborn, J. Fillwalk, K. Galinsky, C. Haueber, J. Miller, J. Murray, M. Salzman, M. Swetnam-Burland, 2017. New light on the Horologium Augusti, the Montecitorio Obelisk, and the Ara Pacis. Studies in Digital Heritage 1:18-119.

Frischer, Bernard. 2014. Video message from the Editor in Chief. Digital Applications in Archaeology and Cultural Heritage 1(1):2. https://www.sciencedirect.com/science/article/pii/S2212054813000052

and John Fillwalk. 2013. A computer simulation to test the Buchner Thesis. In Proceedings of the First Digital Heritage International Congress. Vol. 1. Oct 28 - Nov 1, 2013, Marseille, France. IEEE Press.

2008. From digital illustration to digital heuristics," In Beyond illustration. $2 D$ and $3 D$ Digital technologies as tools for discovery in archaeology. BAR International Series 1805. vxxiv.

Franco Niccolucci, Nick Ryan, and Juan Barceló. 2000. From CVR to CVRO: the past, present and future of cultural Virtual Reality," Proceedings of VAST EuroConference, Arezzo, Italy. 
Fullerton, Tracy. 2014 Game Design Workshop: A playcentric approach to creating innovative games. 4th ed. Natick, Mass.: AK Peters/CRC Press.

Gerth, Philipp, Anne Sieverling, Martina Trognitz. 2017. Data curation: How and why. A showcase with re-use scenarios. Studies in Digital Heritage 2:182-193.

Gilbert, Melissa and Michele Masucci. 2006. The implications of including women's daily lives in a feminist GIScience. Transactions in GIS 10(5):751-61.

Gilchrest, James. 1871. Map of the City of Wheeling, South Wheeling, and Lagrange. F.W. Beers and Company.

Gillings, Mark. 2002. Virtual archaeologies and the hyperreal: Or, what does it mean to describe something as virtually-real? In P. Fisher and D. Unwin, eds., Virtual Reality in Geography.1734. London: Taylor \& Francis.

and Glyn Goodrick. 1996. Sensuous and reflexive GIS: Exploring visualisation and VRML. Internet Archaeology 1.

Glassie, Henry. Pattern in the material folk culture of the eastern United States. Philadelphia: University of Pennsylvania Press, 1968.

Goodchild, Michael F. 2000. Communicating geographic information in a digital age. Annals of the Association of American Geographers 90:344-55.

Great Buildings. 1999. Accessed November 12, 2018. https://web.archive.org/web/19990125085946/ http://greatbuildings.com:80/

Gregory, Ian, and Paul S. Ell. 2007. Historical GIS: Technologies, methodologies, and scholarship. Cambridge University Press.

, D. Dorling, and H.R. Southall. 2001. A century of inequality in England and Wales using standardized geographical units. Area 33:297-311.

2000. Longitudinal analysis of age- and gender- specific migration patterns in England and Wales: A GIS-based approach. Social Science History 24: 471-503.

Griffin, Stephen M. 1998. NSF/DARPA/NASA Digital Libraries Initiative: A program manager's perspective. D-Lib Magazine http://www.dlib.org/dlib/july98/07griffin.html

Grossner, K.E., M.F. Goodchild, and K.C. Clarke. 2008. Defining a digital earth system. Transactions in GIS 12:145-160.

Guidi, Gabriele, Roberto Scopigno, Juan Carlos Torres, and Holger Graf, eds. 2015. Proceedings of the $2^{\text {nd }}$ Digital Heritage International Congress. 2 Vols. Sep 28 - Oct 2, 2015, Grenada, Spain. IEEE Press. 
Haas, J. 2008. Revolution. Accessed August 7, 2012. http://www.educationarcade.org/node/357

Haegler, Simon, Pascal Muller, and Luc van Gool. 2009. Procedural Modeling for Digital Cultural Heritage, EURASIP Journal on Image and Video Processing 1.

Harding, Miss R. B. 1865 (1861). Life in the Iron Mills. In Atlantic tales: A collection of stories from the Atlantic Monthly. Boston: Ticknor and Fields.

. 1861. Life in the Iron-Mills. Atlantic Monthly 7 (Apr.):430-451.

1862. Margret Howth: A story of to-day. Boston: Ticknor \& Fields.

1862. David Gaunt. Atlantic Monthly 10 (Sep.-Oct.):257-271, 403-421.

Harris, Sharon M. 1991. Rebecca Harding Davis and American realism. Philadelphia: University of Pennsylvania Press.

Harris, Trevor M., H. Frank Lefone, and Dan Bonenberger. 2016. Beyond mapping text in space to experiencing text in place: Exploring literary virtual geographies. In David Cooper, Christopher Donaldson, and Patricia Murrieta-Flores, eds. Literary mapping in the digital age, 221-39. London: Routledge.

, J. Rouse, S. Bergeron, and D. Bonenberger. 2008. Immersive and experiential GIS and the humanities, Paper presented at Historical GIS 2008, University of Essex, England.

. 1986. Geographic Information System design for archaeological site information retrieval. In Computer Applications in Archaeology. University of Birmingham.

Harvey, David. 1989. The urban experience. Baltimore, Maryland: Johns Hopkins University Press.

Hawkins, Harriet. In press. Geography's creative (re)turn: Toward a critical framework. Progress in Human Geography. Accessed November 2018. https://journals.sagepub.com/doi/abs/10.1177/0309132518804341\#

Hillier, A. 2010. Invitation to mapping: How GIS can facilitate new discoveries in urban and planning history. Journal of Planning History 9:122-34.

. 2003. Spatial analysis of historical redlining: A methodological exploration. Journal of Housing Research 14:137-67.

Hobbie, Dierk. 2010. The Development of photogrammetric instruments and methods at Carl Zeiss in Oberkochen. Munich: Verlag der Bayerischen Akademie der Wissenshaften. Accessed November 12, 2018. http://www.isprs.org/society/history/Hobbie-The-development-ofphotogrammetric-instruments-and-methods-at-Carl-Zeiss-in-Oberkochen.pdf. 
Hokanson, G., O. Borchert, B.M. Slator, J. Terpstra,J.T. Clark, L.M. Daniels, H.R. Anderson, A. Bergstrom, T.A. Hanson, J. Reber, D. Reetz, K.L. Weis, R.White, and L. Williams. 2008. Studying Native American culture in an immersive virtual environment. Proceedings of the IEEE International Conference on Advanced Learning Technologies (ICALT-2008) 788-792. IEEE Computer Society Press. Santander, Spain. July 1-5.

House, Michael L. 2001. Virtual Reality Notre-Dame (Review). All Game Guide. Accessed July 30, 2018. www.answers.com/topic/virtual-reality-notre-dame.

Hubka, Thomas. 2013. Houses without names. Knoxville: University of Tennessee Press.

ICHIM conference. 1991-2007. Accessed Feb 28, 2012.

http://www.archimuse.com/conferences/ichim.html and

http://www.museumsandtheweb.com/researchForum

ICOMOS. 2017. Seville Charter: International Principles for Virtual Archaeology. Ratified by the $19^{\text {th }}$ ICOMOS General Assembly in New Delhi, India.

International Centre for the Study of the Preservation and Restoration of Cultural Property. Accessed November 12, 2018. https://www.iccrom.org.

International Council on Monuments and Sites. Accessed November 12, 2018. https://www.icomos.org/en.

Ito, Mizuko. 2009. Engineering play: A cultural history of children's software. Cambridge: MIT Press.

Johnson, Chris R. and Allen R. Anderson. 2003. A next step: Visualizing errors and uncertainty IEEE Computer Graphics and Applications 23(5):6-10.

Jokilehto, Jukka. 2011. ICCROM and the conservation of cultural heritage: A history of the organization's first 50 years, 1959-2009. Rome: ICCROM

1995. Comments on the Venice Charter with illustrations. Scientific Journal: The Venice Charter 1964-2004. 4:61-76. Accessed November 12, 2018.

https://www.icomos.org/venicecharter2004/jokilehto.pdf

. 1990. A history of architectural conservation. Butterworth-Heinemann

Jones, Phil and James Evans. 2012. The spatial transcript: Analysing mobilities through qualitative GIS. Area 44(1): 92-99. Accessed November 19, 2018. https://rgsibg.onlinelibrary.wiley.com/doi/full/10.1111/j.1475-4762.2011.01058.x

Joyner, Brian. 2009. Hispanic reflections on the American landscape. Washington, D.C.: National Park Service. 
Service.

2005. Asian reflections on the American landscape. Washington, D.C.: National Park 2003. African reflections on the American landscape. Washington, D.C.: National Park Service.

Kalay, Yehuda, Thomas Kvan, and Janice Affleck. 2007. New heritage: New media and cultural heritage. New York: Routledge.

Karavia, Despoina and Andreas Georgopoulos. 2013. Placing Intangible Cultural Heritage. In Proceedings of the First Digital Heritage International Congress. Oct 28 - Nov 1, 2013, Marseille, France. IEEE Press.

Kervin, L., L. Verenikina, and M. C. Rivera. 2015. Collaborative onscreen and offscreen play: examining meaning-making complexities. Digital Culture \& Education 7(2):228-239.

Kinsley, Samuel. 2014. The matter of 'virtual' geographies. Progress in Human Geography 38(3):364-84.

Klinkenberg, Brian. 2007. Geospatial technologies and the geographies of hope and fear. Annals of the Association of American Geographers 97(2):350-60.

Kniffen, Fred. 1990. The study of folk architecture. In H. Jesse Walker and Randall A. Detro, eds. Cultural diffusion and landscapes: Selections by Fred B. Kniffen, 35-47. Geoscience and Man, Vol. 27. Baton Rouge: Geoscience Publications.

1965. Folk housing: Key to diffusion. Annals of the Association of American Geographers 55:549-577.

Knowles Anne, ed. 2008. Placing history: How GIS is changing historical scholarship. Redlands, California: ESRI Press. . 2005. Past time, past place: GIS for history. Redlands, California: ESRI Press. . 2004. Wheeling iron and the Welsh: A geographical reading of Life in the iron mills. In

Ken Fones-Wolf and Ron Lewis, eds. Transnational West Virginia. Morgantown: West Virginia University Press, 217-41.

Koller, David, Bernard Frischer, and Greg Humphreys. 2009. Research challenges for digital archives of 3D cultural heritage models ACM Journal on Computing and Cultural Heritage 2(3):1.

Kozma, Liat. 2016. Woman's migration for prostitution in the interwar Middle East and North Africa. Journal of Women's History 28(3):93-113.

Kraak, M.-J. and A. M. MacEachren. 1999. Visualization for exploration of spatial data. International Journal of Geographical Information Science 13(4):285-287. 
Kraak, Menno-Jan. 2002. Visual explorations of virtual environments. In Peter Fisher and David Unwin. Virtual Reality in geography, 58-67. London: Taylor \& Francis.

Kuroczynski, Piotr. 2017. Virtual research environment for digital 3D reconstructions Standards, thresholds, and prospects. Digital Culture \& Education 7(2):456-76.

Kwan, Mei-Po and Tim Schwanen, eds. 2017. Geographies of mobility: Recent advances in theory and method. New York: Routledge.

Kwan, Mei-Po. 2008. From oral histories to visual narratives: Re-presenting the post-September 11 experiences of the Muslim women in the USA. Social and Cultural Geography 9(6):653-669.

and Guoxiang Ding. 2008. Geo-narrative: Extending Geographic Information Systems for narrative analysis in qualitative and mixed-method research." The Professional Geographer 60(4):443-465.

2007. Affecting geospatial technologies: Toward a feminist politics of emotion. The Professional Geographer 59 (1):27-34.

and Donna Knigge. 2006. Doing qualitative research using GIS: An oxymoronic endeavor? Environment and Planning A 38:1999-2002.

and J. Lee. 2004. Geovisualization of human activity patterns using 3D GIS: A timegeographic approach. In M. Goodchild and D. Janelle, eds. Spatially integrated social science, 48-66. New York: Oxford University Press.

. 2002a. Is GIS for women? Reflections on the critical discourse in the 1990s. Gender, Place and Culture 9(3):271-9.

. 2002b. Feminist geovisualization: Re-envisioning GIS as a method in feminist geographic research. Annals of the Association of American Geographers 92(4):645-61.

1999. Gender, the home-work link, and space-time patterns of nonemployment activities. Economic Geography 75:370-394.

Lahti, Martti. 2003. As we become machines: Corporealized pleasures in video games. In Mark Wolf and Bernard Perron, eds. The Video Game Theory Reader. London: Routledge, 157-70.

Lancaster, Lynn. 1995. Auguste Choisy and the economics of Roman construction. In J. Giron and S. Huerta, eds. Auguste Choisy (1841-1909) l'architecture et l'art de batir (actas del Simposio Internacional celebrado en Madrid, November 19-20, 2009): 307-28. Accessed November 12, 2018. http://www.augustechoisy2009.net/pdfs/ponencias/13_Lancaster.pdf

Landeschi, Giacomo, et al. 2016. 3D GIS as a platform for visual analysis: Investigating a Pompeian house. Journal of Archaeological Science 65(1):103-13. 
Larson, K.E., ed. 1995. Nara Conference on Authenticity in relation to the World Heritage Convention. Nara, Japan 1-6 November 1995. Proceedings. UNESCO World Heritage Centre, Agency for Cultural Affairs (Japan), ICCROM and ICOMOS. Trondheim, Norway: Tapir Publishers.

LaValle, Steven M. 2017. Virtual Reality. Cambridge University Press

Leighly, John, ed. 1965. Land and life: A selection from the writings of Carl Ortwin Sauer. Berkeley: University of California Press.

Lercari, Nicola, Grant Cox, Gesualdo Busacca, Arianna Campiani, and Jad Aboulhosn. 2018. Data from A Glimpse through Time and Space: Visualizing social memory and history-making at Çatalhöyük. UC San Diego Library Digital Collections. https://doi.org/10.6075/J0SX6BDP

Lercari, Nicola, Maurizio Forte, and Llonel Onsurez. 2013. Multimodal reconstruction of landscape in serious games for heritage: An insight on the creation of Fort Ross Virtual Warehouse serious game. In Proceedings of the First Digital Heritage International Congress. Vol. 2, 231-38. Oct 28 - Nov 1, 2013, Marseille, France. IEEE Press.

Letellier, Robin, ed. 2007. Recording, Documentation, and Information Management for the conservation of heritage places. Vol 1. Guiding principles. Los Angeles: Getty Conservation Institute.

Lewis, Peirce. 1979. Axioms for reading a landscape. In Meinig, D.W. ed. Interpretation of ordinary landscapes, 11-31. New York: Oxford University Press.

Longhurst, Robyn. 1997. (Dis)embodied geographies. Progress in Human Geography 21(4):486-501.

Lowenthal, David. 1985. The past is a foreign country. Cambridge University Press.

Lukesh, Susan S. 1995. Imaging the past. CSA Newsletter. February. Center for the Study of Architecture.

MacDorman, Karl F. and Hiroshi Ishiguro. 2006. The uncanny advantage of using androids in cognitive and social science research. Interaction Studies 7(6):297 -337. https://www.jbeplatform.com/content/journals/10.1075/is.7.3.03mac

MacEachren, A.M. and Menno Jan Kraak. 1997. Exploring cartographic visualization: Advancing the agenda. Computers and Geosciences 23:335-43.

McAlester, Virginia Savage. 2015. A field guide to American houses. New York: Knopf.

McCall, Jeremiah. 2016. Teaching history with digital historical games: An introduction to the field and best practices. Simulation and Gaming 47(4):517-542. 
McLafferty, Sara L. 2002. Mapping women's worlds: Knowledge, power and the bounds of GIS. Gender, Place, and Culture 9:263-9.

2005. Women and GIS: Geospatial technologies and feminist geographies.

Cartographica 40(4):75-90.

McLennan, Marshall. n.d. (c.1978). Identifying house types. n.p.

Manfred and Simpson 1853. Map of the City of Wheeling and Suburbs, Ohio Co., Virginia. Cincinnati, Ohio: Manfred and Simpson.

Marshall, Paul D., and Associates. 1988. North Wheeling (WV) National Register of Historic Places District Nomination. Washington, D.C.: National Park Service.

Martos, Antonio and Bernardino Ruiz. 2013. Realistic virtual reproductions: Image-based modeling of geometry and appearance. In Proceedings of the First Digital Heritage International Congress. Vol. 2. Oct 28 - Nov 1, 2013, Marseille, France. IEEE Press.

Matero, Frank. 2010. Ben's house: Designing history at Franklin Court. Heritage conservation \& archaeology. Archaeological Institute of America. Accessed September 4, 2018.

https://www.archaeological.org/news/hca/72

Matney, Lucas. 2016. VR battle royale: PS VR vs. HTC Vive vs. Oculus Rift. TechCrunch, October 2016. Accessed November 12, 2018. http://social.techcrunch.com/2016/10/13/vr-battleroyale-ps-vr-vs-htc-vive-vs-oculus-rift/

Matthews, Stehen A., James Detwiler, and Linda Burton. 2005. Geo-ethnography: Coupling Geographic information analysis techniques with ethnographic methods in urban research. Cartographica 40(4):75-90.

Massey, Doreen. 1994. Space, place and gender. Minneapolis: University of Minnesota Press.

Meinig, Donald W., ed. 1979. The interpretation of ordinary landscapes. New York: Oxford University Press.

Merleau-Ponty, Maurice. 1968. The visible and the invisible, followed by working notes. trans. by Alphonso Lingis. Evanston: Northwestern University Press.

Milgram, Paul, Haruo Takemura, Akira Utsumi, and Fumio Kishino. 1994. Augmented Reality: A class of displays on the reality-virtuality continuum. SPIE Vol. 2351, Telemanipulator and Telepresence Technologies.

Millspaugh, C. F. and Lawrence William Nuttall. 1896. Flora of West Virginia. Chicago: Field Museum of Natural History.

Monmonier, M. 1989. Geographic brushing: Enhancing exploratory analysis of the scatterplot matrix. Geographical Analysis 21:81-4. 
Mori, M. 1970. The uncanny valley. Energy 7(4):33-35.

Moss, Pamela and Isabel Dyck. 2003. Embodying Social Geography. In Kay Anderson, Mona Domosh and Steve Pile, eds. Handbook of Cultural Geography, 58-73. London: SAGE Publications Ltd.

Mou, Zhenyu. 2012. Using cadastral maps in historical GIS research: The French concession in Shanghai (1931-1941). Annals of GIS 18(2):147-56.

Muenster, Sander, Cindy Kroeber, Heide Weller and Nikolas Prochtel. 2017. Virtual reconstruction of historical architecture as media for knowledge representation. In Marinos Ioannides, Nadia Magnena-Thalmann and George Papagiannakis, eds. Mixed Reality and gamification for cultural heritage, 313-330. New York: Springer.

Murray, Janet. 1998. Hamlet on the Holodeck: The future of narrative in cyberspace. New York: Free Press.

Naimark, M. 1991. Elements of realspace imaging: A proposed taxonomy. Proceedings of SPIE 1457, Stereoscopic Displays and Applications II.

National Map. 2019. https://viewer.nationalmap.gov/basic/

National Park Service. 1997. How to complete the National Register of Historic Places registration form. Bulletin 16A. Washington, D.C.: U.S. Department of the Interior. 1995. How to apply the National Register of Historic Places criteria for evaluation. Bulletin 15. Washington, D.C.: U.S. Department of the Interior.

Nazgol, Bagheri. 2014. What qualitative GIS maps tell and don't tell: Insights from mapping women in Tehran's public spaces. Journal of Cultural Geography 31(2):166-178.

Noble, Allen G. 1984. Wood, brick, and stone: The North American settlement landscape. Vol 1: Houses. Amherst: University of Massachusetts Press.

Nold, Christian, ed. 2009. Emotional cartography - technologies of the self. Published under a Creative Commons, Attribution, NonCommercial, ShareAlike Licence. Accessed November 19, 2018. http://emotionalcartography.net/

Nollenburg. Martin. 2007. Geographic visualization. In Andreas Kerren, Achim Ebert, and Joerg Meyer, eds. Human-centered visualization environments 2006. LNCS 4417, Berlin: SpringerVerlag, 257-94.

O'Sullivan, David. 2006. Geographic Information Science: Critical GIS. Progress in Human Geography 30(6):783-91. 
Packer, J.E. 2006. Digitizing Roman imperial architecture in the early 21 st century. Purposes, data, failures, and prospects. In L. Haselberger, J. Humphrey, D. Abernathy, eds. Imaging Ancient Rome: Documentation, visualization, imagination, 309-320. Portsmouth, Rhode Island: Journal of Roman Archaeology.

Parreñas, Rhacel Salazar. 2011. Illicit flirtations: Labor, migration, and sex trafficking in Tokyo. Stanford, Califorinia: Stanford University Press.

Paterson, Mark. 2009. Haptic geographies: Ethnography, haptic knowledges, and sensuous dispositions. Progress in Human Geography 33(6):766-88.

Pavlovskaya, Marianna and Kevin St. Martin. 2007. Feminism and Geographic Information Systems: From a missing object to a mapping subject. Geography Compass 1(3):583-606.

Peet, Richard. 1998. Modern geographical thought. Malden, Mass.: Blackwell.

Pickles, John. 2006. Ground truth 1995-2005. Transactions in GIS 10(5):763-72. . 1999. Arguments, debates and dialogues: The GIS-social theory debate and the concern for alternatives. In P.A. Longley, M. Goodchild, D. Maguire, and D. Rhind, eds. Geographical Information Systems Vol. 1. Principles and Technical Issues. New York: John Wiley and Sons.

1995. Ground truth: The social implications of Geographic Information Systems. New York: Guilford Press.

Pietrobruno, Sheenagh. 2013. YouTube and the social archiving of intangible heritage. New Media \& Society 15(8):1259-76.

Pietroni, Eva, Alfonsina Pagano, and Claudio Rufa. 2013. The Etruscanning Project: Gesturebased interaction and user experience in the virtual reconstruction of the Regolini-Galassi tomb. In Proceedings of the First Digital Heritage International Congress. Vol. 2. Oct 28 - Nov 1, 2013, Marseille, France. IEEE Press.

Pietroni, Eva, Alfonsina Pagano, Marco Amadei, Federica Galiffa, 2016. Livia's Villa Reloaded virtual museum: User experience evaluation. In Proceedings ICERI 2016, 9th annual International Conference of Education, Research and Innovation, Seville, Spain, November 2016, 349-359.

Poisson, Olivier. 2014. Eugène Viollet-le-Duc. Paris: Picard.

Polig, Martina. 2017. 3D GIS for building archaeology. Combining old and new data in a threedimensional information system in the case study of Lund Cathedral. Studies in Digital Heritage 1(2):225-38.

Pred, A. 1977. The choreography of existence: Comments on Hagerstrand's time-geography and its usefulness. Economic Geography 53:207-221. 
Quintero, Mario Santana and Ona Vileikis. 2011. Heritage recording and information management in the digital age (SMARTdoc-heritage). Change Over Time 1(2):156-164.

Raitz, Karl. 2001. Field observation, archives, and explanation. Geographical Review 91(1\&2):120-31.

Raper, Jonathan. 2000. Multidimensional Geographic Information Science. London: Taylor \& Francis.

Ray, B.C. 2002. Teaching the Salem witchcraft trials. In Anne Knowles, ed. Past time, past place: GIS for history, 19-33. Redlands, California: ESRI Press.

Reilly, Paul. 1991. Towards a Virtual Archaeology. In K. Lockyear and S. Rahtz, eds. CAA90: Computer Applications and Quantitative Methods in Archaeology 1990, BAR International Series 565, Oxford, 133-139.

Revill, George. 2016. How is space made in sound? Spatial mediation, critical phenomenology and the political agency of sound. Progress in Human Geography 40(2):240-56.

Rua, Helena and Pedro Alvito. 2011. Living the past: 3D models, Virtual Reality and game engines as tools for supporting archaeology and the reconstruction of cultural heritage - the casestudy of the Roman villa of Casal de Freiria. Journal of Archaeological Science 38:3296-3308.

Relph, Edward. 1985. Geographical experiences and being-in-the-world: The phenomenological origins of geography. In Seamon, David \& Robert Mugerauer, eds. Dwelling, place, and environment: Toward a phenomenology of person and world, 15-31. Dordrecht: Martinus Nijhoff.

1976. Place and Placelessness. London: Pion.

Robinett, W. 1992. Synthetic experience: A proposed taxonomy. Presence 1(2):229-247.

Sanborn Map Company. 1884. Wheeling, West Virginia, Sheet 9. Map. New York.

Sanders, D. 2008. Why do Virtual Heritage? In Clark, Jeffrey T. and Emily M. Hagemeister, eds. Digital Discovery: Exploring new frontiers in human heritage. Proceedings from the 34th Computer Applications and Quantitative Methods in Archaeology conference, Fargo, North Dakota, April 2006. Budapest: Archaeolingua, 427-36.

Sauder, Robert A. 1980. The use of Sanborn maps in reconstructing 'geographies of the past': Boston's waterfront from 1867 to 1972. Journal of Geography 79(6):204-13.

Schafer, R. Murray. 1977. The Soundscape. New York: Knopf.

Shapiro, Gideon. 2015. How Mount Vernon's HBIM is helping to change historic preservation. Architect (April 14). Accessed November 20, 2018. 
https://www.architectmagazine.com/technology/how-mount-vernons-hbim-is-helping-to-changehistoric-preservation_o

Schurrman, Nadine. 1999. Critical GIS: Theorizing an emerging science. Cartographica 36(4).

Scott, Geoffrey R. 2003. The cultural property laws of Japan: Social, political, and legal influences. Pacific Rim Law and Policy Journal 12(2):315-402.

Seamon, David. 1979. A geography of the lifeworld: Movement, rest and encounter. London: Croom Helm.

and Anne Buttimer, eds. 1980. The human experience of space and place. London: Croom Helm.

Sheridan, T.B. 1992. Musings on telepresence and Virtual Reality. Presence 1(1):120-126.

Seifert, Christin, et al. 2017. Ubiquitous access to Digital Cultural Heritage. ACM Journal of Computing in Cultural Heritage 10(1).

Siegel, Dina. 2012. Mobility of sex workers in European cities. European Journal on Criminal Policy and Research 18(3):255-268.

Silberman, Neil. 2009. Process not product: The ICOMOS Ename Charter (2008) and the practice of heritage stewardship. CRM: The Journal of Heritage Stewardship 6(2). Accessed November 12, 2018. https://home1.nps.gov/CRMJournal/Summer2009/view.html

. 2006. The ICOMOS-Ename Charter initiative: Rethinking the role of heritage

interpretation in the 21st century. George Wright Forum 23(1):28-33.

http://www.georgewright.org/231silberman.pdf

. 2004. Beyond theme parks and digitized data: What can cultural heritage technologies contribute to the public understanding of the past? In Kevin Cain, Yiorgos Chrysanthou, Franco Niccolucci, Daniel Pletinckx, Neil Silberman, eds. Interdisciplinarity or The best of both worlds: The grand challenge for cultural heritage informatics in the $21^{\text {st }}$ century. Budapest: European Program for Open Cultural Heritage.

Smith, Neil, Kyle Knabb, Connor Defanti, Philip Weber, Jurgen Schulz, Andrew Prudhomme, Falko Kuenster, Thomas E. Levy, and Thomas Defanti. 2013. ArtifactVis2: Managing real-time archaeological data in immersive 3D environments. In Proceedings of the First Digital Heritage International Congress. Vol. 1. Oct 28 - Nov 1, 2013, Marseille, France. IEEE Press.

Smith, Susan J. 1993. Bounding the borders: Claiming space and making place in rural Scotland. Transactions of the Institute of British Geographers NS 18(3):291-308.

Soja, Edward. 1996. Third Space: Journeys to Los Angeles and other real-and-imagined places. Malden, Mass.: Blackwell. 
Stipe, Robert. 2003. A richer heritage: Historic preservation in 21st century. Chapel Hill: University of North Carolina Press.

Stone, R.J. 1999. Virtual Heritage. UNESCO World Heritage Review 18-27.

Stovel, Herb. 1990. Heritage recording: Growth of a profession. APT Bulletin: The Journal of Preservation Technology 22:4-8.

Strothotte, Thomas, Marc Masuch, and Tobias Isenberg, 1999. Visualizing knowledge about virtual reconstructions of ancient architecture. Computer Graphics International. Los Alamitos, CA: IEEE Computer Society, 39.

Summerhayes, Catherine. 2016. Google Earth: Outreach and activism. New York: Bloomsbury.

Swink, Steve. 2009. Game feel: A game designer's guide to virtual sensation. Burlington:

Elsevier.

Takeuchi, L.M. and S. Vaala. 2014. Level up learning: A national survey on teaching with digital games. New York: The Joan Ganz Cooney Center at Sesame Workshop.

Tamborini, R. and P. Skalski. 2006. The role of presence in the experience of electronic games. In P. Vorderer and J. Bryant, eds. Playing video games: Motives, responses, and consequences. Mahwah, New Jersey: Lawrence Erlbaum Associates.

Taylor, Laurie N. 2002. Video games: Perspectives, point-of-view, and immersion. MA Thesis University of Florida. http://etd.fcla.edu/UF/UFE1000166/taylor_l.pdf

Teather, E. K., ed. 1999. Embodied geographies: Spaces, bodies, and rites of passage. London: Routledge.

Thrift, Nigel. 2007. Non-representational theory. London: Routledge.

Tierney, William G., Zoë B. Corwin, Tracy Fullerton, and Gisele Ragusa, eds. 2014. Postsecondary Play: The role of games and social media in higher education. Johns Hopkins University Press.

Tinwell, Angela. 2014. The Uncanny Valley in games and animation. A. K. Peters.

Tomlan, Michael, ed. 1998. Preservation of what for whom? Ithaca, New York: National Council for Preservation Education.

Trace, Ferenc. 2005. Resemblance of the long existing: Virtual reconstruction of the Cistercian monastery of Pilis, Hungary. Thesis (MS) University of Cincinnati.

Truax, Barry. 2001 (1984). Acoustic communication. New York: Praeger.

Tukey, John W. 1977. Exploratory data analysis. London: Pearson. 
Tuan, Yi-fu. 1979. Landscapes of Fear. Minneapolis: University of Minnesota Press. . 1977. Space and place: The perspective of experience. Minneapolis: University of Minnesota Press.

Tyler, Norman, Ilene Tyler, and Ted Ligibel. 2018. Historic preservation: An introduction to its history, principles, and practice. $3 \mathrm{~d}$ ed. New York: W.W. Norton and Company.

Unwin, David and Peter Fisher. 2002. Virtual Reality in geography. London: Taylor and Francis.

Verbree, Edward, Gert van Maren, Rick Germs, Frederik Jansen, and Menno-Jan Kraak. 1999. Interaction in virtual world views - linking 3D GIS with VR. Accessed 2 February 2007. http://karma.geo.tudelft.nl/ijgis_main.html

Verbree, Edward, Lisette Verzijl and Menno-Jan Kraak. 1998. Integrated 3D-GIS and VR: Use of Virtual Reality and 3D-GIS within the planning process concerning the infrastructure. Proceedings of the Spatial Information Research Centre's 10th Colloquium, University of Otago, New Zealand, 16-19 November. 360.

Verhagen, P., 2008. Dealing with uncertainty in archaeology. In On the Road to Reconstructing the Past, Computer Applications in Archaeology, 99. Budapest, Hungary, April 2-6.

Vijayah, TAnantha. 2011. Digitizing worldviews and Intangible Cultural Heritages. Fourth World Journal 10(2):31-55.

Vogel, Robert. 1983. The Secretary of the Interior's Standards for Architectural and Engineering Documentation. Federal Register 48(190):44730-34. https://www.nps.gov/history/locallaw/arch_stnds_6.htm).

VRND - Notre Dame Cathedral Demo (Unreal Engine) video. https://www.youtube.com/watch?v=x283cGFN0hQ

UNESCO. 1994. Nara Document on Authenticity. Accessed November 12, 2018. http://whc.unesco.org/archive/nara94.htm 1972. World Heritage Convention. Accessed November 12, 2018.

http://whc.unesco.org/archive/convention-en.pdf 1964. International Charter for the Conservation and Restoration of Monuments and sites. Accessed November 12, 2018. https://www.icomos.org/charters/venice_e.pdf.

Wallach, Brett. 2005. Understanding the cultural landscape. New York: Guilford Press.

Weir, Kimberly and Michael Baranowski. 2008. Simulating history to understand international politics. Simulation and Gaming 39(3):441-461. 
West Virginia GIS Technical Center http://wvgis.wvu.edu/data/data.php ftp://ftp.wvgis.wvu.edu/pub/Clearinghouse/elevation/3MeterDEM_SAMB_2003_utm83/tiff/zipp $\underline{\text { ed }}$

Wheatley, David and Mark Gillings. 2002. Spatial technology and archaeology: The archaeological applications of GIS. London: Taylor and Francis.

Witmer, B.G. and Singer, M.J. 1998. Measuring presence in virtual environments: A presence questionnaire. Presence: Teleoperators and Virtual Environments 7:225-240.

World Heritage Center. 2017. Operational Guidelines for the Implementation of the World Heritage Convention. Paris: UNESCO. Accessed November 12, 2018. http://whc.unesco.org/en/guidelines/

Zeltzer, D. 1992. Autonomy, interaction and presence. Presence 1(1):127-132. 